$$
\begin{aligned}
& \text { UCRL-ID--105336 } \\
& \text { DE91 } 006218
\end{aligned}
$$

\title{
Strategic Forces: Future Requirements and Options
}

Roger D. Speed

Nevember 1990

Lawrence Livermore National Laboratory Livermore, CA 94550 


\section{Acknowledgments}

The author wishes to thank Michael May, Roland Herbst, Kent Johnson, and George Bing for their thoughtful comments and criticisms. This work was performed under the auspices of the Evaluation and Planning Program, D-Division, at Lawrence Livermore National Laboratory. 


\section{Table of Contents}

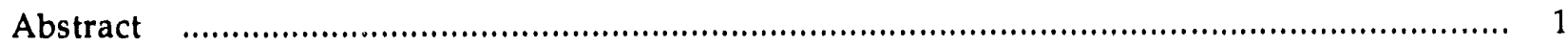

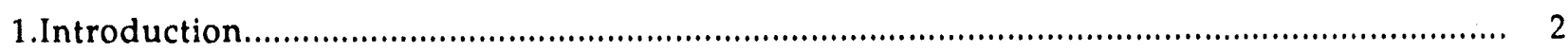

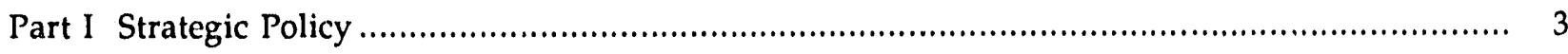

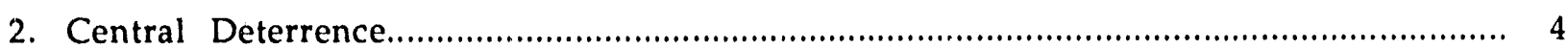

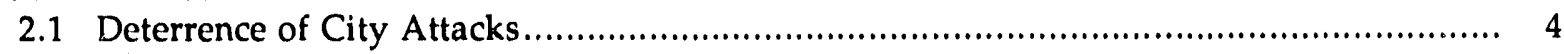

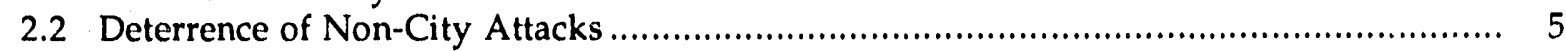

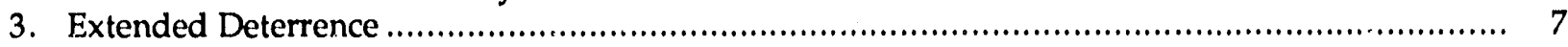

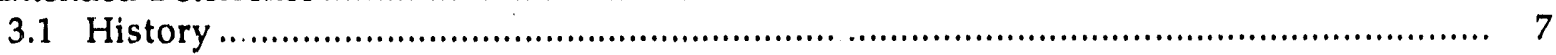

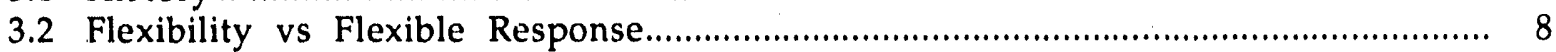

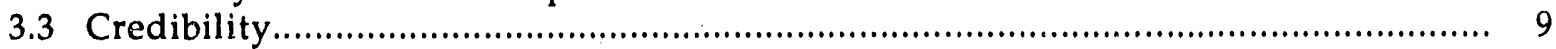

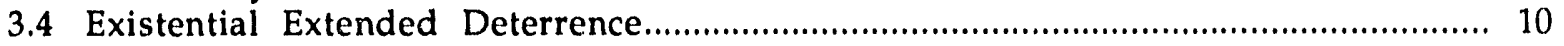

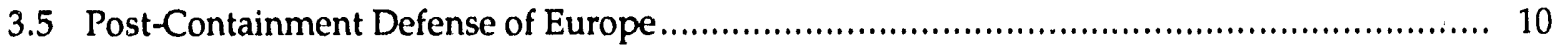

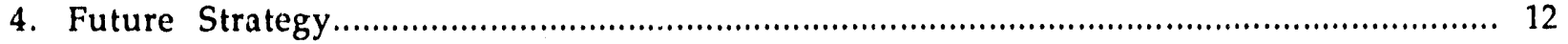

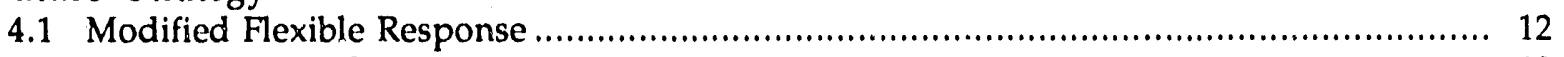

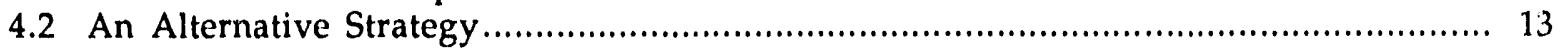

Part II Survivability at Low Force Levels.................................................................. 16

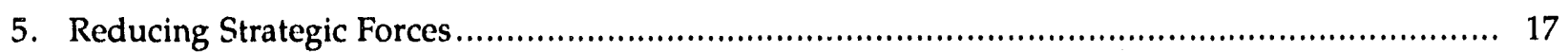

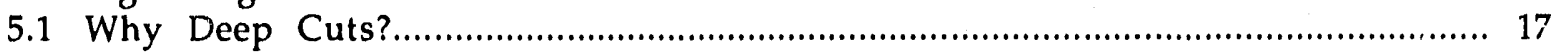

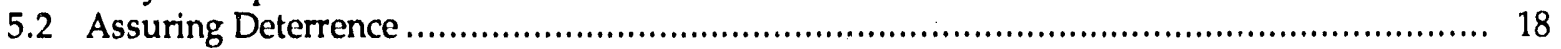

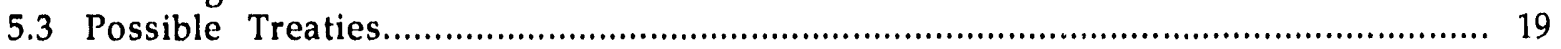

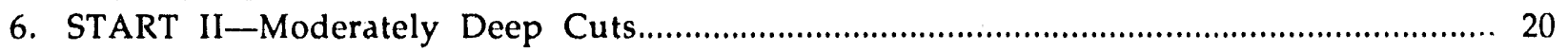

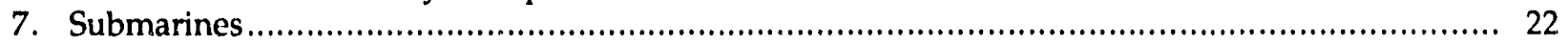

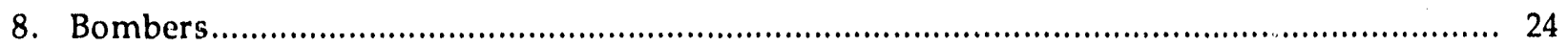

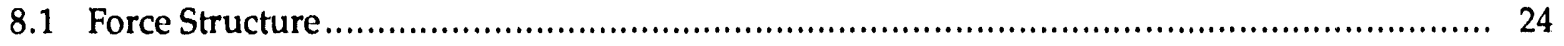

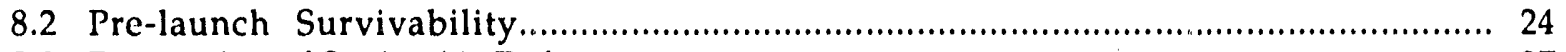

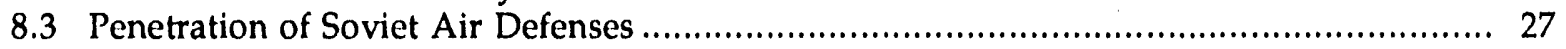

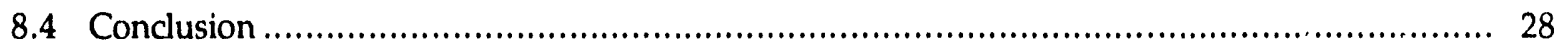

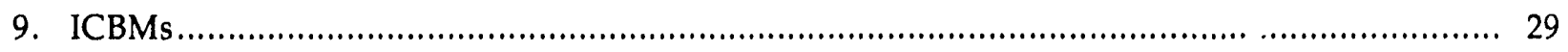

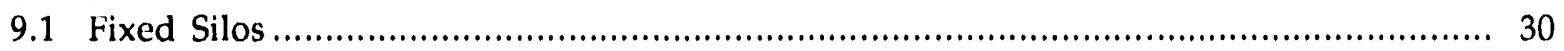

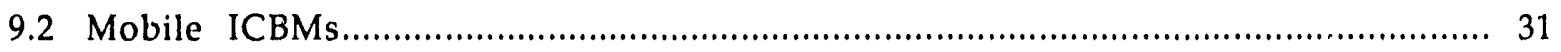

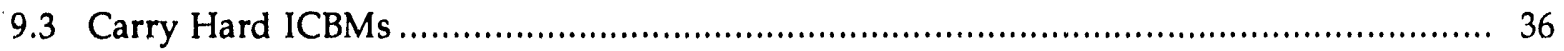

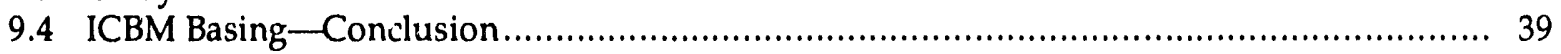

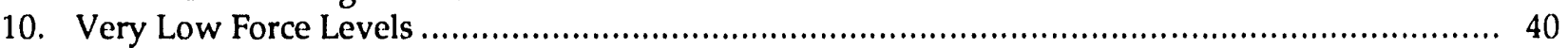

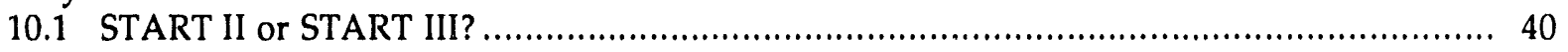

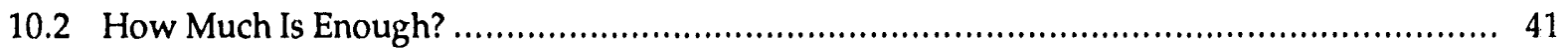

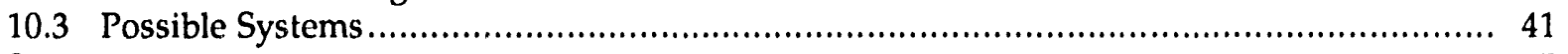

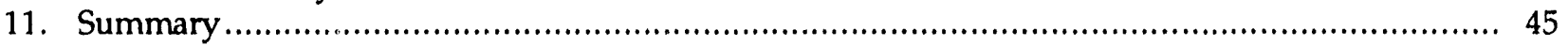

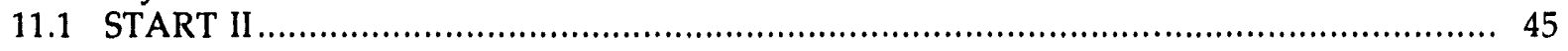

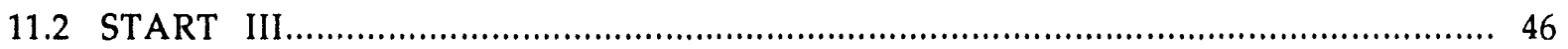

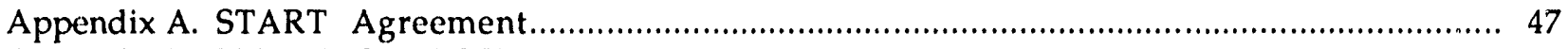

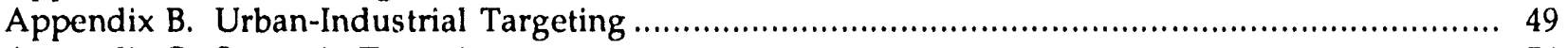

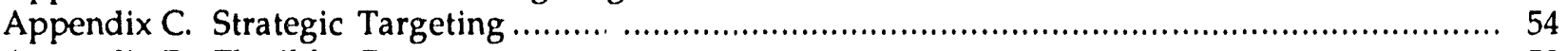

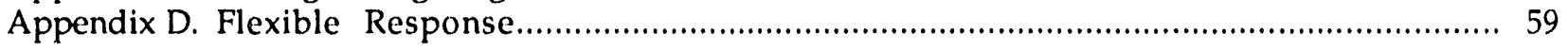




\title{
Strategic Forces: Future Requirements and Options
}

\begin{abstract}
In the wake of the collapse of the Warsaw Pact and the apparent ending of the Cold War, there have been renewed calls for radical cuts in U.S strategic forces to levels far below the 10,000 or so warheads allowed each side under the current START proposal. Since it now appears that NATO for the first time will have the capability to defeat a Soviet conventional attack without the necessity of threatening to resort to nuclear weapons, this should pave the way for the rethinking of U.S. strategy and the reduction of U.S. strategic weapons requirements. In this new environment, it seems plausible that, with a modification of the Flexible Response doctrine to forego attempts to disarm the Soviet Union, deterrence could be maintained with 1500 or so survivable strategic weapons. With a new strategy that confined U.S. strategic weapons to the role of deterring the use of nuclear weapons by other countries, a survivable force of about 500 weapons would seem sufficient. With this premise, the implications for the U.S. strategic force structure are examined for two cases: a treaty that allows each side 3000 warheads and one that allows each side 1000 warheads.
\end{abstract}




\section{Introduction}

With the collapse of the Warsaw Pact and the apparent ending of the Cold War, the strategic concepts that have guided America's defense policy over the last four decades will inevitably come under scrutiny. President Bush has begun this process with a call for the development of a new national and alliance strategy. Any resulting policy changes could significantly affect the role and size of all U.S. military forces-including strategic nuclear weapons.

Already there have been numerous suggestions that the modest armis reductions proposed in the current Strategic Arms Reduction Talks (START) are insufficient and that the U.S. should seek agrecments that would make deep, significant cuts in the strategic nuclear arsenals of the superpowers. ${ }^{1}$ Determining what lower force level would be reasonable and acceptable ("How much is enough?") is of course a matter of debate.

Paul Nitze, a senior arms control advisor to President Reagan, recently suggested that equal force levels of around 3000 warheads would be sufficient for deterrence. ${ }^{2}$ He also argued that this is at a high enough level that there would be no serious concerns about such matters as Third Countries with nuclear weapons or about the consequences of the Soviets hiding weapons. Harold Brown, Secretary of Defense under President Carter, also has suggested that the next strategic arms control agreement, START II, should reduce the force levels to around 3000 weapons or slightly less. ${ }^{3}$ He further argued that if one looks only at U.S. and Soviet forces, it would be possible to design a very stable deterrent with 1000 nuclear warheads on each side.

In contrast to these proposals, the START Treaty would allow the U.S. to retain over 10,000 warheads. Moreover, in 1989, Air Force Chief of Staff Gen. Larry Welch and Strategic Air Command (SAC) commander Gen. John T. Chain argued before Congress that deterrence would be threatened if they did not have the full force levels allowed by START, including the 2600 weapons that could be carried on the $132 \mathrm{~B}-2 \mathrm{~s}$ requested by the Air Force. ${ }^{4}$ In discussing a proposed START II follow-on treaty, Gen. Chain re-emphasized this point by contending that any reduction in force levels below the levels allowed by the current START proposal would be unwarranted-unless there was a significant change in defense policy guidance from the President. ${ }^{5}$

Hence, to be acceptable, any calls for deep cuts in strategic nuclear weapons will have to address the underlying question of what role these weapons will play in future U.S. defense and foreign policies and how many weapons will be required to carry out their designated missions.

Two fundamental roles have been assigned to strategic nuclear weapons in the past: deterrence of nuclear attacks on the homeland and deterrence of conventional or nuclear attacks on America's allies. While the first mission is not likely to be altered, the changes taking place in Eastern Europe and the Soviet Union and the consequent reduction in political tensions will very likely cause a re-evaluation of the weapons requirements for the second. This point is important because the driving force for the size of our strategic forces has always been the defense of Europe rather than the defense of the homeland.

In Part I of this paper, the weapons requirements for deterrence are examined in light of recent changes in the geopolitical environment. In Part II, it is assumed that the President and Congress have decided that deep cuts in strategic forces are acceptable. With this premise, the implications for the U.S. strategic force structure are examined for two cases: a treaty that allows each side 3000 warheads and one tha' dllows each side 1000 warheads.

\footnotetext{
ISee Appendix A for a description of the terms of the proposed START Treaty.

2 Press conference, June 5, 1990, CSPAN Television.

"Harold Brown, "Navigating the Security Sea Change," Arms Control Today, May 1990, p. 4.

${ }^{4}$ Aviation Week and Space Technology, July 31, 1989, p. 24. This would have resulted in a START force level of about 11,000 actual-as opposed to accountable-weapons. More recently, Secretary of Defense Richard Chency reduced the B-2 request to 75 aircraft.

${ }^{5}$ Television broadcast of America's Defence Monitor, "Targeting for Nuclear War," May 25, 1990.
} 


\section{Part I}

Strategic Policy 


\section{Central Deterrence}

The primary function of any nation's defense policy is to defend the homeland from attack and destruction. Against a conventional attack, America has always been and remains easily defendable. However, the advent of nuclear weapons and long-range delivery systems created for the first time the possibility of destruction by a foreign power. To deter an attack on the U.S. ("central deterrence") or the blackmail that might follow from such a threat, the U.S. has adopted a policy of threatening to retaliate with nuclear weapons.

\subsection{Deterrence of City Attacks}

To deter an attack on U.S. cities, it is generally thought that the Soviets must believe inat they will incur a level of damage in retaliation sufficiently high to make the attack not worth any political or military objective that they might have had. This level of damage is obviously uncertain. Some have argued that a few weapons exploded over a few major Soviet cities would be perceived as such a disaster in the minds of the Soviet leaders that no political objective would be worth the resulting catastrophe. And since an attack on U.S. cities would surely cause such a retaliatory attack, the Soviets are deterred from ever deliberately initiating attacks on our cities as long as the U.S. maintains the barest of a minimal surviving deterrent force. At the other extreme, people have argued that unless the U.S. can maintain a threat of genocide against the Soviet people (or at least the Russians), deterrence is at risk.

The U.S. has generally sought a middle ground, threatening to destroy a large percent of Soviet industry if U.S. cities were attacked. Secretary of Defense Robert McNamara, in the 1960s, announced what came to be known as the "assured destruction" level of strategic forces. If the Soviet Union attacked the U.S., we must have enough forces capable of surviving a well-coordinated surprise attack to inflict "unacceptable" damage on the Soviet Union. This level of force was variously described as the equivalent of 200-400 MT of nuclear explosives and capable of destroying 50 percent of Soviet industry and $20-25$ percent of the Soviet population. ${ }^{6}$

The specific industrial targets have varied over time as the nuances of the U.S. targeting doctrine changed from administration to administration. However, from a deterrence point of view, it is unlikely that the details of the targeting doctrine make any difference. Since the targeting plan (the Single Integrated Operational Plan or SIOP) is secret, presumably all that the Soviets know is they can expect to suffer enormous damage to their cities in retaliation (barring an extremely successful counterforce attack). Therefore, for deterrence, perhaps the most important aspect of assured destruction is that it is indeed assured.

Soviet industry appears to be highly concentrated (see Appendix B). Currently, according to former Pentagon analyst William W. Kaufmann, there are about 1400 Soviet industrial targets worth attacking. ${ }^{7}$ Thus, most of Soviet industry probably could be destroyed with about 1400 "small" yield $(40 \mathrm{kt})$ weapons. If medium-sized weapons ( $100 \mathrm{kt}$ to $500 \mathrm{kt}$ ) were used, less than half this number of weapons would be adequate. ${ }^{8}$ (See Appendix B.)

Currently, with over 12,000 strategic weapons, the U.S. has no real reason to economize on weapons for an urban-industrial attack. Hence, the targeting of facilities of even marginal value is probably considered acceptable. However, if it were desired to cut the number of strategic weapons significantly, a closer scrutiny of the target list would be required. For example, it can be argued that while there may be about 1400 manufacturing facilities, refineries, and electric power plants of value in the Soviet

\footnotetext{
${ }^{6}$ Alain C. Enthoven and K. Wayne Smith, How much Is Enough? Shaping the Defense Program, 1961-1969 (New York: Harper \& Row, 1971) p. 207. In 1972, the delivery of weapons with the firepower equivalent of $100 \mathrm{MT}$ would have been able to destroy about 59 percent of Soviet industrial capacity.

${ }^{7}$ Aviation Week and Space Technology, May 2, 1988, p. 105.

${ }^{8} \mathrm{Many}$ of the larger weapons would be able to destroy more than one target since many of the industries are located close enough to each other to be encompassed within the "kill radius" of the larger weapons.
} 
Union, probably only about 400 of these facilities are of real military significance. ${ }^{9}$ Thus, it seems likely that with a judicious selection of targets the assured destruction mission could still he carried out by a SIOP containing considerably fewer industrial targets than today's target list.

There also is another factor to consider. The war planners design their attacks on individual targets by assuming that a certain level of blast overpressure is necessary to destroy a particular facility. The resulting fires and destruction in the surrounding city are ignored when calculating the effectiveness of the attack. Most (about two-thirds) of the industrial facilities in the Soviet Union are located in the top 200 or so cities. The analysis in Appendix B indicates that the resulting blast and fires from even a few hundred medium-sized nuclear weapons would probably obliterate these cities. The resulting economic destruction and societal chaos could destroy the Soviet Union as a modern industrial society.

In summary, today the assured destruction mission of the strategic forces probably can be accomplished (under the present targeting doctrine) with the delivery of several hundred 500-kt warheads. If only "critical" targets were attacked, or if a more realistic view" of the collateral damage and likely societal disruption that would be caused by numerous nuclear explosions were taken into account, it seems likely that the mission could be accomplished with less than 200 of these weapons.

\subsection{Deterrence of Non-City Attacks}

Of course, a threat to retaliate against Soviet cities is only likely to be credible in deterring an attack on U.S. cities. To deter other possible attacks, the U.S. needs (and has) additional forces with the capability and flexibility to retaliate against a wide variety of military and other targets. But what is the likelihood of such attacks?

The primary concern over time has been the possibility that the Soviets might attack our strategic nuclear forces. If the Soviets had the capability to launch a successful disarming first strike against all U.S. strategic forces, they would be in a position to coerce the U.S. by threatening to attack U.S. cities without fear of retaliation. Obviously, the best way to deter such an attack is to build sufficient strategic forces and base them in such a way that there can be no doubt on either side that a significant retaliatory force will survive under even the most adverse circumstances.

Without a disarming first-strike capability, it is difficult to imagine that the Soviets would ever perceive that there would be any advantage in initiating a nuclear strike against the U.S. The Soviets have long been students of Clausewitz and recognize that the first question to ask about war is what is the political goal that justifies the military cost. This is not to say they always make the correct decision, as witness Afghanistan. But to launch a nuclear strike that would kill hundreds of thousands (or, more likely, millions) of civilians even if directed only at military targets, while still leaving the U.S. with the means to retaliate, must clearly be seen to be irrational by even the most obtuse political leader. Since the U.S. would not have to acquiesce to Soviet demands following an attack, the Soviets would recklessly be initiating a possibly uncontrollable round of nuclear exchanges with no real hope of achieving any political advantage. Thus, as Bernard Brodie noted, "Unless one can wipe out the enemy's retaliatory force fully or nearly so with one's initial strike, there really is no suitable target to strike at. This is of course only one reason for refraining from attack, but a sufficient one." 10

But what should we do if nevertheless a Soviet counterforce strike took place? Once an intercontinental nuclear exchange has begun, every effort should be made to avoid civilian casualties and to bring the war to an early conclusion. Since the U.S. is unlikely to ever achieve a capability to disarm the Soviets, the only practical way to protect American lives is through mutud self-restraint. Thus, the U.S. should avoid targeting cities, save in retaliation for Soviet attacks on U.S. cities. And even in

\footnotetext{
${ }^{9}$ Michael M. May, George F. Bing, John D. Steinbruner, "Strategic Arsenals After START: The Implications of Deep Cuts," International Security, Summer 1988 (Vol. 13, No. 1), pp. 90-133. Also see Appendix C. Their paper does not explicitly address the concept of central deterrence and only considers targeting in a general context which includes attacks on Soviet military forces and the Soviet political leadership.

${ }^{10}$ Bernard Brodie, War and Politics (New York: Macmillan, 1974), footnote, p. 330.
} 
retaliation, it would be morally preferable to have an announced policy of giving civilians time to evacuate these targets. ${ }^{11}$

More generally, our retaliation should be appropriate to our objectives. For example, if the Sovict attack on the U.S. were against a small set of targets, the U.S. could respond in kind or against targets of its own choosing. ${ }^{12}$ If the Soviet attack (whether small or large) were coupled with an invasion of Europe, our strikes should be geared to defeating the Soviet invasion. This does not mean that the U.S. should attempt a futile disarming attack against the Soviets, although limited military strikes could be of some value. Nor does it mean that we should be under the illusion that strategic strikes could win a war in the sense that they could coerce a nuclear-armed Soviet Union into surrendering. At best, we could hope to use strategic nuclear weapons to support a strong battlefield defense (using conventional and tactical nuclear weapons) designed to thwart the military/political objectives of the Soviets. A few huridred survivable strategic weapons should be sufficient for this (unlikely) contingency (sce Saction 4).

In summary, without a disarming capability, neither side has the ability to coerce the other with nu ilear threats or attacks. This lack of utility for a non-disarming strike, when combined with the U.S. capability to respond against a wide variety of non-urban targets and the possibility of an undesired, runaway escalation in violence once a nuclear exchange starts, should act as a strong deterrent to the Soviets initiating any nuclear attack against the U.S.

\footnotetext{
${ }^{11}$ There is no military necessity to attack cities quickly since military production is likely to become important only if the war becomes very protracted.

${ }^{12}$ Since an attack of this nature would basically be irrational, it would do little good to try to specify beforehand the exact type of retaliation that the Soviets could expect. It might, in fact, be counterproductive.
} 


\section{Extended Deterrence}

\subsection{History}

Although central deterrence of an attack on the homeland is logically the primary objective of U.S. defense policy, it has never actually been the primary concern of defense policy, since it has always been looked upon by policymakers as fairly easy to achieve. Indeed, as Albert Wohlstetter has pointed out, "the original second-strike theory of deterrence originated in the U.S. in the early-1950s in the context of the use of long- or intermediate-range nuclear forces to deter or defeat a Soviet invasion of Western Europe ${ }^{\prime 13}$ and had little to do with the defense of the U.S. homeland.

In the early-1950s, the Soviet Union possessed few long-range nuclear delivery systems. Since the U.S. was relatively invulnerable to nuclear attack, NATO opted for a nuclear warfighting strategy as an inexpensive means to deter a Soviet conventional attack. If the Soviet Union invaded Western Europe, the U.S. threatened to initiate massive nuclear attacks against the Soviet Union that would eventually lead to the defeat and the destruction of the invader. Thus, America's nuclear deterrent capability was "extended" to cover its NA rO allies.

As the number of Soviet long-range forces (first bombers, then intercontinental ballistic missiles [ICBMs] and submarine-launched ballistic missiles [SLBMs]) increased during the late-1950s and early1960s, the damage that the Soviets could inflict on the U.S. in a retaliatory strike began to increase. This was a very serious problem since it was clear that the only plausible way that the U.S. could continue to threaten to initiate nuclear strikes against the Soviet Union and "win" a war would be if it could disarm the Soviets. ${ }^{14}$

How the U.S and NATO should cope with the Soviets' growing capability to retaliate had became an important policy issue as early as the late-1950s. Some argued that a $s$ tate of mutual deterrence would soon exist no matter what forces the U.S. deployed and that this new situation required a revolution in our way of thinking about strategic nuclear weapons. Henceforth, it would be irrational to base our strategy on the threat to initiate nuclear strikes against the Soviet Union. Strategic weapons would now have one function-to deter the Soviets from initiating nuclear strikes by providing a credible threat of retaliation.

The Navy, in particular, under Adm. Arleigh Burke, called for a shift in U.S. and Nf TO strategy: We should move to a much improved conventional force in Europe to be backed up by a "finite deterrence" nuclear retaliatory force ${ }^{15}$ to deter Soviet nuclear attacks. However, this approach was rejected by President Eisenhower.

Nevertheless, by the mid-1960s, it was apparent that the U.S. could no longer prevent a destructive Soviet retaliatory strike and that the U.S.-NATO strategy had lost its rationale and credibility. In response, President Kennedy's Secretary of Defense, Robert McNamara, devised a new strategy (called Flexible Response) that sounded very much like Adm. Burke's proposal.

Flexible Response called for the building up of NATO's conventional forces to such a level that they could defeat a Warsaw Pact conventional invasion without the use of nuclear weapons. McNamara also introduced the idea of a finite, assured destruction level of strategic nuclear forces (200) to $400 \mathrm{MT}$ ) that would be sufficient to deter a Soviet nuclear strike.

However, in practice, the basic policy did not change. While Flexible Response has remained NATO's official doctrine since 1967, the conventional build-up to offset the Warsaw Pact's forces never occurred. Thus, NATO's defense against a massive Soviet conventional attack continued to rest on the threat of a U.S.-initiated nuclear war-including a rapid escalation to the level of nuclear attacks on the Soviet Union.

\footnotetext{
${ }^{13}$ Stephen Prowse and Albert Wohlstetter, "Stability in a World with More Than Two Countries," in Sanford Lakoff, ed., Beyond START? A Soviet Report Proposing Radical Reductions in Nuclear Weapons, University of California, IGCC Policy Paper No. 7, 1988, p. 47.

${ }^{14}$ Even a few hundred surviving nuclear weapons could destroy the major U.S. cities.

${ }^{15}$ This force would have been much smaller than the strategic force advocated by the Air Force, whose stated goal was to maintain a "credible first-strike capability." Enthoven and Smith, op. cit., p. 170.
} 
Since initiating nuclear attacks on the Soviet Union remained U.S. policy, the military naturally called for the funds and forces necessary to make this warfighting, warwinning strategy credible-that is, they wanted to restore the U.S. to its previously invulnerable position by pursuing a counterforce, disarming strategy. But Secretary McNamara and his successors never completely supported this strategy since they recognized that it would be an open-ended drain on resources and that success was exceedingly unlikely against a responsive opponent like the Soviet Union. However, they also have been unwilling (or politically unable) to completely abandon counterforce targeting.

From 1960 to 1970, the U.S. had around 3500 strategic warheads, about half of which were on alert. Less than a quarter of these weapons (250-350) were assigned to urban-industrial targets, with the rest being allocated to military targets. (A brief history of strategic targeting force requirements is given in Appendix C.)

The introduction of multiple-warhead (MIRV) missiles greatly expanded the number of weapons available to the U.S. (see Fig. 3-1 ${ }^{16}$ ) and the Soviet Union. Thus, today the U.S. has over 12,000 strategic warheads in its inventory, and the Soviets possess a comparable number. Of course, as the number of weapons increased, the target list also expanded to accommodate the new warheads. By the late-1970s, the number of targets to be hit by forces on day-to-day alert had grown to about 4,000.

Today, there may be as many as 5000 to 6000 primary targets ${ }^{17}$ for the U.S. forces anticipated to survive a Soviet surprise attack. ${ }^{18}$ Of these targets, only about one-quarter are industrial-which has been the case for more than three decarles. The rest of the weapons are assigned to conventional and nuclear military targets and government control facilities in order that the U.S. might "prevail" in a nuclear war. But even with the massive increase in nuclear weapons since 1970, the U.S. is now probably even less close to being able to initiate and "win" an intercontinental nuclear war. (Despite the formidable number of targets ror our strategic weapons, Flexible Response in reality is not a strategy for defeating a Soviet invasion, but at best an attempt to coerce the Soviet Union through nuclear strikes. See Appendix D for a general critique of this strategy.)

Thus, for the past 23 year's under Flexible Response, the U.S. has maintained the same basic policy developed in the 1950s. The real driving force that continues to establish the size of our strategic forces remains the elusive goal of developing a damage-limiting warfighting capability. However, both political and economic constraints have prevented an all-out attempt to achieve this goal. And, of course, the Soviets continues to act to offset our limited attempts to develop a capability to disarm them. Hence, we are left with an expensive, half-hearted strategy with no real guidelines as to "how much is enough." Moreover, it is a strategy that few believe would ever be implemented if war broke out-since it would appear to be sicidal to initiate nuclear strikes against the Soviet Union.

\subsection{Flexibility vs Flexible Response}

One point should be clarified. Advocates of the Flexible Response doctrine often accuse their critics of being opposed to "flexibility" in targeting. They claim that critics would leave the President with one option, a suicidal attack on Soviet cities to meet all contingencies. But this is a false

\footnotetext{
${ }^{16}$ Sources: W. Bruce Winerod, ed., Arms Control Handbook (Washington, D.C.: The Heritage Foundation, 1987) and "Deterring Through the Turn of the Century," The Foreign Policy Institute/The Center for Strategic and International Studies, 1989.

${ }^{17}$ See M. May, et al., op. cit. p. 114, and Aviation Week and Space Technology, May 2, 1988, p. 105.

${ }^{18}$ Of course, many more weapons might be survivable if the U.S. had strategic warning (hours or days in advance) of . $n$ impending attack and had time to put its nont-alert forces on alert. But these so-called "generated" weapons (and their targets) are only considered as a bonus, and have never been considered as a necessary part of the deterrent force. Although recently, the Defense Department has begun to talk about basing deterrence on the belief that the U.S. will always obtain strategic warning. For example, see Barry E. Fridling and John R. Harvey, "On the Wrong Track? An Assessment of MX Rail Garrison Basing," International Security, Winter 1988/1989 (Vol. 13, No. 3) pp. 113-141.
} 
FIG. 3-1 U.S. STRATEGIC WEAPONS INVENTDRY

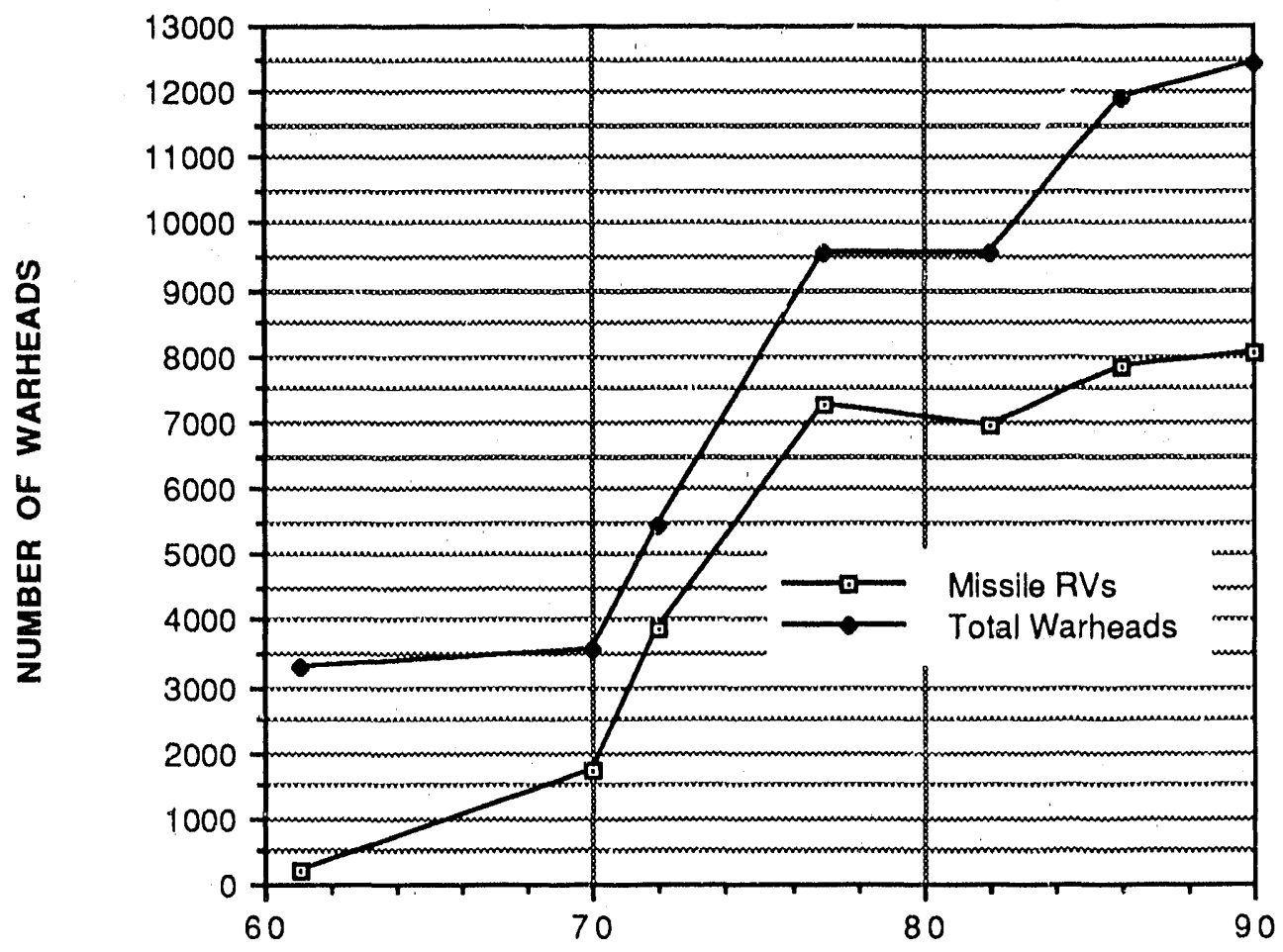

YEAR

dichotomy. The question is not whether we should have flexibility and the capability for a less than all-out city attack--we do and always have had such a capability. The real question is not one of capabilities, but one of policy: should the U.S. have a policy of initiating nuclear strikes against the Soviet Union or should strategic nuclear weapons be used only to deter nuclear attacks on the U.S. or its allies and to retaliate in an appropriate fashion (including non-urban attacks) if deterrence should fail?

\subsection{Credibility}

That Flexible Response lacks credibility has of course not gone unnoticed. It is openly acknowledged by past government officials such as the originator of the doctrine, Robert McNamara, ${ }^{19}$ and former Secretary of State Henry Kissinger. ${ }^{20}$ Even President Reagan's Commission on Long-Term Strategy pointed out that as long as both sides are mutually vulnerable, our stated policy can only be viewed as a bluff. ${ }^{21}$ One of the co-chairmen of that panel, Fred Ikle, Undersecretary of Defense for

\footnotetext{
19"[T] he launch of strategic nuclear weapons against the Soviet homeland ...would be an act of suicide. The threat... has lost all credibility as a deterrent to Soviet conventional aggression." Robert S. McNamara, "The Military Role of Nuclear Weapons: Perceptions and Misperceptions," Foreign Affairs, Fall 1983, p. 73.

20"[W]e must face the fact that it is absurd to base the strategy of the West on the credibility of the threat of mutual suicide." Henry A. Kissinger, "NATO Defense and the Soviet Threat," Survival, November/December 1979, p. 266.

${ }^{21}$ Fred C. Ikle and Albert Wholstetter, Co-chairmen, Discriminate Detarrence: Report of the Commission on Integrated Long-Term Strategy, U.S. Government Printing Office, January 1988, p. 30.
} 
Policy under Prsident Reagan, once out of office, went even further, characterizing Flexible Response as "a totally incoherent doctrine."22

President Reagan himself apparently recognized the unsatisfactory tature of current U.S. strategy and instigated programs that he hoped would bring about a radical change in that strategy. In his now-famous 1983 speech, he pre posed that we try to develop technologies that would make nuclear weapons "impotent anid obsolete." The President in effect proposed that we seek to establish a world free of nuclear weapons to be enforced and insured by defensive shields over the U.S. and the Soviet Unuor. The obvious implication was that once the shields were in place, the U.S. could no longer defend Europe by threatening to astack the Soviet Union with nuclear weapons.

\subsection{Existential Extended Deterrence}

If NATO's strategy so obviously lacks credibility, one might ask why has there been no war in Europe. Several possibiliries exist. For example:

1. By the time the U.S. nuciear threat began to lose its credibility in the 1960s, the Soviet leadership may have no ionger considered the conquest of Western Europe as an attractive option (assuming that they ever did). While Stalin was perfectly willing to impose the Soviet system on the countries he o wupied at the end of World War II, the new Soviet leadership under Khrushchev may not have been prepared to risk even a conventionul war to spread Communism by force. Although on paper their conventional advantage might have looked good, they could in fact have had grave doubts about their ailies or even their own troops. Furthermore, in a conventional war, the U.S. with its vast industrial capability could ensure that the war would 1. .come protracted and, hence, the final result would be uncertain. All in all, whatever gains from an invasion the Soviets might have envisioned (and the economic gains cculd actually have been quite small) could easily have been off-set by the considerable real and potential losses.

2. Others argue that there is an additional impurtant iactor. With an attack on Western Europe, the Soviet Union would be initiating a war against a nuclear superpower over an area that has long been considered crucial to that superpower. Thus, although therc might be no rational advantage to the use of nuclear weapons, once engaged in combat it would be difficult to predict whether everyone would behave rationally - nuclear weapons could be used and an unintended escalation could ensue. Even if the probability of this were quite small, the resuits would be catastrophic if it occurred. Hence, any possible gain would be seen to be not worth the risk.

"The reality of this "existential extended deterrence" (both conventional and nuclear) of course can not be pruved. Nor, fur that matter, can the U.S. threat to initiate nuclear war be shown to have prevented a Sovist invasion of Western Europe. But if existential extended deterrence exists at all, it is unlikely to depend upon elaborate intercontinental targeting schemes, but just on the existence of a significant number of survivable strategic weapons (with flexible targeting capabilities) and a credible co:nmitment of U.S. involvement in the defense of Western Europe.

\subsection{Post-Containment Defense of Europe}

While the weakness of NATO defense strategy has been evident for years, neither the Americans nor the Europeans have been willing to pay for the large forces considered necessary to offset the conventional force threat from the Warsaw Pact. However, the dramatic changes underway in Eastern Europe and the Soviet Union alter all previous assessments about the threat and the size of the forces needed to defend Western Europe.

In recognition of this, the leaders of NATO recently called for the adoption of a "new NATO strategy making nuclear forces truly weapons of last resort." ${ }^{23}$ They also announced that U.S. ruclear artillery shells would be removed from Europe providing that the Soviet Union did the same. While

${ }^{22}$ Fred C. Ikle, "The Ghost in the Pentagon," The National Interest, Vol. 19, Spring 1990. p. 20.

${ }^{23}$ Aviation Week and Space Technology, July 23, 1990, p. 69. 
these announcements do not outwardly change the Flexible Response doctrine, they are an indication of a possible gradual move to a real conventional defense strategy for Europe.

But is a credible conventional deterrent now feasible? Early in 1990, the Chairman of the House Armed Services Committee, Les Aspin, concluded (based on testimony of the U.S. military chiefs' that the U.S. and its NATO allies could now-for the first time in the history of NATO-defeat invading Soviet forces without resorting to nuclear weapons. ${ }^{24}$ And since that assessment, there have been a number of events further strengthening NATO's position: East Germany has withdraw .rom the Warsaw Pact and reunited with West Gimany, the Soviets have agreed to withdraw their troops from Hurigary and Czechoslovakia by mid-1991, and a Conventional Armed Forces in Europe (CFE) Treaty that will decrease the Warsaw Pact tank forces from the present level of about 60,000 to 20,000 (a reduction of over 100 armored divisions worth of tanks) has been signed.

Of course, it would be useful to codify with additional arms control agreements (CFE II) appropriate changes in NATO and Warsaw Pact force structures that would strengthen the defense relative to the offense. Such agreements, if carefully drawn, could probably further reduce the potential threat of war and enhance the security of all of Europe.

But even without further formal agreements, the political/military situation in Europe appears promising. The current Soviet Jeadership apparently has little ambition to reestablish its military superiority in Europe and has even given up its buffer zone in Eastern Europe. It is now NATO that has a buffer zone of friendly states separating it from the Soviet Union. Moreover, according to NATO's Secretary General, Manfred Woerner, the Warsaw Pact military structure has now ceased to exist, and the Pact no longer presents a military threat to NATO. ${ }^{25}$ Under these circumstances, it seems very likely that a high-confidence conventional-force defense strategy could indeed be developed and maintained.

\footnotetext{
24 San Francisco Chronicle, March 14, 1990, p. A1.

${ }^{25}$ San Francisco Crronicle, November 20, 1990, p. A17.
} 


\section{Future Strategy}

The centerpiece of NATO's new strategy should be the development and maintenance of a conventional defense strong enough to deter a Soviet conventional attack on Western Europe. However, some might argue that even an apparently strorg conventional defense will not be sufficient since NATO (or the Soviet Union) might miscalculate its true effectiveness-providing a temptation for the Soviets to attack. Thus, NATO may be unwilling to abandon completely the nuclear component of its defense against a conventional attack. However, if NATO is to retain a nuclear back-up and if the U.S. is to move to much lower strategic weapons levels, it will be necessary to devise a new nuclear strategy. A number of alternatives are possible.

\subsection{Modified Flexible Response}

The current Flexible Response doctrine envisions the possibility of U.S...initiated nuclear stri: against the Soviet Union in the event that the conventional defense of Western Europe begins to fail following a Soviet invasion. The targets include a wide range of conventional and nusclear military targets, the civilian and military command and control structure of the Soviet Union, and a number of war-supporting industries. Of course, a strike against many of these rgets, particularly the urbanindustrial targets, obviously could cause a devastating retaliation against U.S. cities.

One approach to limiting the weapons requirements of Flexible Response would be to abandon the futile attempt to disarm the Soviets. In the event of a Soviet invasion of Western Europe, the Soviets would obviously be alert and prepared to launch their ICBMs and bombers on warning of an incoming U.S. attack Nevertheless, in pursuit of its disarming goal, the U.S. continues to expand its set of military targets in the Soviet Union and even proposes to buy the quite expensive B-2 bomber for the primary purpose of tracking down Soviet mobile missiles. Even if the B-2 could successfully accomplish this task (which the Air Force admits is impossible at this point), it could just provoke the preemptive launch of these missiles on U.S targets. ${ }^{26}$

A study ${ }^{27}$ by Michael May and George Bing of Lawrence Livermore National Laboratory and John Steinbruner of the Brookings Institute indicated that, if an attempt at a disarming counterforce attack were abandoned, the number of reliable, available, and surviving strategic weapons necessary to carry out the rest of the current Flexible Response doctrine would be a'sout $150 \mathrm{C}$ to 2000.28 Thus, a somewhat modified Flexible Response policy could considerably lower the strategic weapons requirements (from the current level of about 6000 surviving weapons) without changing the fundamental character of current NATO strategy. ${ }^{29}$

\footnotetext{
${ }^{26}$ The Air Force claims that the B-2 would also be especially effective against some hard targets, like command bunkers. The attack on these targets also would not always clearly be to our advantage; e.g., if we were trying to bring the war to an early end. In passing, it should be noted that when Secretary Cheney reduced the request for B-2s from 132 to 75 , he justified the reduction by suggesting that with the disintegration of the Warsaw Pact, the number of targets in Eastern Europe had been reduced, freeing these weapons for Soviet targets. This is a somewhat peculiar argument, since the rationale for the B-2 was that it has a unique capability to attack certain targets inside the Soviet Union.

${ }^{27}$ M. May, et al., op. cit. p. 94 . Also see Appendix C.

${ }^{28}$ This number apparently assumes the development of a post-attack retargeting capability to optimize the retaliatory strike by avoiding unnecessary redundant targeting of individual targets.

${ }^{29}$ The required number of deployed weapons to provide 1500 survivable weapons might be 3000 or more. Thus, if the U.S. had the option of using nuclear weapons first, which advocates of Flexible Response seem to believe, there could be considerably more than 1500 weapons available.
} 


\subsection{An Alternative Strategy}

While modifying the Flexible Response doctrine could reduce weapons requirements, it will not make the strategy any more credible (or rational). Of course, since the policy has to most observers not been credible for over 20 years, one might argue that its credibility does not really matter-it only has to be politically acceptable to our allies and the American public. Furthermore, since the current Soviet leadership seems far from belligerent, it could be argued that NATO's nuclear strategy is basically irrelevant, since war is now unlikely.

Nevertheless, it still seems misguided to base force planning and strategy on a war plan that no one is ever likely to implement. It not only causes the misallocation of resources, but it could still be used as an inappropriate crutch to allow NATO to forgo developing or maintaining a viable conventional defense. Hence, a new general strategy to cope with the changed geopolitical situation seems not inapropriate.

\section{European Defense}

If a nuclear fall-back defense is deemed necessary, it should be a strategy that could actually be implemented. President Reagan's Commission on Long-Te'm Strategy pointed the way for reorienting NATO's nuclear doctrine in response to a conventional attack when it suggested that the "Alliance should threaten to use nuclear weapons not as a link to a wider and more devastating war. . but mainly as an instrument for denying success to the invading Soviet forces." 30

Indeed, today's central strategic reality is that the initiation of nuclear strikes against the homeland of a nuclear superpower or its allies will almost assuredly result in retaliation and possibly uncontrolled escalation. Hence, as a prelude to a credible strategy, NATO should announce a new nuclear use doctrine: "no first use of nuclear weapons on foreign territory." Of course, if a country or alliance is invaded, it should be free to choose what weapons it will use to defend itself on its own territory. Thus, the new policy would permit the first use of nuclear weapons by NATO on NATO territory if its conventional defense was failing. Such a defensive use could not legitimately be considered escalatory. From this perspective, the onus (and risk) of nuclear escalation would fall on the Soviets, not NATO.

A strategy to use nuclear weapons on the battlefield would have to meet severe political restraints such as very low "collateral damage" from the nuclear explosions. One proposal that potentially could meet these requirements is a strategy to support NATO's conventional forces with a Nuclear Zone Defense. $^{31}$

In this strategy, the use of nuclear weapons would be confined to a narrow zone (say, $10 \mathrm{~km}$ wide) of NATO's choosing (perhaps roughly along the former inter-German border). This zone would be highly instrumented with surveillance equipment to locate Soviet units as they moved through. If it became clear that the conventional defense could not hold, strikes in the Nuclear Zone would begin. These attacks would not use U.S. strategic weapons, but would rely on shorter-range air-iaunched or groundlaunched missiles. These nuclear weapons might be primarily European (British and French), perhaps backed up by weapons stored in the U.S. ${ }^{32}$

The changed geopolitical/military balance in Europe makes it very unlikely that even a hostile Soviet Union would find it advantageous to launch an invasion of Western Europe. But if there were a war, probably the last thing that the Soviets would want to do is attack Western Europe or the U.S. with nuclear weapons since it would guarantee retaliatory nuclear strikes against the Soviet homeland. For example, a massive counterforce strike against the U.S. could result in a retaliatory strike of such a magnitude that millions of Soviets could be killed even if the U.S. strike were confined

${ }^{30}$ F. Ikle and A. Wholstetter, op. cit. p. 30.

${ }^{31}$ A. L. Latter and R.D. Speed, "A New Approach to European Defenre," R\&D Associates, internal document, Dec. 1986.

${ }^{32}$ Thus, a treaty abolishing all tactical nuclear weapons would not be advisable, even in the unlikely event that it could be verified. 
to military targets. And further uncontrolled escalation could not be ruled out. Under those circumstances, the Soviets would be deliberately initiating a process that could easily result in consequences that would overwhelm the significance of their original objective in Europe. Hence, it scems likely that, unless the Soviets had a disarming first-strike capability, the primary role of Soviet strategic forces in any European war would be confined to deterring NATO's use of nuclear weapons against the Soviet homeland. ${ }^{33}$

If nevertheless the Soviets did initiate nuclear strikes against U.S. or NATO territory, NATO's nuclear attacks could then be expanded beyond the Nuclear Zone. U.S. and allied strategic and tactical nuclear forces would be used with the objecrive of supporting the battlefield defense. The nature and number of the targets for these weapons would have to be determined after careful analysis of the chosen battlefield strategy. But it seems unlikely that in defending Europe more than a hundred or so fixed targets inside the Soviet Union would be of significance. ${ }^{34}$ Destruction of Soviet military units as they approached NATO's defense lines might still be the most critical mission for NATO's forces. Thus, the improvement in NATO's reconnaissance and $\mathrm{C}^{3}$ capability to locate and target Soviet units in the field should be given a high priority. Of crurse, whatever the targets, every effort should be made to minimize civilian casualties to prevent the war from escalating beyond control.

Obviously, the Nuclear Zone concept is just one approach to a possible viable conventional-nuclear defense. Once NATO changed its nuclear use doctrine and made a commitment to a "last-resort" battlefield defense, many new ideas would undoubtedly be advanced.

What if the Europeans reject a battlefield nuclear defense strategy (as they have in the past)? It is, of course, their prerogative to seek an alternative strategy since it is their territory which would be under attack. But, in any event, the U.S. should adhere to a policy of no first use on foreign (non-NATO) territory and reject the unrealistic policy of threatening to initiate nuclear attacks on the Soviet Union in response to a conventional attack.

A possible alternative for NATO is a strong conventional defense backed up by a European nuclear deterrent arsenal, an arsenal that would gain significant credibility if the two superpowers radically reduced their nuclear forces. In an era when NATO declares that the Cold War is over and that it "does not look upon [the Soviet Union] as an adversary, but as a new partner," 35 the Europeans may soon consider this approach sufficient for deterrence of a potential Soviet conventional attack. ${ }^{36}$

\section{U.S. Strategic Policy}

With a reorientation of NATO's defense posture, the role of U.S. strategic nuclear weapons would rever to that of deterrence of nuclear attack by threats of retaliation. That is, their role would be to prevent the of fensive use of nuclear weapons by other countries. The number of weapons required for this mission could be significantly less than that required under the current Flexible Response doctrine.

Assured Destruction. The primary goal of strategic nuclear weapons would remain the prevention of an attack on U.S. cities. To accomplish this, a force of 300 survivable mid-sized strategic warheads should be sufficient to both threaten the destruction of Soviet society and provide a Strategic Reserve of 100-150 warheads. ${ }^{37}$

Flexibility . In addition to the nuclear weapons for the assured destruction mission, it would be necessary to have some other strategic weapons for such contingencies as a possible selective retaliation against a limited use of nuclear weapons against the U.S. or its allies by the Soviet Urion ${ }^{38}$ or other

\footnotetext{
${ }^{33}$ Of course, the present Flexibile Response doctrine with its threat of initiating nuclear attacks on the Soviet Union gives the Soviets some incentive to preempiively attack, assuming that they thought NATO might actually carry out the threat. A revised NATO doctrine of "no first foreign use" would remove this potential instability.

${ }^{34}$ For example, today there are about 16 Soviet bomber main operating bases, about 13 major naval bases, and 25 minor naval bases. Probably no more than 25-50 other airfields would be useful for projecting forces into Europe. ${ }^{35}$ San Francisco Examiner, July 15, 199n, p. A9.

${ }^{36} \mathrm{And}$, of course, there would remain the existential deterrence that comes from having a nuclear-armed America committed to the defense of Europe.

${ }^{37}$ Appendix B ind icates that about 150 medium-sized weapons could probably destroy over 50 percent of the Soviet industrial capacity. The Strategic Reserve would be held back to prevent total disarmament and hence to ensure post-war deterrence.

${ }^{38}$ As noted, such an attack would seem very unlikely if U.S. strategic forces are based in a survivable mode.
} 
nuclear powers. Against the extreme case of a massive counterforce strike by the Soviet Union, U.S. strategic forces should be based in such a way that a minimum of 200 extra weapons (beyond the 300 for assured destruction) would survive. In a European war, these surviving weapons-when combined with U.S. tactical nuclear weapons, the nuclear forces of Britain and France, and a strong conventional defense-should be sufficient to discourage or, if necessary, defeat a Soviet invasion. In other (perhaps non-Soviet) contingencies, without an all-out counterforce attack against the U.S., many more than 200 extra strategic weapons would be expected to survive and be available for retaliation.

Required Number of Strategic Warheads. The actual number of warheads that would have to be deployed to support this strategy would depend on the type of basing chosen, possible arms control agreements, and concerns about Soviet cheating on the agreements. A conservative approach might require that each leg of the strategic Triad provide 500 surviving warheads. In that case, a force of around 3000 deployed warheads might suffice. A less conservative approach without redundancy might require about 1000 deployed weapons. 


\section{Part II}

Survivability at Low Force Levels 


\section{Reducing Strategic Forces}

In Part I, it was argued that it will take a rethinking of the requirements for strategic nuclear weapons before arms control agreements proposing deep cuts in the force structure could be considered. For the purposes of this report, it will be assumed that this rethinking has been done and that it has been decided-whatever the rationale-that, with equal force levels on each side, 500 to 1500 survivable weapons would be s!!ficient to deter the Soviet Union from attacking the U.S. or (when combined with strong conventional forces) its allies in Europe. As a point of comparison, in 1970 (before U.S. missiles were MIRVed), the U.S. normally had about 1500 or so strategic weapons on a day-to-day alert.

\subsection{Why Deep Cuts?}

But even if this lower level of required survivors is accepted, one might still question whether it is advantageous to seek deep cuts in our present forces levels. After all, providing 1500 surviving warheads would seemingly be much easier to achicve with a force level of 10,000 warheads than with one of say 3000 warheads. Despite the apparenti advantage of a large force structure, a number of groups advocate radical cuts in the strategic nuclear arsenals.

\section{President Reagan's Version of SDI}

President Reagan evidently believed that current U.S. strategy was unsatisfactory and instigated a strategic defense program that he hoped would bring about a radical change in that strategy. Advocates of President Reagan's version on the Strategic Defense Initiative (SDI) argte that it is wrong to leave the U.S. vulnerable to nuclear attack and also wrong to retaliate against innocent civilians. Apparently their view is that we must move toward a world without nuclear weapons. But since we can never be sure that the other side might not cheat or that other parties will not deploy nuclear weapons, this nuclear-free world must be safeguarded by strategic defenses.

To many, the transition to this new strategic regime is of serious concern since it offers the potential for instability if not managed correctly. For example, a former Pentagon official, Gen. Glenn Kent, has argued that the only plausible way to arrive at a "defense dominant" world would be in cooperation with the Soviets. ${ }^{39}$ The logical first step in the transition would be to reduce strategic offensive forces on both sides to a much lower level-as low as possible consistent with survivability and deterrence. Strategic defenses would then be introduced. Once in place, the further reduction of strategic forces would be possible.

Thus, if President Reagan's vision of SDI is to be implemented, radical (but stable) cuts in the strategic forces of both sides are probably a logical prerequisite.

\section{Mutual Nuclear Disarmament}

Of course, the Reagan view that nuclear weapons should be eliminated from the affairs of mankind has long been held by a number of people. But these advocates of complete and mutual nuclear disarmament generally do not believe in the necessity of strategic defenses-indeed, they view them as counterproductive.

The more thoughtful of the advocates of this position acknowledge that disarmament could not be achieved overnight and that a series of transition steps would be required. For example, Richard Garwin takes the position that we should first reduce the strategic forces of both sides to 1000 warheads each, and then work out all the details and safeguards that would allow a transition to zero. ${ }^{40}$ Thus, as in the case of President Reagan's plan, radical cuts would be a first, but not final, step in the transition to a non-nuclear world.

\footnotetext{
${ }^{39}$ Glenn A.Kent, "A Suggested Framework for Strategic Defenses," RAND Corp., N-243-FF/RC, December 1986.

${ }^{40}$ Richard Garwin, "A Blucprint for Radical Weapons Cuts," Bulletin of the Atomic Scientists, March 1988, p. 10.
} 


\section{Finite Deterrence}

The other principal group holds that while radical reductions in nuclear weapons are possible and desirable, the complete elimination of nuclear weapons is not practical. ${ }^{41}$. Their view is that the primary role of strategic nuclear weapons is to deter the use of nuclear weapons by the other side, and these weapons are not too useful for anything else.

Beginning with Adm. Barke and others in the late-1950s, they have held that the force levels required to a complish deterrence are relatively moderate and do not require an unending effort to deploy a capability to eliminate the other side's nuclear weapons-since the Soviets are already deterred by threats of retaliation. If we consider force deployments of around 3000 warheads, many of these advocates (e.g., Paul Nitze and Harold Brown) would argue that the current Flexible Response doctrine could still be implemented at this lower level.

Individuals within this group might present several arguments why significant reductions of current force levels are appropriate. For example, it is now generally assurned (and advocated) that international tensions can be even further reduced by reducing strategic weapons. With a reduction of tensions will, it is ioped, come a further reduction in the possibility of war. Also, there is perhaps the more mundane hope amon! some that reducing forces will save money. This is not clearly the case, but it is a long-range possibility.

Perhaps of more substance is the possibility that a reduction in force levels on both sides could (paradoxically) enhance deterrence by increasing the survivability of our strategic forces. For example, the U.S. has been anxious about the survivability of its ICBMs for many years, but has not been able to fashion a satisfactory solution in face of the very large threat from Soviet ICBMs. It is possible that a survivable basing scheme for the ICBMs could be more easily devised if the threat were reduced to a manageable size.

\subsection{Assuring Deterrence}

While the three groups above have different perspectives on the role of nuclear weapons and other matters, they would all seem to agree that deep cuts in our present forces structure are desirable. Also, all three apparently agree that either strategic nuclear weapons are not necessary for the defense of Europe or that many fewer than we presently have would suffice.

If the arguments for lower force levels eventually prevail, it is clear that careful attention will have to be paid to the nature of the resulting strategic force structure. Unless the President and Congress can be assured that deterrence can actually be maintained at lower force levels, no radical changes will occur.

The general principles for assuring deterrence were expressed by Alain Enthoven, Assistant Secretary of Defense for System Analysis under Robert McNamara:

If the overriding objective of our strategic nuclear forces is to deter a airst strike against us, the United States must have a second-strike capability; that is, strategic forces of such size and character that they can survive a well-planned, large-scale surprise attack with sufficient strength remaining to penetrate the attacker's defenses and still destroy him This capability to destroy him even after absorbing his surprise attack must be a virtual certainty, and clearly evident to the enemy. This is the foundation of U.S. deterrent strategy. Consequently, as long as deterrence remains the priority objective, the U.S. must be prepared to offset any Soviet effort to reduce the effectiveness of our assured-destruction capability below the level we consider necessary. ${ }^{42}$

\footnotetext{
${ }^{41}$ Others hold that the mere existence of even a small number of nuclear weapons provide an existential extended deterrent for our allies. Thus, they would argue that the elimination of nuclear weapons is not even desirable. ${ }^{42}$ Alain C. Enthoven and K. Wayne Smith, op. cit., p. 175.
} 
Survivability is thus the key to deterrence. If deep cuts in strategic forces are undertaken, survivability will be all the more critical. Strategic stability after deep cuts will iequire a policy of prudence that fully recognizes the uncertainties involved, maintains diversified forces, fully accounts for the possibility of a surprise attack, and pursues research and development programs to hedge against technological surprise.

\subsection{Possible Treaties}

In this paper, two arms control treaties will be considered: one that allows each side to deploy a force of 3000 warheads (START II), and one that allows the deployment of 1000 warheads by each side (START III). Of course, the political situation in the Soviet Union is very uncertain, and there is even the possibility that the country could break up into a number of separate countries, greatly complicating the treaty-making process. However, it will be assumed that some single entity (perhans a Russian Republic) will continue to control the nuclear weapons covered by these treaties.

In addition to reducing the force levels, an arms control treaty might include a number of other provisions to enhance survivability and strategic stability. For example:

\section{Warhead Yield}

Since the present warheads of each side could be replaced with larger-yield weapons, the threat to some basing schemes would not necessarily be reduced by just reducing the number of warheads. Thus, a restriction of the yield of each weapon to, say, $500 \mathrm{kt}$ should be included in a "deep cuts" treaty. To implement this provision would require a restriction on the weight of each warhead and would require careful monitoring of Soviet missile flight tests and (very likely) intrusive on-site inspection of the warheads aboard missiles and bombers.

\section{Number of RVs Per Missile}

The START agreement restricts the number of warheads on any missile to 10 or less. This provision should be included in any new treaty (and perhaps even lowered) to reduce the likelihood of a sudden breakout of the treaty with the deployment of large numbers of high-accuracy, low-yield weapons (which could affect the survivability of some basing concepts).

\section{ABM/SDI}

The advisability of deploying an anti-ballistic missile (ABM) defense system is still a hotly debated subject. In this paper, we take the position of Gen. Kent that the only practical way to achieve President Reagan's objective is through the cooperation of the Soviets-something that has not yet been attained. Even if the cooperation were forthcoming, it appears that the best approach would be to first make deep cuts in both sides' nuclear arsenals before deploying an ABM system. Thus, it will be assumed that no expansion of ABM systems will be allowed until (at least) sometime after the implementation of START III.

The following sections examine the kinds of stratigic force structures that would be necessary to assure that at least half of the weapons allowed under the treaties would survive a well-coordinated surprise attack. 


\section{START II-Moderately Deep Cuts}

Before agreeing to a treaty that allows the U.S. and the Soviet Union each to deploy 3000 warheads, the Soviets might insist on significart reductions in the nuclear arsenals of the other nuclear powers-Britain, France and China. ${ }^{43}$ Alternatively, Soviet short-range air-launched nuclear cruise missiles deployed on tactical aircraft might be allowed to compensate for these European and Asian threats.

If it is assumed that these very difficult politica! problems can be dealt with, the question then becomes one of how to best distribute the 3000 warheads among the strategic forces and how to base these forces to ensure their survivability.

In the past, Soviet military planning seems to have focused on developing a damage-limiting capability to protect the homeland-not unlike the expressed objectives of th? U.S. military. Of course, Soviet society is now in a state of flux. It is possible that the Soviet Union may eventually evolve into a democracy and truly abandon its self-declared life-and-death struggle with the West. If so, this could significantly alter Soviet military planning. If these changes in policies and capabilities actually occur, U.S defense programs can be modified to take them into account. However, at this stage, the Soviets still possess threatening strategic offensive and defensive forces and continue to modernize them. Deterrence requires that the realities of the military situation, and not just hopes for the future, be used in force planning. Thus, the prudent course is to assume that (for the foreseeable future) the Sovict military will continue to vigorously pursue programs designed to counter U.S. strategic forces.

Since the late-1950s, the U.S. strategic force structure has consisted of a Triad of weapon systemsICBMs, bombers, and strategic subrnarines. This diversity has provided a critical hedge against the catastrophic failure of one or more systems and safeguarded the U.S. deterrent against Sovict technological breakthroughs. Diversity can also be expected to complicate the execution of an effective counterforce strike as well as complicating the Soviets' defense against a retaliatory strike. Hence, we will consider a diversified force structure along the lines of our current systems.

In the following sections, we will examine the requirements to assure that each leg of the Triad will have at least 500 warheads that could survive a Soviet surprise attack and then penetrate Soviet defenses. As a concrete example, we will consider a U.S. force structure that consists of a distribution of weapons found in Table 6-1.

Table 6-1. Strategic force structure.

\begin{tabular}{lc}
\hline \multicolumn{1}{c}{ System } & Number of warheads \\
\hline Submarines (SLBMs) & 1300 \\
Bombers (ALCMs) & 950 \\
ICBMs & 750 \\
Total & 3000 \\
\hline
\end{tabular}

Of course, this is not the only distribution of forces possible. One might, for example, include submarine-launched cruise missiles (SLCMs) in the submarine force. This example should only be considered as an "existence proof" to show that with 3000 warheads it might be feasible to build a balanced force with at least 1500 surviving warheads.

Moreover, if the U.S. were starting over to design a strategic nuclear force regime to ensure that deterrence was maintained at low levels, the strategic force structure that resulted might look quite different from the one that now exists. Of course, in the near future, the U.S. is restricted to the

\footnotetext{
${ }^{43}$ Today, the British have 64 SLBMs (carrying MRVs), the French have about 350 strategic warheads on missiles, and the Cninese probably have about 200 missile warheads (plus perhaps 400 aircraft-deliverable bombs). By the end of the decade, the British could have 512 strategic warheads, and the French could have over 600 .
} 
weapons that it already has or those that could be deployed by the time a new treaty went into effect (or shortly thereafter). However, if radical cuts appear to be a real possibility, it might be advisable to begin considering new basing concepis. 


\section{Submarines}

The START agreement limits the number of ballistic missile warheads to 4900 . Various possible ways to allocate these warheads between ICBMs and SLBMs have been suggested by the Defense Department. One possible deployment is 1444 ICBM warheads and 3456 SLBM warheads carried on 18 Trident strategic submarines (SSBNs). Each SLBM would carry eight warheads, each with a yield of $100 \mathrm{kt}$ (if the C-4 missile were used) or 300-500 kt (if the D-5 missile were used).

If the U.S. wanted to retain at least 18 SSBNs, one possible deployment consistent with deep cuts would be to reduce the number of warheads on an SLBM to three, each with a yield of $500 \mathrm{kt}$. This would allow 1296 warheads with a total yield of about 820 EMT. 44 As indicated in Table 7-1, this is comparable to the firepower of previous deployments of SL3Ms and would even be greater than the EMT of the START force if $100-\mathrm{kt}$ warheads were deployed.

Table 7-1. SLBM EMT.

\begin{tabular}{ccccc}
\hline Time frame & SSBNs & $\begin{array}{c}\text { No. of } \\
\text { warheads }\end{array}$ & $\begin{array}{c}\text { Yield } \\
(\mathrm{kt})\end{array}$ & $\begin{array}{c}\text { Total } \\
\text { EMT }\end{array}$ \\
\hline 1978 & 41 & 5120 & 40,200 & 760 \\
1989 & 36 & 5632 & 40,100 & 960 \\
START & 18 & 3456 & 100 & 740 \\
& & & 500 & 2180 \\
Deep cuts & 18 & 1296 & 500 & 820 \\
\hline
\end{tabular}

With 18 SSBNs, about 12 could be kept at sea at all times. This would mean that about 864 warheads carrying about 550 EMT would be available. If, like START, a new arms control agreement did not count SSBNs in overhaul, there could actually be around 20 SSBNs with perhaps 13 boats (carrying up to 936 warheads) at sea on a normal day-to-day alert rate. ${ }^{45}$ In either case, these extra warheads at sea (over the 500 or 600 required) would hedge against a moderate (but not total) breakthrough in Soviet anti-submarine warfare (ASW) technology.

An alternative submarine force might include some number of submarine launched cruise missiles (SLCMs). For example, if the number of SSBNs were reduced to 15, this would allow 216 SLBM warheads to be replaced by SLCMs. Determining whether this trade-off would be advantageous would require a careful assessment of such matters as U.S. objectives, relative costs, other potential uses of the SLCM launch platforms, and Soviet defensive capabilities.

It might be argued that the 1300 warheads should be deployed on an even smaller number of SSBNs, since at least 8 warheads could be placed on each SLBM. But this wculd dangerously concentrate the submarine force into just a few targets. Of course, the Navy argues that U.S. strategic submarines are now invulnerable and will remains so for the foreseeable future. This view has even prompted some to argue that the U.S. could safely abandon the land-based ICBMs, and perhaps the bombers as well, and place sole reliance on a sea-based strategic deterrent force.

it he problem with this idea is that submarines can in reality be detected by a variety of acoustic and non-acoustic techniques. ${ }^{46}$ It is just that-to this point-the Soviets have not had the technology to exploit this fact. For example,

[I]t is clear that the ocean surface in the vicinity of a moving submarine must be disturbed to some degree, and that detection of this signal from a remote air or space

\footnotetext{
${ }^{44} \mathrm{EMT}=$ Equivalent Megatons $=(\text { Yicld })^{2 / 3}$.

${ }^{45}$ Present plans call for capping the Trident program at 18 submarines, but some of the older Poseidon SSBNs could be retained. (The construction of the $18 \mathrm{th}$ Trident is likely to be authorized by the current Congress.)

${ }^{46}$ For a discussion of potential threats to strategic submarines see Roger D. Speed, Strategic Deterrence in the 1980s (Stanford, CA: Hoover Institute Press, 1979), pp. 56-64.
} 
platform (capable of surveying a large area of the ocean in a short time) is difficult because of the noise background due to wind-driven ocean waves and other natural phenomena. With clever processing of the surveillance data, however, which will become increasingly feasible as com ${ }_{\mathrm{r}}$ 'ter technology develops, it may be possible to find the submarines in the noise, especially since the number of submarines is small and therefore a large number of false signals can be tolerated. Even if precise location is not feasible, localization may be. Further localization may be derived from submarine operational practices as well as additional surveillance data from underwater sensors. Localizing the submarines might render them vulnerable to $a$ barrage attack since the number at sea is small and the kill distance is large. The small number of submarines also raises worries of covert tagging and trailing. ${ }^{47}$

Considering the wide range of possible threats, the extensive Soviet ASW program, ${ }^{48}$ and the likely Soviet access to the rapidly developing computer and information processing fields, it would seem imprudent to take for granted the long-term survivability of the current SSBNs. ${ }^{49}$ In the future, instead of relying on the very large Trident submarines, it might be preferable to deploy smaller submarines, each carrying fewer missiles, in order to decrease any potential non-acoustic signal produced by the submarines and to proliferate the number of targets for Soviet ASW systems. This particularly would be important if a treaty calling for an even smaller number of warheads (say, 1000) were adopted (see Section 10).

\footnotetext{
${ }^{47}$ A.L. Latter and E.A. Martinelli, "The Need For Survivable ICBMs," Lawrence Livermore National Laboratory, internal memo, Sept. 27,1988, p. 2. A "tag" is a device covertly attached to the hull of a submarine (probably by a frogman, trained dolphin, or remotely guided underwater platform as the SSBN leaves port) that can reveal the submarine's position to external sensors.

${ }^{48}$ Recent reports suggest that space-based radars may be an important part of the Soviet and American ASW programs. Aviation Week and Space Technology, October 8, 1990, p. 22.

${ }^{49}$ Arms control agreements to restrict ASW technology (and hence reduce the threat) would probably be unmonitorable.
} 


\section{Bombers}

The START agreement gives special advantages to bormbers when accounting for the number of warheads allowed under the treaty. Bombers that do not carry air-launched cruise missiles (ALCMs) are counted as carrying just one warhead even though they may carry up to 20 Short-Range Attack Missiles (SRAMs) or bombs. Also, for ALCM-carrying bombers, only half the cruise missiles that could be deployed are counted.

Any agreement calling for deep cuts in strategic forces is likely to close this loophole, and each deployed weapon is likely to be counted. Because of this, penetrating bumbers (like the B-2) that have to face severe Soviet air defenses are not likely to be a cost-effective method of delivering weapons. Thus, we will only consider bombers that carry ALCMs.

\subsection{Force Structure}

We will assume a force of about 950 advanced ALCMs. If START counting rules apply, there would be 95 B-1 bombers with each one counted as carrying 10 ALCMs. But contrary to START, we assume that the allowed total number of deployed ALCMs will actually be restricted to 950 . We also assume that the treaty (similar to START) will allow all the ALCMs to be kept on 47 "alert" B-1Bs (with 20 ALCMs per bomber). These 47 strip-alert bombers would be constantly ready to take off within a few minutes of the detection of an SLBM launch. The other (unarmed) bombers would be used for training and to replace alert aircraft undergoing repair. ${ }^{50}$

\subsection{Pre-launch Survivability}

Today, about 30 percent of the bombers are on alert. Most analyses assume that these alert bombers would escape a surprise Soviet attack. This may be correct under certain assumptions about Soviet strategic submarine patrol areas, SLBM flight times, and the "reaction time" of the bormbers. But, it is clearly not correct under other assumptions.

\section{SLBM Flight Time}

One critical factor determining whether the bombers will escape is the SLBM iine-of-flight. This in turn depends on the distance flown and the type of trajectory used.

Today, most 'joviet SSBNs stay relatively close to their home ports. However, a few have normally patrolled off the U.S. coasts, usually at distances greater than a few hundred miles, although on occasion they have come much closer. ${ }^{51}$ Unfortunately, there is nothing to constrain the Soviets from changing their SSBNs' patrol habits in the future. Furthermore, as Soviet SSBNs grow quieter, it may become increasingly difficult for the U.S. to always have high confidence in detecting Soviet SSBNs as they approach the coasts. It is possible that a few SSBNs might slip in close to the coasts undetected by the U.S. underwater sound surveillance system (SOSUS). Detection might be particularly difficult on the Atlantic coast where an extensive continental shelf makes detection a problem and in the Gulf of Mexico were SOSUS coverage is limited.

\footnotetext{
${ }^{50}$ Such an arrangement would allow some possibility of cheating since ALCMs are relatively small and presumably easy t.o hide. If there were hidden missiles, they could be quickly added to the non-alert aircraft in a first-strike strategy. Off-setting this is the possibility that stringent arms control has some possibility of detecting these missiles as they leave the factories. But more importantly, ALCMs do not really increase the effectiveriess of a Soviet first strike and thus the effect of Soviet cheating probably would be minimal. Hence, being able to keep all the allowed ALCMs on alert for retaliation would be to the advantage of the U.S.

${ }^{51}$ A recent Senate Armed Services Committee report said that the Sovieis have now ceased submarine patrols off the U.S. San Francisco Chronicle, July 28, 1990, p. A10.
} 
Soviet SLBMs have ranges ${ }^{52}$ of between about $1600 \mathrm{nmi}$ and $4500 \mathrm{nmi}$, but the maximum distance of any point in the continental United States from its seacoasts is about $1150 \mathrm{nmi}$. These missiles, when launched from submarines operating close to the American coasts, could use their excess energy to lower the missile launch angle, significantly reducing the time of flight.

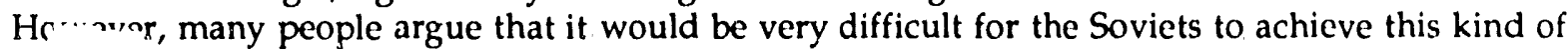
capabi scause depressing the trajectory of an SLBM can severely stress the missile due to greatly increased structural loads and heating. Others disagree. But, whatever the outcome of that argument, it should be noted that simply depressing the trajectory of a missile is not the only way to achieve short times-of-flight.

An SLBM designed for a conventional minimum-energy trajectory can be flown on a specially shaped trajectory that produces no significant increases in mechanical or thermal loads on its booster and can have a flight time almost as short as that theoretically achievable by maximum depression of the trajectory. Essentially, the SLBM flies a normal minimum-energy trajectory until it gets out of the atmosphere, and then it makes a turn to shorten its range. To fly this shaped trajectory probably would require only minor modifications i:t the flight control program. .5

\section{Basing}

Today, the B-1s are based on four SAC bases, two of which are within $600 \mathrm{nmi}$ of the Gulf coast. Figures 8-1 and 8-2 illustrate the survivability of the B-1 (with current basing) as a function of the number of attacking SLBMs, the type of trajectory flown by the SLBM, ${ }^{54}$ the distance the SSBNs are off the U.S. coasts, and the bomber reaction time.

If the Soviet SSBNs remained at least $600 \mathrm{nmi}$ off the coasts and the SLBMs flew minimum energy trajectories, the bombers should be highly survivable. Even with a short-time-of-flight trajectory, the survivability is likely to be around 0.8 for large attacks if the bomber reaction time can be held to around $250 \mathrm{~s}$. If the reaction time slipped to about $6 \mathrm{~min}$, about 30 percent of the bombers could be destroyed with just one SSBN.

If the submarines come within about $100 \mathrm{nmi}$ of the coasts, the bombers are still highly survivable against SLBMs flown on minimum energy trajectories (even with a 6-min reaction time, about 80 percent of the bombers should survive an attack by five SSBNs). However, if the SLBMs fly short-time-offlight trajectories, 50-75 percent of the bombers could be lost from an attack by as few as three SSBNs. ${ }^{55}$

Whether the Soviets will develop a capability to fly short-time-of-flight trajectories is impossible to predict. But it appears that the capability would not be that technically difficult to develop in a fairly short time and could possibly be done without the U.S. even discovering it. ${ }^{56}$ In any event, the prudent approach would be to hedge against this possibility.

If the U.S. redeployed the B-1s on eight bases deep in the interior of the country $(950-1150 \mathrm{nmi}$ from the coasts), Fig. 8-3 indicates that an attack by 10 SSBNs (each carrying 16-20 SLBMs), $100 \mathrm{nmi}$ off the coasts, flying SLBMs on short-time-of-flight trajectories, would kill less than 25 percent of the bombers - if the bomber reaction time were held to $25 \mathrm{C} \mathrm{s}$. Of course, the presence of this many SSBNs this close to our coasts would certainly be cause for alarm and reason enough to keep a very short reaction time. But it should be noted that even three boats could catch almost 45 percent of the bombers if the reaction time slipped to $6 \mathrm{~min}$.

\footnotetext{
${ }^{52}$ The range of a ballistic missile is determined by the burnout velocity (velocity achieved at the end of the powered phase of flight) and by the angle of launch. Given a fixed burnout velocity c c pability, there is an optimum launch angle that yields the maximum range for that system. This flight $\mathfrak{r}$ ath is called the maximumrange trajectory or the minimum-energy trajectory.

${ }^{53}$ R.D. Speed, START and Bomber Survivability, Lawrence Livermore Nationai Laboratory, UCID-21713, May 1989. For MIRVed missiles, the accuracy would likely be somewhat less than on a normal trajectory. But this would be of little significance in a barrage attack on the bomber bases.

${ }^{54}$ In the figures, "ME" stands for minimum energy trajectory and "DT" for depressed or short-tine-of-flight trajectory.

${ }^{55}$ These results are probably optimistic for the U.S. since the assumed time of flight is based on liquid-fuel technology, and the Soviets now have faster accelerating solid-fueled SLBMs. (Unfortunately, no data on these solid-fueled missiles was available.)

${ }^{56}$ R.D. Speed, START and Bomber Survizability, op. cit., p. 34.
} 
FIG. 8-1 B-1 SURVIVABILITY--600 NMI STAND-OFF

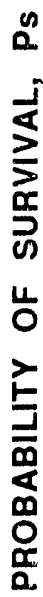

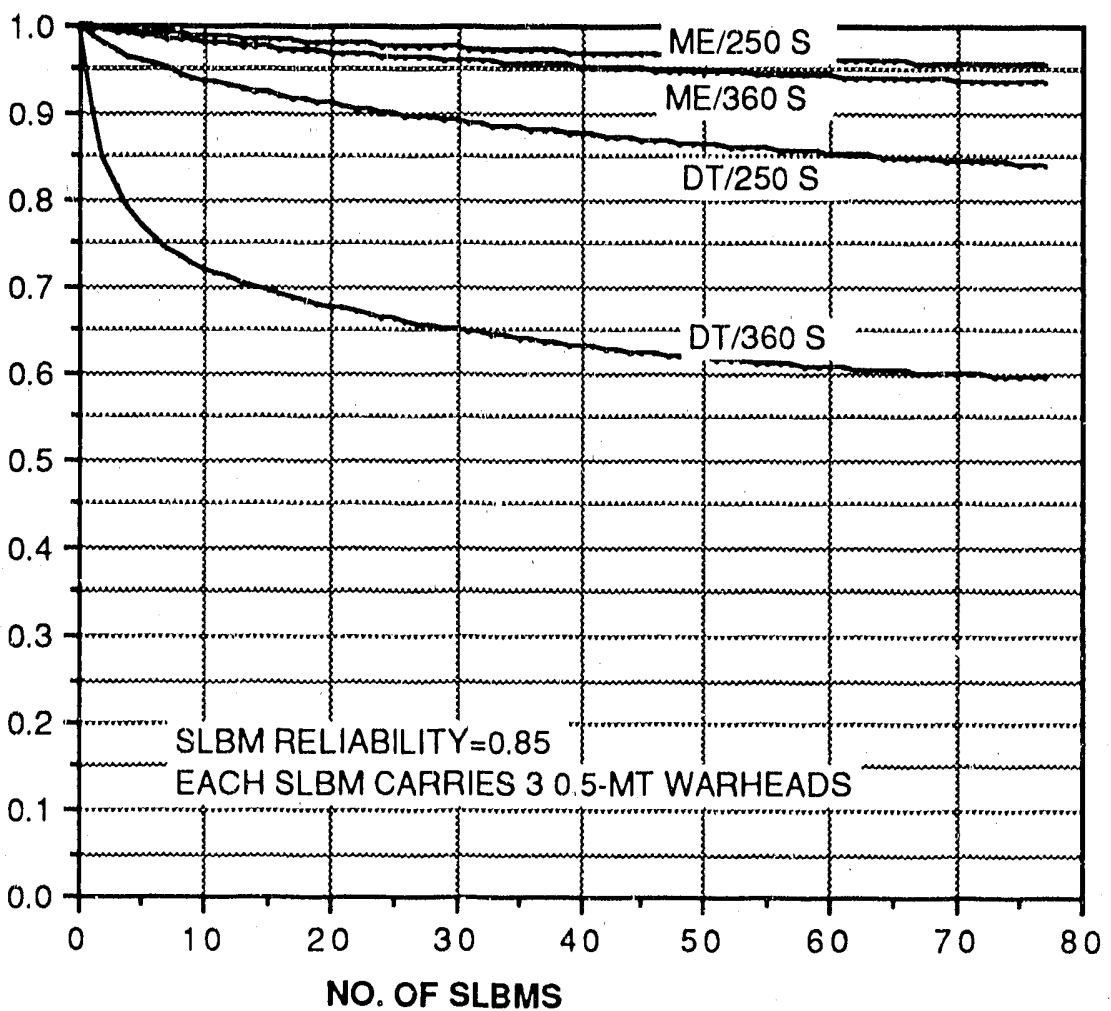

FIG. 8-2 B-1 SURVIVABILITY--100 NMI STAND-OFF

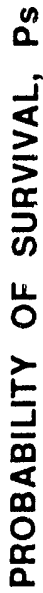

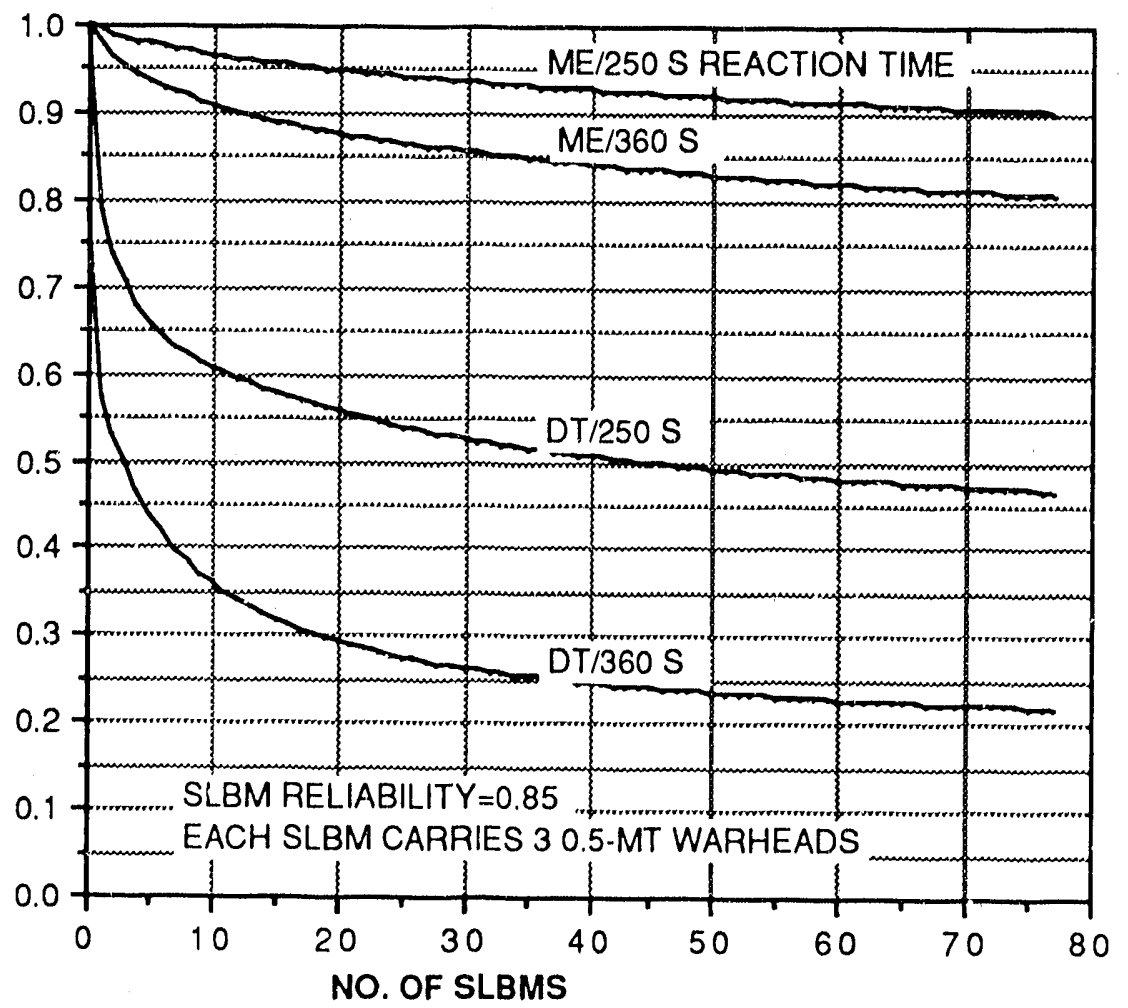


FIG. 8-3 "DEEP" INTERIOR BASING

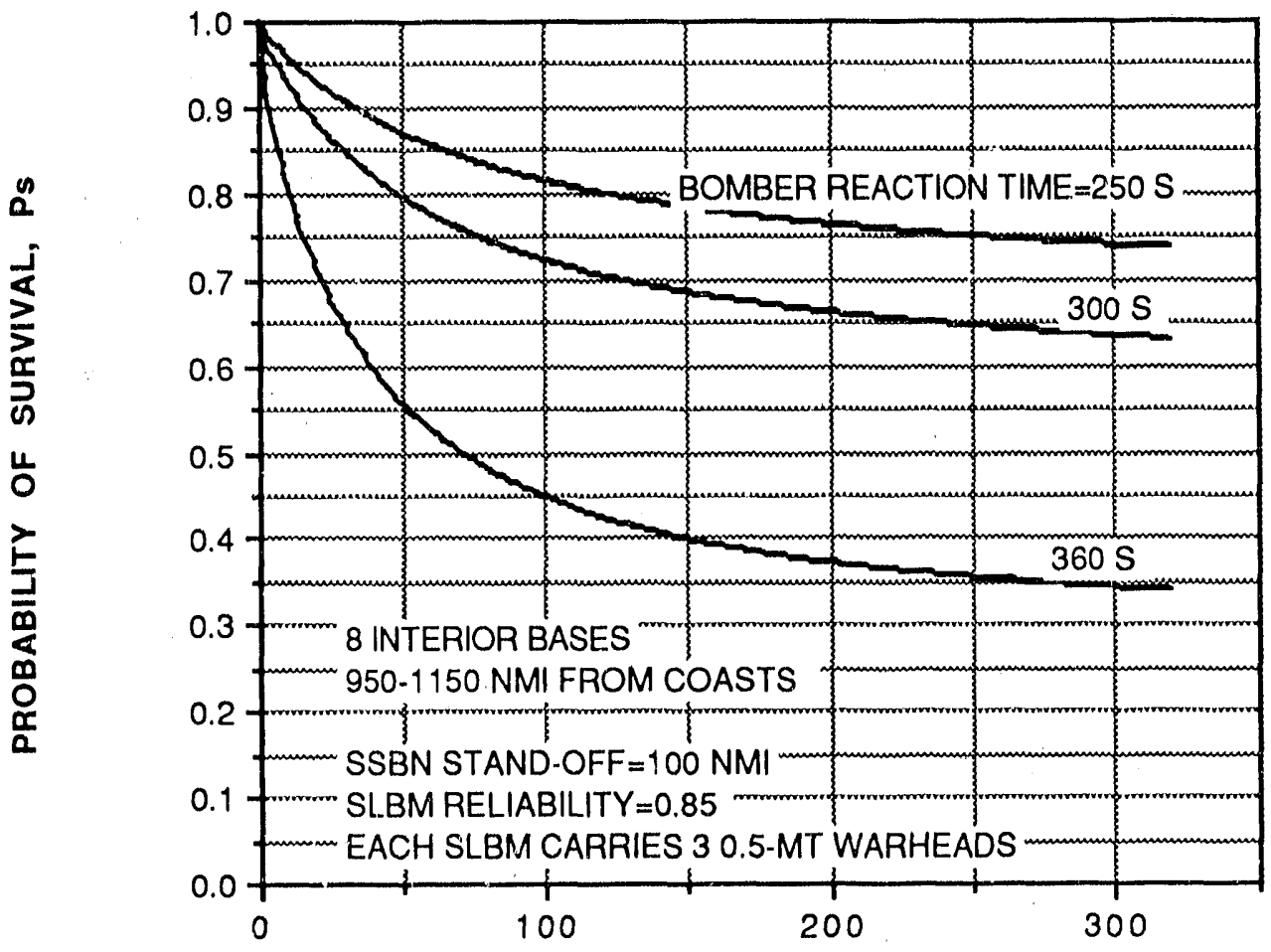

NO. OF SLBMS

\section{SSBN Stand-Off Treaty}

Bomber survivability obviously could be enhanced if the SSBNs were kept far from the coasts. Thus, it might be worthwhile considering a treaty that restricted the submarines from coming within, say, $600 \mathrm{nmi}$ of the other side's coasts. To enforce the treaty, it would probably be necessary to significantly improve the present ocean surveillance systems that monitor the restricted area. However, because the agreement could easily be abrogated, the U.S. would still not want to rely on it for survivability. But the breaking of an international treaty by the Soviets would at least give clear warning of a developing threat, allowing all the strategic forces to be put on a higher alert status.

\subsection{Penetration of Soviet Air Defenses}

Soviet air defenses are the most extensive in the world, and the Soviets continue to improve them. Currently they have more than 9000 strategic SAM launchers, nearly 5000 tactical SAM launchers (excluding handheld), and 10,000 air defense radars. Also about 2300 air defense forces interceptors are dedicated to strategic defense. Over 400 of these are fourth-generation interceptors with a lookdown/shoot-down capability, and the modernization of this force continues. In addition, 2100 interceptors assigned to Soviet Air Forces could be drawn upon for strategic defense. These interceptors can act as an area defense, forming barriers across expected penetration routes. The U.S. may also have to be concerned about long-range interceptors, acting in coordination with Soviet AWACS aircraft, moving beyond Soviet borders and attacking the bombers before they release their missiles.

The Air Force claims that ALCMs can easily penetrate the Soviet air defense during the next decade or so. Nevertheless, it would seem reasonable to expeditiously pursue the development of very long-range "stealth" cruise missiles that could be ready for deployment by the time of START II. 
Moreover, as long as the U.S. is dependent upon bombers and cruise missiles for deterrence, it seems inconsistent to reduce these forces without placing restrictions on Soviet air defenses. ${ }^{57}$ Just as restrictions on $\mathrm{ABM}$ gystems have been viewed as stabilizing (since ABMs raise doubts about the other side's ability to retaliate following a first strike), so should restrictions on air defenses.

\subsection{Conclusion}

The continued survivability of the alert bombers under a START II Treaty can not be assumed if current bomber basing practices are followed. Prudence would require the basing of the alert bombers on a relatively large number of bases ${ }^{58}$ deep in the interior of the country and maintaining these bombers on a very quick reaction alert status.

If this is done, about 85 percent or more of the alert bombers might be expected to survive a surprise attack by SLBMs-even if they fly depressed trajectories. ${ }^{59}$ If we assume (without any analysis) that about 75 percent of the launched ACLMs would penetrate the Soviet air defense system and that the reliability of each ALCM is 0.85 , then, about 510 of the 940 alert ALCMs should arrive on their targets.

${ }^{57}$ U.S. air defenses are negligible.

${ }^{58}$ Some or all of these could be satellite, austere bases, with training and maintenance performed at existing main operating bases.

${ }^{59}$ A nother potential threat (not considered here) is the use of cruise missiles to attack the bomber bases.

Countering this threat will probably require a much-improved Early Warning System. 


\section{ICBMs}

Since the early-i960), ICBMs have been housed in hardened underground silos. As the accuracy of Soviet ICBMs has improved, the survivability of these missiles has increasingly been questioned. Finding a solution to this vulnerability has pre-occupied defense planners and politicians for over a decade, and still there is no final decision on how to meet this challenge.

To illustrate the nature of the problem, Fig. $9-1$ shows the survivability of missiles in hardened shelters as a function of the attacking missile's accuracy (CEP). Current U.S. missile silos can withstand overpressures of about $\left.2000 \mathrm{psi} .{ }^{60}\right)$ The MX missile reportedly has an accuracy of about $300 \mathrm{ft}$ and the older Minuteman III an accuracy of about $600 \mathrm{ft} .61$ Current Soviet ICBMs reportedly have an accuracy of between $800 \mathrm{ft}$ and $1200 \mathrm{ft}$. The follow-on to the SS-18 (now undergoing testing) is expected to have an accuracy of about $600 \mathrm{ft} .62$ If this is correct, and if two RVs were used to attac: each silo, perhaps less than 5 percent of the U.S. missiles in their present silos would survive a future attack. if 2000 of these more accurate warheads were deployed and used. ${ }^{63}$

Under policies established by Secretary of Defense McNamara in the 1960s, it has been a requirement that U.S. strategic forces be able to undergo a well-coordinated surprise attack and still have enough surviving nuclear forces to be able to inflict in a retaliatory strike unarceptable damage on the attacker. In their despair over the difficulty in finding a survivable basing scheme foi the ICBMs, some people have advocated launching the ICBMs on tactical warning of an incoming attack. This would seem to be a dangerous, ill-advised strategy. First, it might not be technically feasible in the face of a Soviet attack on the U.S. command, control, and communications $\left(\mathrm{C}^{3}\right)$ system. And second, the possibility of a computer or sensor mistake that could result in catastrophe can never be ruled out.

Alternatively, some have argued that the solution to the ICBM survivability problem is to deploy a system like Rail Garrison MX. The system currently proposed by the A.ir Force would place $50 \mathrm{MX}$ missiles (with 500 warheads) on 25 trains. These trains would normally be parked in garrisons on seven military bases dispersed throughout the U.S. Upon direction by the President, the trains carrying the $\mathrm{MX}$ missiles would leave the garrisons and try to hide themseives among the other trains on the national rail system. However, without hours of advanced warning to allow the dispersal of the trains, the system could be destroyed by a relatively few SLBM or ICBM warheads.

Advocates of this system argue that the U.S. would always receive strategic warning (i.e., hours or days) of an impending attack because the Soviets, before launching an attack, would want to reconfigure their military forces (bombers, submarines, and conventional forces) in a more survivable mode-and the U.S. would detect and act on this information.

This argument might seem plausible, but the historical record gives little justification for the expressed confidence that the intelligence system would recognize or that the political system would act upon the signals of an impending attack. 64 Moreover, there is another problem with the argument.

The primary reason for having a Triad is to hedge against the failure of the other legs of the strategic force structure. As long as one leg is survivable, the Soviets are unlikely to delibcrately initiate a nuclear strike on the U.S. The argument that the Soviets would have to reconfigure their forces before a strike assumes that they would fear a retaliation. But if the bombers and submarines become vulnerable, then a surprise attack on the in-garrison MX system would leave few U.S. strategic forces left to attack potentially vulnerable Soviet military forces-relieving the Soviets of the necessity to reconfigure their forces in the first place. "It follows that a system like rai!-ga: rison

\footnotetext{
${ }^{60}$ Congressional Record-Senate, S15524, November 7, 1983.

${ }^{61}$ CBO Study, "Modernizing U.S. Strategic Forces: Costs, Effects, and Alternatives," Congressional Budget Office, November 1987, p. 85.

${ }^{62}$ Ibid., p. 91.

${ }^{63}$ Even the older systems with a $1000 \mathrm{ft} \mathrm{CEP} \mathrm{could} \mathrm{reduce} \mathrm{the} \mathrm{survivabiiity} \mathrm{to} \mathrm{around} 6$ percent if a 3-on-1 attack were executed.

${ }^{64}$ If one could guarantee that the U.S. would always receive strategic warning, considerable money could be saved by kecping all the SSBNs in port and taking all the bombers off alert. Advocates of Rail Garrison have not gone this far-yet.
} 


\section{FIG. 9-1 SURVIVABILITY}

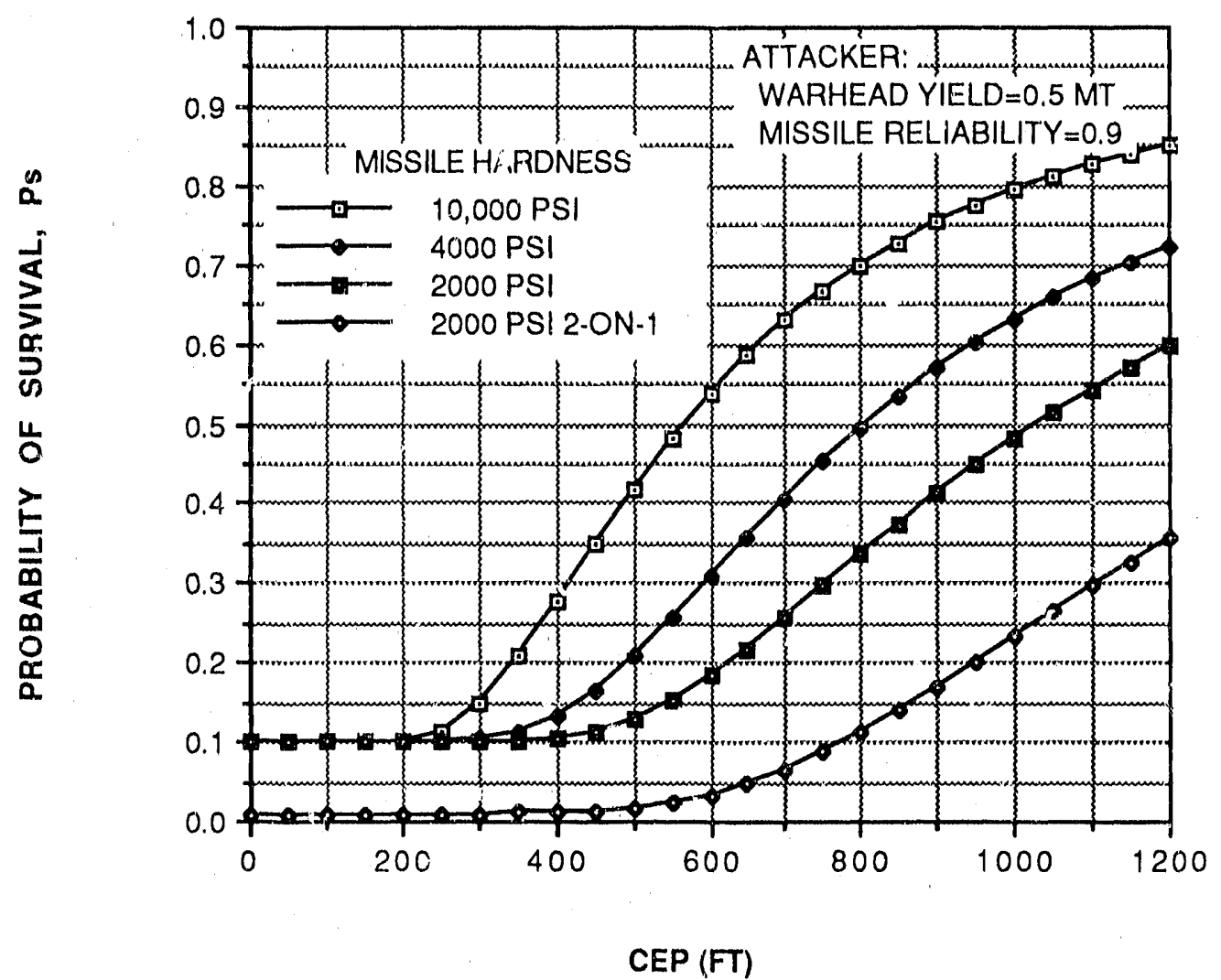

mobility that depends on strategic warning cannot provide a hedge against Soviet breakthroughs in countering the submarines and aircraft." 65

In this section, we will explore possible ways to base 750 land-based ICBM warheads to assure 500600 survivors in the face of a large Soviet attack. We will not consider systems that require a launchunder-attack capability or strategic warning for survivability.

\subsection{Fixed Silos}

One possibility is to deploy 750 single-RV ICBMs in 750 hardened silos. If Soviet missiles have a CEP of $600 \mathrm{ft}$ and an overall reliability of 0.9 , the probability of missiles in 2000 psi silos surviving (Ps) a single RV attack would be about 0.13 (see Fig. 9-1). For a 2-on-1 attack, the Ps would be 0.017. Thus, following a 1-on-1 attack, there might be 98 survivors, and following a 2-on-1 attack there might be only about 13 survivors.

The latter attack would take half of the Soviet inventory of allowed weapons-leaving them with a residual force of 1500 warheads. Of course, increasing the hardness of the silos would enhance the survivability somewhat. But improvements in Soviet missile accuracy would eventually off-set the increased hardness.

Would the use of 1500 Soviet ICBM warheads prevent or restrict an attack on the other legs of the Triad? The threat to the SSBNs does not rely heavily on counterforce targeting from Soviet strategic forcs it rather on ASW forces. Bomber survivability primarily depends on escaping an attack by Soviet SLBMs and then penetrating the Soviet air defense system. If the bombers are based poorly or

${ }^{65}$ Latter and Mar: velli, op. cit., p. 7. Emphasis in original. 
not kept on a high alert status, they could probably be destroyed with a only few SLBMs. Otherwise, the bombers and their cruise missiles will have to be handled by the Soviet air defense system. In either case, the Soviet strategic weapons requirements should not be too great.

Of course, if the Soviets were able to hide some nuclear warheads (say 200) and delivery systems, the Soviets could devote the entire 3000 warheads to attacks on the ICBMs, bombers, and $\mathrm{C}^{3}$ system and still have enough weapons to destroy or threaten to destroy U.S. cities.

In summary, at this force level and with a mixed force of weapons, ICBMs in fixed silos would still seem to be vulnerable to a Soviet attack, and thus it would appear to be an unsatisfactory approach to providing a significant number of survivable weapons.

\subsection{Mobile ICBMs}

While limiting the number of the attacker's accurate warheads may not improve the survivability of silo-based ICBMs (at least at this level of forces), it could conceivably help make mobile or multiple-aimpoint basing schemes more viable.

One suggested approach to achieving survivability is to deploy the Small ICBM (SICBM) in a hard mobile launcher (HML). The SICBM could carry one or two RVs, depending on the design. The crew for the HML would be housed in a "tractor" that pulls the missile. The HML, when in its battened-down, hardened position, ${ }^{66}$ is designed to withstand about 30 psi overpressure from a nuclear explosion. When on the move, the HML is only about 7 psi hard. The kill radius ${ }^{67}$ and area of kill of 100-kt and 500-kt weapons are given in Table 9-1. After the HML is hardened, the tractor can be detached from the missile, which will allow the crew to escape from the area being attacked-if enough time is available.

Table 9-1. Kill radius and area of kill.

\begin{tabular}{cccccc}
\hline $\begin{array}{c}\text { Yield } \\
(\mathrm{kt})\end{array}$ & \multicolumn{2}{c}{30 psi } & & \multicolumn{2}{c}{7 psi } \\
\cline { 2 - 6 } \cline { 5 - 6 } & Radius (mi) & Area $\left(\mathrm{mi}^{2}\right)$ & & Radius (mi) & Area $\left(\mathrm{mi}^{2}\right)$ \\
\hline 100 & 0.56 & 1.0 & 1.6 & 7.8 \\
500 & 0.96 & 2.9 & 2.7 & 23 \\
\hline
\end{tabular}

Two basic deployment modes have been considered for the HMLs and are discussed below.

\section{Garage Basing}

One basing concept is to park the HMLs in "garages" at the current Minuteman silos and have them dash on warning of an incoming attack onto surrounding roads and the countryside. The HMLs would probably be based at three Minuteman bases in the north-central U.S.: Malstrom AFB, Montana (about $500 \mathrm{nmi}$ from the coast); F.E. Warren AFB, Wyoming (about $900 \mathrm{nmi}$ from the coast); and Ellsworth $\mathrm{AFB}, \mathrm{SD}$ (about $950 \mathrm{nmi}$ from the coast).

A fundamental problem with this basing mode is that-like the strategic bombers-it depends on the smooth and timely functioning of the tactical warning system and the $\mathrm{C}^{3}$ network for survivability. Thus, there would be two legs of the Triad that could have the same failure mode. This might be considered unnecessarily risky when the strategic weapons are reduced to such low numbers.

As an example system, consider the deployment of 375 SICBMs each with two warheads (for a total of 750 warheads). Generally, two HMLs would be parked at each garage. Upon tactical warning of an incoming attack, the HMLs would move out of their garages and try to escape the area. Assume the average dash velocity of the HML is $30 \mathrm{mph}^{68}$ Then, as Fig. 9-2 indicates, with as little as $10 \mathrm{~min}$

\footnotetext{
${ }^{66}$ Generally, some sort of spike-in-the-ground system will be deployed to help prevent the blast wave from overturning the HML.

${ }^{67}$ Assuming an airburst at the optimum altitude.

${ }^{68}$ John M. Deutch, "The Decision to Modernize U.S. Intercontinental Ballistic Missiles," Science 244, 1445 (1989).
} 
of dash time, an area of uncertainty of almost $15,000 \mathrm{mi}^{2}$ could be generated, requiring about 5000 0.5-MT warheads to barrage the area.

The actual dash time available to the HML is determined by the flight time of the attacking missile less the reaction time of the HML. This reaction time includes the time from when the attacking missiles are launched until they are detected, the time for the Command Authorities to make a decision about the attack and to relay that decision to the HML crews, and the time to board and start the HMLs and move out of the garage area. Since the HMLs are considerably softer to a nuclear blast when moving, the reaction time might also include the time required to deploy the HML in a hardened configuration at the end of the dash (perhaps on the order of a minute or two). Also, in the past, it has not been the general policy of the U.S. to require pilots to go on suicide missions (although any combat mission obviously involves great risk). Thus, the reaction time might also include the time necessary for the crew to unhook the HMLs and to escape the attack area. ${ }^{69}$

The flight time of ICBMs might be around $25-30 \mathrm{~min}$. Thus, if tactical warning is obtained, an ICBM attack would seem to be impractical even if the HML reaction time were 15 min or so.

However, SLBMs flown on short-time-of-flight trajectories could present a serious problem. Current liquid-fueled missiles launched from $100 \mathrm{nmi}$ off the coast could arrive at the nearest base in about $6.7 \mathrm{~min}$ and at the deepest base in about $8.7 \mathrm{~min} .{ }^{70}$ Launches from $500 \mathrm{nmi}$ off the coast would add about 2 min to the flight time. Thus, unless the HML reaction time could be kept very short, the system could be quite vulnerable.

For example, Fig. 9-3 shows the survivability of the HMLs when attacked by just one SSBN (using short-time-of-flight SLBMs) sitting $100 \mathrm{nmi}$ or $500 \mathrm{nmi}$ off the coast. The figure indicates that if the reaction time were $6 \mathrm{~min}$, the number of surviving HMLs could be reduced to about 100 if the HMLs were caught on the move ${ }^{71}$ by an SSBN $100 \mathrm{nmi}$ off the coast. ${ }^{72}$ An SSBN $500 \mathrm{nmi}$ off the soast would be just as effective if the reaction time were $8 \mathrm{~min}$. Even if the HML were stopped and hardened, an 8-min reaction time would reduce the survivors to around 100, if the SLBMs were launched from $100 \mathrm{nmi}$ off the coast.

If there were two SSBNs sitting $100 \mathrm{nmi}$ off the coast, only about 100 warheads would be expected to survive if the reaction time were greater than $4.3 \mathrm{~min}$ and the HMLs were caught on the move. The same result world be obtained from three SSBNs located $500 \mathrm{nmi}$ off the coast if the reaction time were as much as $4.5 \mathrm{~min}$.

To increase the survivability, the U.S. could deploy more garages, more SICBMs, or both. But this would not be very effective unless the HMLs were kept on a high-alert, quick-reaction status and there was no delay in the tactical warning and $\mathrm{C}^{3}$ systems.

\section{Random Mobile}

In another basing concept, the HMLs would be randomly dispersed over several large military bases in the southwestern area of the U.S. ${ }^{73}$ The peacetime deployment area ${ }^{7 / 4}$ would be about

\footnotetext{
${ }^{69}$ In the case of attacks by short-ime-of-flight SLBMs, there is unlikely to be time to put the HMLs in a hardened position or for the drivers to escape-unless they leave the HMLs in the garages.

${ }^{70} \mathrm{This}$ is the flight time to the farthermost garages and assumes that the garages extend $100 \mathrm{nmi}$ beyond Malstrom $\mathrm{AFB}$ and $50 \mathrm{nmi}$ beyond the other two bases. Solid-fueled SLBMs could arrive even quicker.

${ }^{71}$ If the reliability of the SLBMs is 0.85 , about 112 warheads would be expected to survive, even if the entire area is targeted with a lethal overpressure because some of the missiles would never arrive.

${ }^{72}$ The analysis in Fig. 9-3 is of course simplified. But it is indicative of the problem faced by having to rely on tactical warning. For example, the HML at the garage most distant from the coast would be able to dash about 1.3 $\mathrm{mi}$ by the time the $\mathrm{RV}$ arrives. The kill radius of a $100-\mathrm{kt}$ warhead for a mobile $\mathrm{HML}$ is about $1.6 \mathrm{mi}$. This exaggerates the threat somewhat since it ignores the inaccuracy of the SLBM, which may be increased because of the "depressed" trajectory. On the other hand, the missiles could be even faster than suggested here. Also only 18 of the 20 SLBMs (on the assumed Typhoon SSBN) were used in the calculation.

${ }^{73}$ Bases under consideration are White Sands/Ft. Bliss, NM; Luke AFR, AZ; Yuma P.G., AZ; Nellis AFR, NV; and China Lake/Ft. Irwin, CA.

${ }^{74} \mathrm{CBO}$ Study, op. cit., p. 56, and B.G. Levi, M. Sakitt, A. Hobson, eds., The Future of Land-Based Strategic Missiles, (New York: American Institute of Physics, 1989) p. 199.
} 
FIG. 9-2 HML--DASH MODE

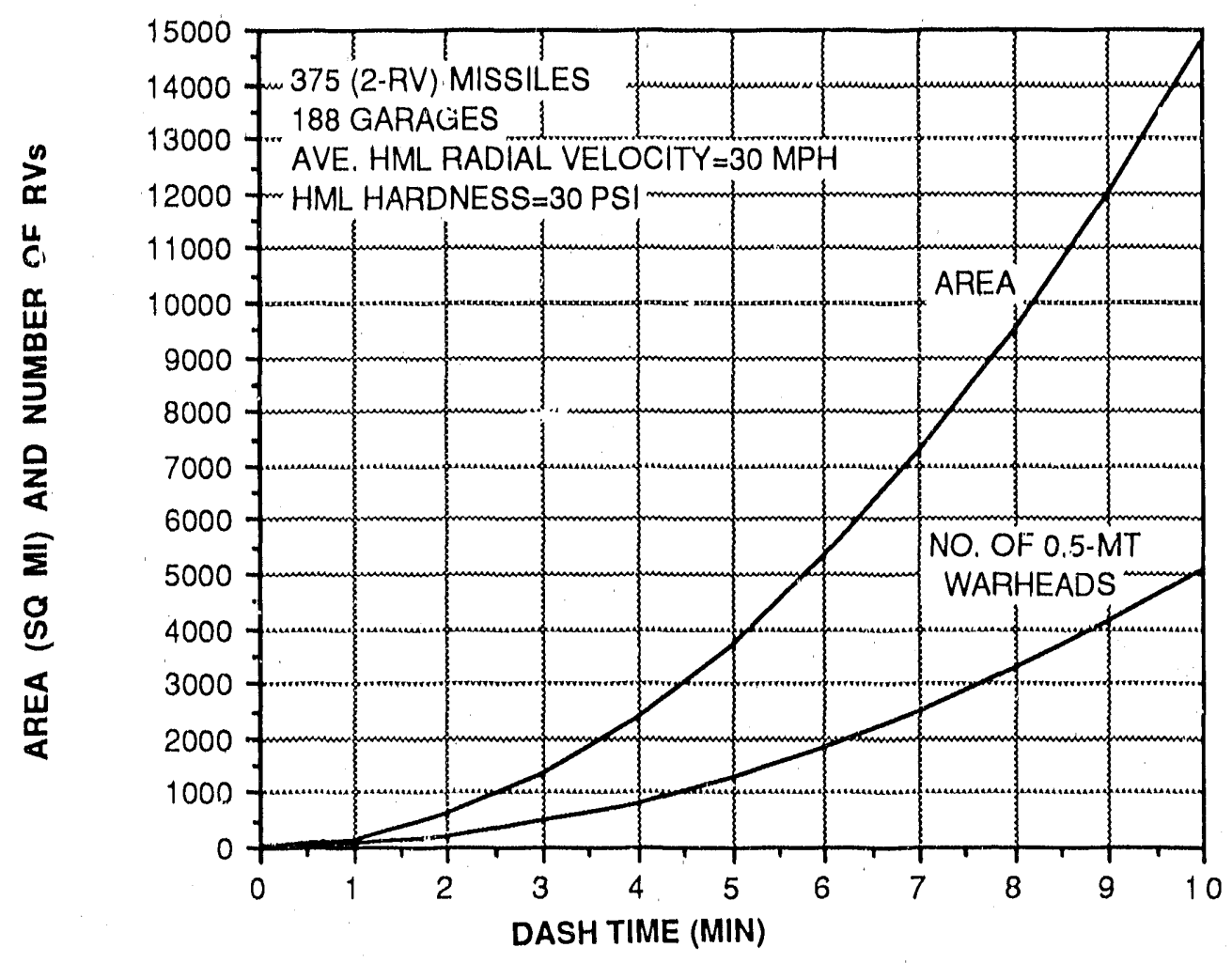

FIG. 9-3 HML -- GARAGE BASING

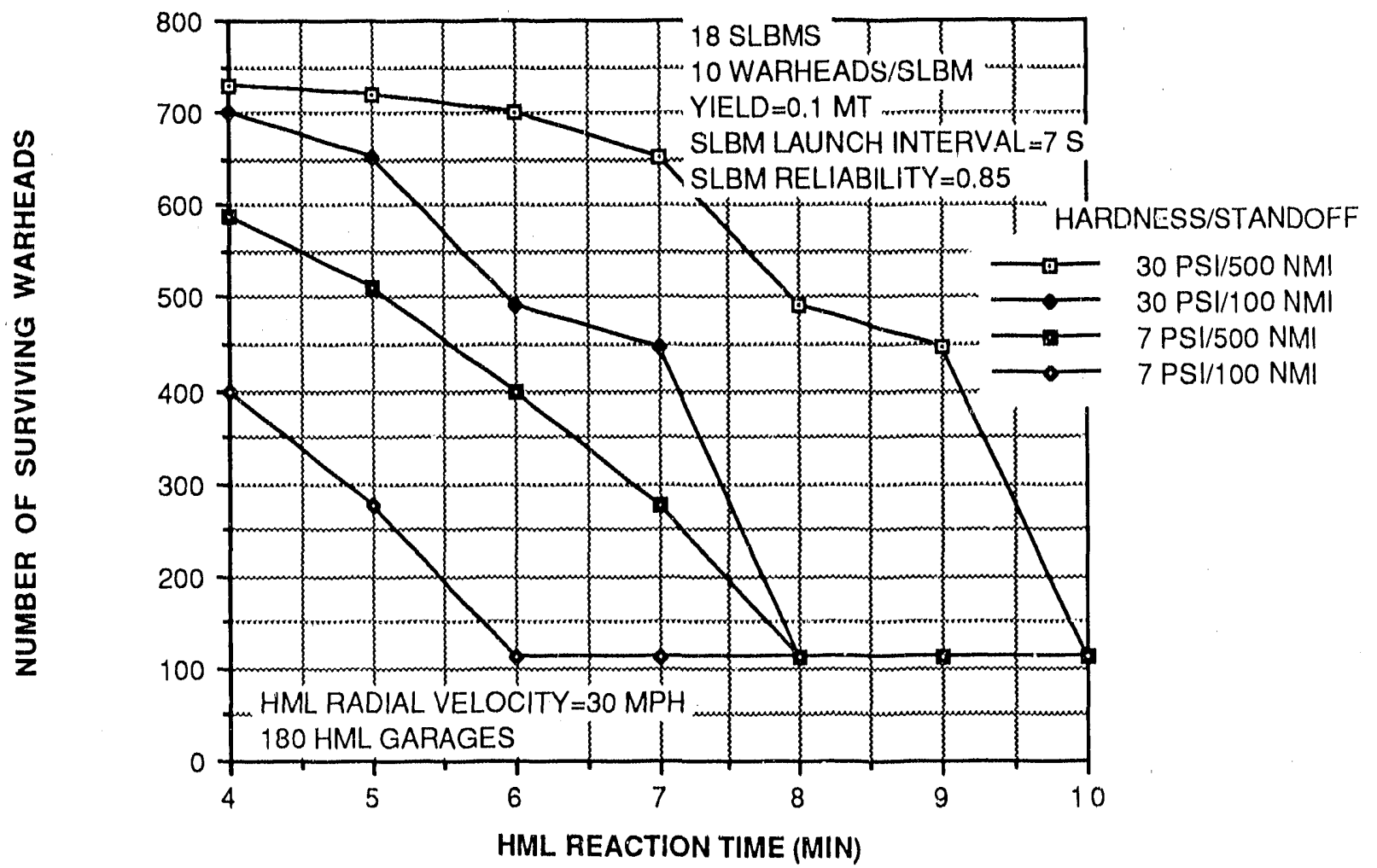


$4000 \mathrm{mi}^{2}$. The HMLs would be stationary most of the time, but would move often enough to defeat (it is hoped) any Soviet attempt to target their individual locations. If there were two RVs per missile, the missile size of the proposed SICBM would probably have to be increased somewhat to account for the required increase in range from the Southwest. ${ }^{75}$

Consider the case where no tactical warning is obtained. If the Soviets were unable to localize the HMLs and had to barrage the entire peacetime deployment area, it would require about 1400 0.5-MT warheads. This is comparable to the requirements for an attack on a silo-based system and would result in about 75 survivors (if the Soviet ICBM reliability is assumed to ve 0.9 ). Thus, to make a highly survivable system will require either the peacetime deployment over a much larger area or the reliance upon tactical warning.

Upon tactical warning of an incoming attack, the HMLs could move off the military bases, expanding the area that would have to be barraged. The goal apparently is to enlarge the deployment area to about $22,000 \mathrm{mi}^{2}$. If we assume a linear expansion to the maximum area in about $30 \mathrm{~min}$, the number of surviving HML warheads can be plotted as a function of the number of attacking warheads and the dash time available to the HMLs (see Figs. 9-4 and 9-576).

Against ICBMs, if there was as much as $20 \mathrm{~min}$ of dash time available, it would require a barrage attack of around 2000 attacking warheads to reduce the number of surviving SICBM warheads to 500 and over 4000 attacking warheads to reduce the number of survivors to 250 . To reduce the number of survivors below 100 would require around 5500 warhuads-which would require a quite large force of hidden weapons.

Using SLBBs and assuming little or no dash time, it would require at least nine SSBNs ${ }^{77}$ to reduce the survivability to below 500 warheads. To drive the number of surviving warheads below 250 would require at least 17 SSBNs sitting close off the coast. Presumably, this many submarines this close to the coast could be detected and (even without a stand-off treaty) would cause the HMLs to expand their peacetime deployment area, increasing their survivability.

This assumes that the Soviet SLBMs carry three 0.5-MT' warheads. However, Soviet SLBMs are normally very long range. If they are launched from close off the coasts, they could considerably increase the throwweight of their missiles and reduce the number of SLBMs required. Any arms control treaty would have to make provisions (including verification procedures) to block such a move.

In summary, HMLs based in a peacelime area deployment of $4\left(000 \mathrm{mi}^{2}\right.$ are not likely to be survivable without tactical warning. If tactical warning is available, and the Soviets have no information on the location of the HMLs (and hence must barrage the total area of uncertainty), it could be quite expensive for them to reduce the force level to 100 or less HML warheads.

\section{Real-Time Surveillance}

As surveillance and data processing capabilities improve, it might be possible to locate the HMLs from space and reduce the number of weapons required to attack HMLs deployed over a large area. If Soviet space surveillance systems could detect the HMLs in "real time" and rapidly relay these data to the SSBNs, the number of weapons required to attack the HMLs could be significantly reduced. The bases proposed in the Southwest are so close to the coasts (about 150-525 $\mathrm{nmi}^{78}$ ) that if there are 375 HMLs and the HML reaction time is as much as 2 or $3 \mathrm{~min}$, two SSBNs should be sufficient to destroy most of the HMLs. ${ }^{79}$

Also, it is reported ${ }^{80}$ that the Soviets plan on developing Reconnaissance-Strike Complexes (RSCs) that would, through a multitude of satellite sensors and data-fusion/command centers, allow them to attack mobile targets at any range using non-nuclear ballistic and cruise missiles. If successful,

\footnotetext{
${ }^{75}$ Devoloping a new, lighter guidance system and new RVs could help keep any increase in size to a minimum. J. Deutch implies that the current missile would be adequate in those circumstances. John Deutch, op. cit., p. 1448

${ }^{76}$ The overlap and gaps in weaponi coverage are ignored in this graph.

${ }^{77}$ Assuming 20 SLBMs per SSBN and three 0.5-MT warheads on each SLBM.

${ }^{78}$ This assumes the boats are located off Baja California, Mexico. If an SSBN went into the Gulf of California, it would only be about $350 \mathrm{nmi}$ or less from the deepest base (in New Mexico).

${ }^{79}$ Assuming 20 SLBMs per SSBN and 10100 -kt warheads per SLBM.

${ }^{80}$ For example, see Edward N. Luttwak, "The Shape of Things to Come," Commentary, June 1990, pp. 17-25.
} 
FIG. 9-4 HML DEPLOYMENT AREA

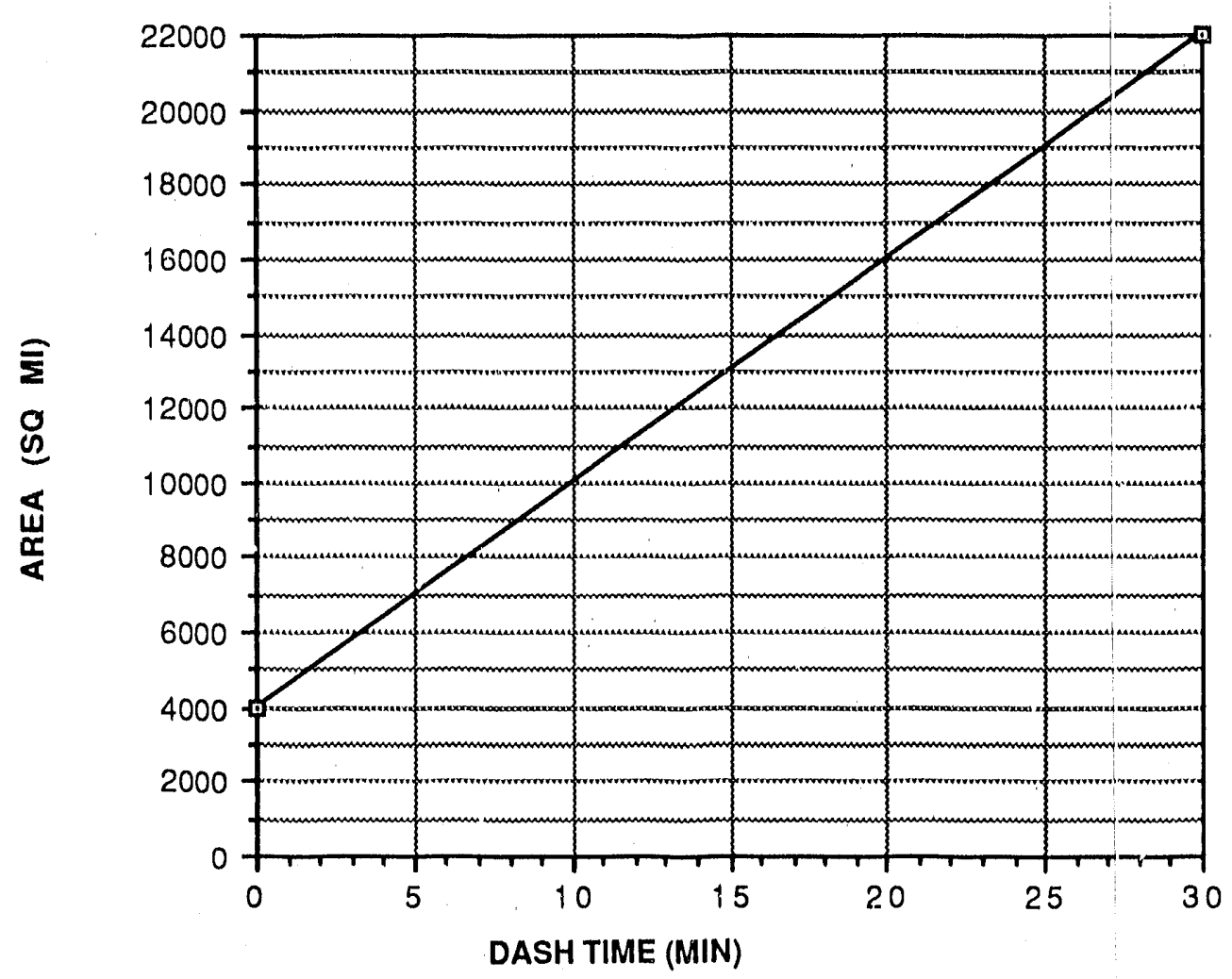

FIG. 9-5 HML SURVIVABILITY-RANDOM DEPLOYMENT

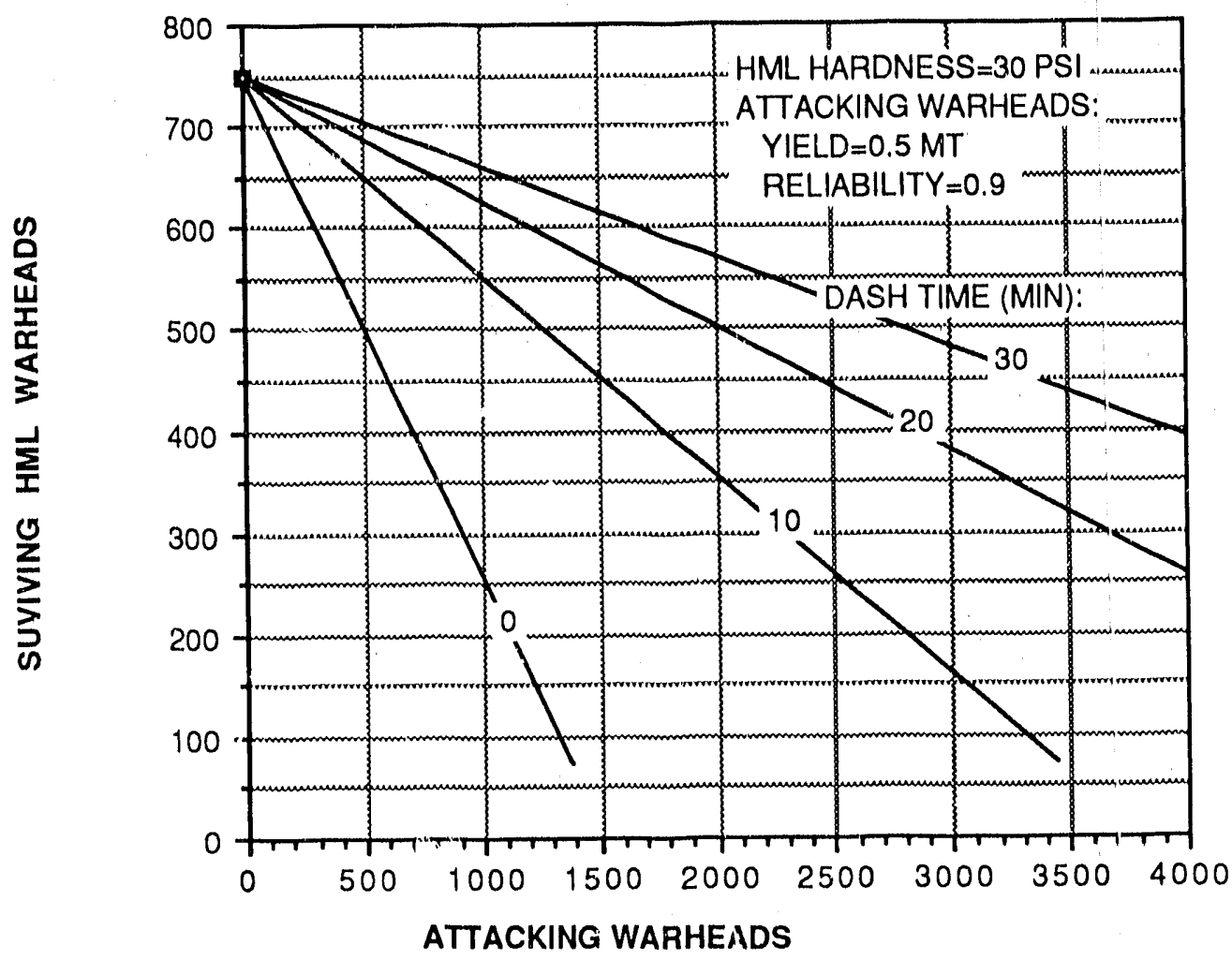


a moving target, like an HML, could be detected and "tatgred by ballistic missiles whose maneuvering warhead would be command-guided to destroy it, with slivering updates as necessary to keep up with [its] movements." ${ }^{11}$ Of course, nuclear warheads would be even more effective.

Such a capability is probably at least a decade or more away. However, if this capability were eventually developed and deployed, it obviously would pose a severe threat to all mobile systems, including the relatively slow HMLs. Whether arms control agreements to limit such a capability are feasible is uncertain. Moreover, it is not clear that the U.S. military would support such restrictions since they might justifiably wish to pursue such technology themselves.

\section{Costs}

Costs for the HML system are very uncertain. Based on reported costs for 500 single-RV SICBMs and 250 2-RV SICBMs, a rough estimate of the 15-year life-cycle cost of the 750-warhead systems discussed here can be made 82 and is shown in Table 9-2:

Table 9-2. HML system costs.

\begin{tabular}{lcc}
\hline System & Missiles & Cost (\$B) \\
\hline Garage & 750 & 40 \\
Garage & 375 & 29 \\
Area & 750 & 42 \\
Area & 375 & 31 \\
\hline
\end{tabular}

\section{Summary}

The HML system relies on tactical warning for survivability. Thus, along with the bombers, there would be two legs of the Triad that could catastrophically fail if the there was a significant delay in detecting missile launches and relaying an authorization to move the strategic forces away from their peacetime locations.

With northern basing of the HMLs in garages (whose positions are well know), a reaction time of eren 4 or 5 min could make the HMLs vulnerable to SLBMs flown on short-time-of-flight trajectories. Southwestern basing of the HMLs over a large area should be relatively safe (with tactical warning) in the near-term. However, if the Soviets develop a capability to detect the HMLs in their peacetime positions and could relay that information in real-time to the SSBNs, the HMLs could be quite vulnerable to short-tirne-of-flight SLBMs. In the longer run, the Soviets could possibly even develop the technology that would allow ICBM-launched RVs to "home" on the relatively slow-moving HMLs.

\subsection{Carry Hard ICBMs}

Finally, consider the Carry Hard basing concept. This is a multiple-aimpoint system in which transportable, hardened, encapsulated missiles are deceptively shuttled among a large number of austere, unhardened vertical shelters. ${ }^{83}$ The encapsulated missile is expected to have a hardness of about 10,000 psi when in its shelter. The missile used in the system could be MX, Minuteman, the SICBM, or some new comparable ICBM.

\section{Survivability}

The survivability of the system depends neither on lactical nor strategic warning but rather on proliferating enough cheap aimpoints (shelters) to absorb a large Soviet attack. The only potential

\footnotetext{
${ }^{81}$ Ibid., p. 23.

${ }^{82}$ Deutch, op. cit., p. 1448.

${ }^{83}$ For details of the system, see J. Harvey, et al., Carry Hard ICBM Basing: A Technical Assessment, Lawrence Livermore National Laboratory, UCID-21840, Nov. 1989.
} 
significant weakness of the system is that somehow the Soviets could discover the actual locations of all the missiles. However, it should not be too difficult to design a system that would preclude the missiles from being detected by remote sensors. Intruders or autonomous short-range enemy sensors placed in the field could be detected by placing a double security fence around the entire field and deploying a high level of security sensors and patrols within the missile field. ${ }^{84}$ A possible concern about internal agents accumulating data would be addressed by designing operations and maintenance procedures so that no one person could know where more than perhaps 5 percent of the missiles were actually located. Thus, if the security program were pursued vigorously (which it would have to be), there should be little chance of the Soviets locating a significant number of missiles. ${ }^{85}$

\section{System Size}

The optimum number of shelters depends on how many survivors are required, the anticipated size of the attack, and the effectiveness of the attacking warheads. Figure 9-6 illustrates the survivability of a 750-warhead Carry Hard system that has 12 shelters per warhead for a total of 9000 shelters. Figure 9-7 shows the survivability of the system when fewer shelters are deployed. If the 9000-shelter system were attacked by $30000.5-\mathrm{MT}$ warheads (the total strategic force allowed under the treaty), the number of survivors might vary from about 540 to 635 depending on the accuracy of the attackers. Even if the Soviets had an extra 2000 accurate warheads hidden away, 400 to 550 warheads might still survive an all-out Soviet attack.

\section{Cost}

The expected cost of various Carry Hard systems with 750 warheads is given in the Tables 9-3 and $9-4$.

Table 9-3. Unit costs.

\begin{tabular}{lccc}
\hline \multicolumn{1}{c}{ System } & $\begin{array}{c}\text { Unit } \\
\text { aimpoint cost } \\
(\$ \mathrm{M})\end{array}$ & $\begin{array}{c}\text { Unit missle/ } \\
\text { capsule cost } \\
(\$ \mathrm{M})\end{array}$ & $\begin{array}{c}\text { Fixed costs } \\
\text { (\$B) }\end{array}$ \\
\hline MX & 2 & 97 & 10.6 \\
Minuteman III & 1.7 & 37 & 9.6 \\
SICBM 2 RVs & 1.5 & 47 & 15.3 \\
SICBM 1 RV & 1.5 & 44 & 14.9 \\
\hline
\end{tabular}

Table 9-4. Carry-Hard system costs.

\begin{tabular}{lcc}
\hline \multicolumn{1}{c}{ System } & $\begin{array}{c}\text { System cost- } \\
9000 \text { shelters } \\
\text { (\$B) }\end{array}$ & $\begin{array}{c}\text { System cost- } \\
6000 \text { shelters } \\
\text { (\$B) }\end{array}$ \\
\hline MX & $34^{*}$ & $28^{*}$ \\
Minuteman II & 34 & 29 \\
SICBM 2 RVs & 46 & 42 \\
SICBM 1 RV & 62 & 57 \\
\hline
\end{tabular}

* Assumes present $50 \mathrm{MX}$ missiles used at a savings of $\$ 1.9 \mathrm{~B}$.

\footnotetext{
${ }^{84}$ This should prove economically feasible because the high missile hardness allows the shelters to be placed relatively close to each other (about $1500 \mathrm{ft}$ apart) and hence reduces the land requirements of the system. ${ }^{85} \mathrm{Also}$, there is the question of how much confidence the Soviets could have in whatever information they obtained. The information would have to come from either sensors (with a vigorous security program in the deployment area, there should be little possibility of this) or from an agent (presumably, some Air Force employec). Would the Soviets risk a war on the basis of information obtained from fallible remote sensors or from someone who could be lying to obtain money or could possibly be a double agent?
} 
FIG. 9-6 EFFECT OF NUMBER OF ATTACKERS AND CEP

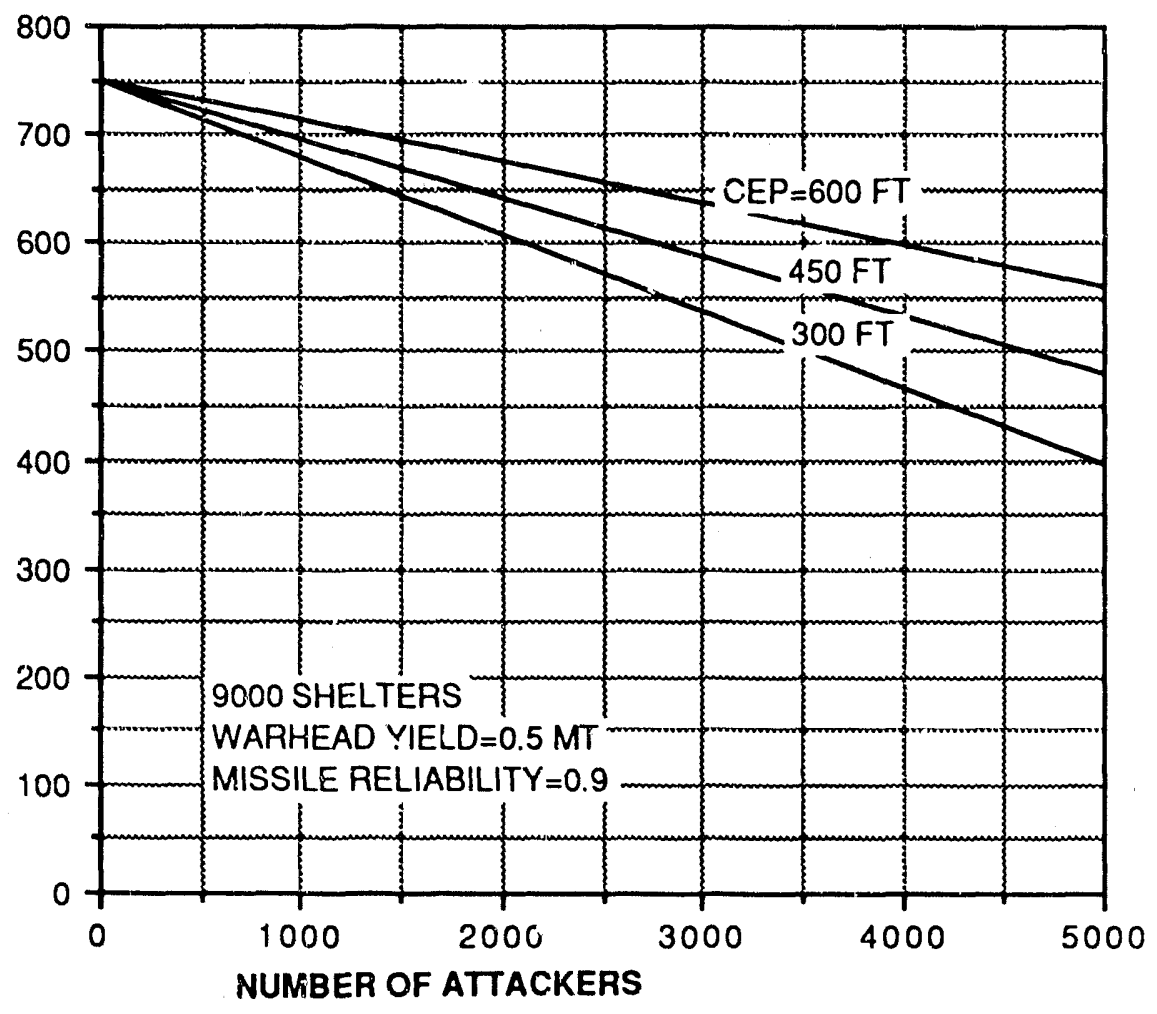

FIG. 9-7 NUMBER OF SHELTERS

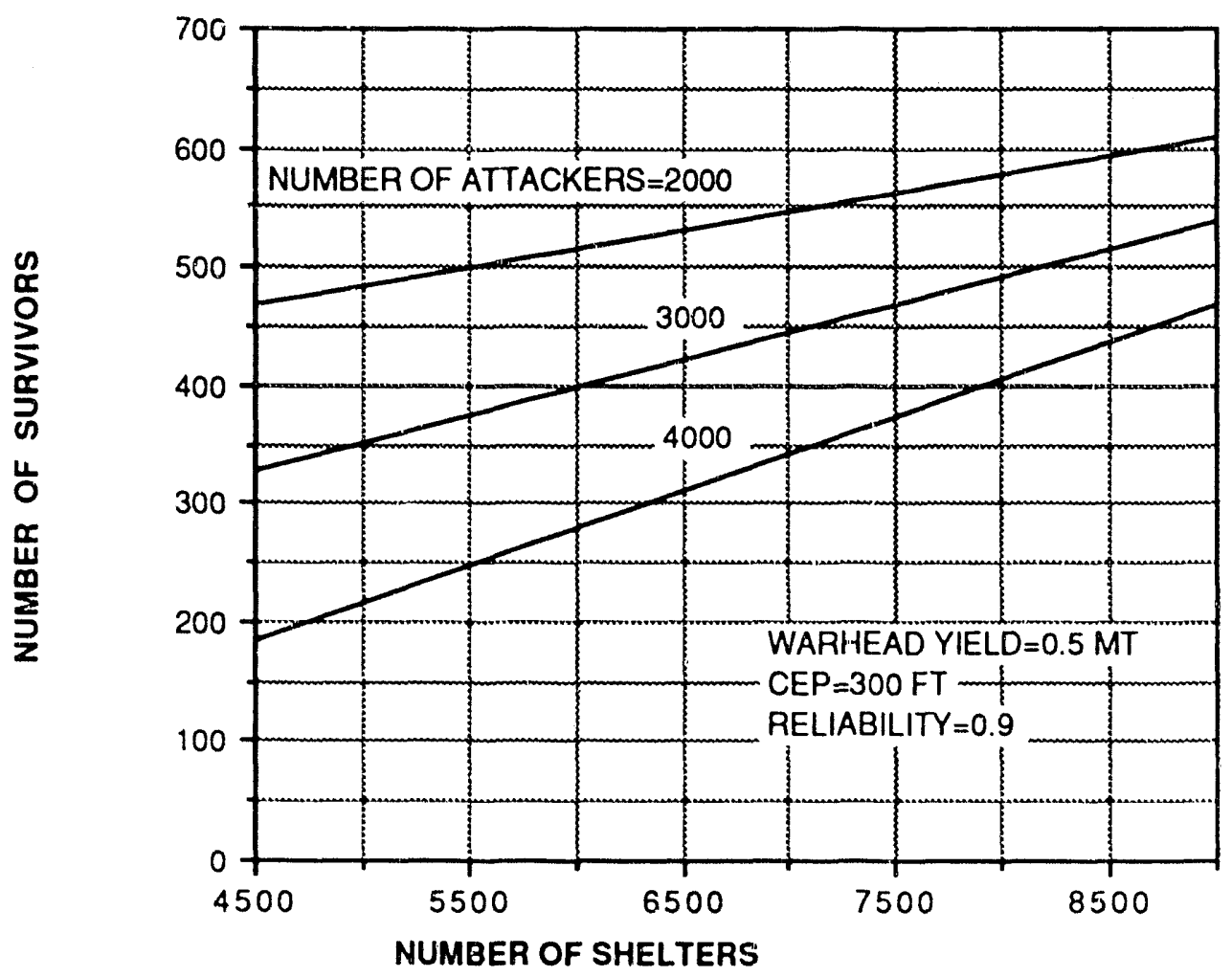


Hence, MX and Minuteman systems would be comparable in cost while a 2-RV SICBM would cost an extra $\$ 12 \mathrm{~B}$ or so. The 1-RV SICBM system would cost considerably more, almost double the cost of the MX systern.

\subsection{ICBM Basing-Conclusion}

Compared to other land-based ICBM basing concepts, the Carry Hard system has the advantage of not depending on either strategic or tactical warning for survivability. Moreover, improvements in Soviet missile accuracy or space surveillance are unlikely to endanger the system as would be the case in normal hard-silo deployments or the HML system. The system can also be made robust to the possibility of hidden Soviet missiles.

The cost of deploying MX, Minuteman III, or the 2-RV SICBM system in the Carry Hard mode are comparable to or !ess than the HML system and the confidence in their survivability should be significantly higher. Only the 1-RV SICBM system would be considerably more expensive in the Carry Hard basing than the HML basing. While there may be some strategic advantage to 1-RV missiles if they are deployed in fixed silos, there is no real advantage if the missiles are deployed in a "sea" of silos such that the attacker does not know where the missiles are located.

Of course, at this stage, the Carry Hard system is less well developed than the HML system. However, preliminary analysis indicates that the missiles can indeed be made to be quite hard to nuclear explosions and techniques can be developed to assure that the location of the missiles in the field can be kept secret. ${ }^{86}$ If this proves to be the case, then under a regime of deep cuts in strategic forces, a missile with two or more RVs deployed in a Carry Hard mode would appear to offer the possibility of an affordable system that could solve the long-standing land-based missile survivability problem.

\footnotetext{
${ }^{86}$ See J. Harvey, et al., op. cit., p.6-8
} 


\section{Very Low Force Levels}

\subsection{START II or START III?}

With the dramatic changes taking place in Europe, it might be argued that in the next round of strategic force reductions following current START Treaty it would be possible to reduce to even less than 3000 nuclear warheads on each side-perhaps to 1000 or less. While conceivable, it would appear very unlikely that it would be possible to go immediately to this level. Such reductions would raise many political and technical problems. For example:

\section{Other Nuclear Powers}

At low levels of forces, the nuclear arsenals of the lesser nuclear powers become much more important. For legitimate security reasons, the Soviets could well object to having a number of potentially hostile states (the U.S., Britain, France, and China) with nuclear forces comparable in size to their own. Also there may be political and psychological reasons why the Soviets or even the Americans might object to radical reductions. After all, the possession of large nuclear arsenals is one of the prime ingredients in being a superpower-particularly in the case of the Soviets. Thus, barring a significant change in the way politicians view the world, it seems likely that only if the other nuclear powers significantly reduced their forces or disarmed would either superpower consent to greater reductions. Even if the other powers agreed, bringing all of them into the negotiations would undoubtedly complicate and prolong negotiations, foreclosing the reaching of a new treaty in the near future.

\section{Strategic Policy}

With 3000 warheads, the U.S. could still proclaim that it was adhering to the Flexible Response doctrine, albeit in a somewhat modified form. With radical reductions to 1000 warheads, it would be impossible to continue with this posture, and a new policy would have to be adopted and implemented. Because of the apparent ending of the Cold War, such a policy shift is probably feasible in the long run. But it might be too much to expect such a change in the next few years while the next round of arms control negotiations were underway. It is more likely that, in the interests of alliance stability and unity, facing up to official policy changes would be put off for the future.

\section{Verification}

Verification of compliance with a treaty that allowed only 1000 weapons or less on each side would be of utmost importance and require unprecedentedly intrusive on-site inspections. Going from the present world to this radical new situation without an intermediate "safe" step would seem unduly risky. With 3000 warheads and proper basing, there would still be sufficient forces for some margin of crror if the Soviets cheated. Experience with the verification techniques required for a reduction to 3000 weapons could eventually give boih sides confidence to proceed to even lower levels-or it could convince them that further reductions were unwarranted.

\section{Stability}

With 3000 warheads and proper basing, it would appear fairly straightforward to show that one could have very high confidence that a significant force (500-1500 warheads) would survive a surprise attack by a technologically innovative Soviet Union. Furthermore, the U.S. forces could consist of current forces or those that could be available within a reasonable time.

However, reductions to 1000 warheads or less will raise many technical questions about survivability and, hence, strategic stability. These questions eventually might be answered (although it could require the development of new basing concepts and systems), but it probably would be unwarranted to decide the issue at this stage.

Cutting the nuclear weapons of the superpowers by 85 percent or so from a total of around 50,000 (including tactical weapons) to around 6000 strategic weapons (plus a few hundred short-range weapons) obviously has great political appeal, and could enhance world stability, as long as sufficient 
survivable forces were maintained. However, if pushing on immediately to a total of 2000) or so nuclear weapons would renew fears of instability, it could reasonably be asked "why take the risk?" After all, the main reason for reducing forces is to produce greater security and trust between the U.S. and the Soviet Union, not just to reach some arbitrary number of weapons.

In summary, it seems that even with a continuing improvement in the political climate and with the best of intentions on all sides, any really deep reductions to a level of 1000 or less warheads on each side would almost certainly have to await the implementation of a somewhat more modest START II Treaty.

If a general consensus for further reductions beyond START II develops, there would still be significant technical difficulties. The rest of this section addresses some of the concerns that might arise from an attempt to reduce strategic forces to a very low level.

\subsection{How Much Is Enough?}

If the U.S. reduced its force levels to 1000 warheads or less, there would have to be a significant reorientation of strategic policy. In Part I of this paper, it was argued that the current security needs of the U.S. and its allies could be met with a strategic force level of 500 survivable nuclear warheads and a strong conventional defense in Europe. This should be sufficient even if the Soviet Union reverted to its previous state of hostility towards the West.

In principle, it should be possible to build a mixed force structure of 1000 warheads that would allow at least 500 warheads to survive. However, it would be very difficult to hedge against unexpected technological breakthroughs and still assure the survival of 500 warheads. A conservative planner might be willing to count on only 250 to 300 surviving warheads from 1000 deployed warheads.

Of course, determining how much is enough to deter is in large part a political question. It may be that, by the time START III could be negotiated, the Soviet Union will have evolved into a true democratic, pluralistic society no longer hostile to the West. If democracy does arrive and is accompanicd by a clear reorientation of Soviet military doctrine away from a threatening, damagelimiting strategy, then in the long run, politicians might decide that a 1000 warheads would be sufficient for deterrence. Indeed, to a prudent planner, the further democratic evolution of the Soviet Union might be a prerequisite for the lowering of forces to this level.

\subsection{Possible Systems}

An arms control agreement to restrict the U.S. and the Soviet Union to 1000 (or fewer) nuclear warheads each is probably far in the future. Any discussion of possible force structures that might be deployed at that time is thus somewhat speculative. However, we can address some of the general problems that might be encountered and suggest possible directions to explore in more detail if such radical reductions are contemplated.

Since at this level of forces there is little margin for error, even higher standards of survivability should be required than in the past. Politically, this would also be important. Otherwise, it could be very difficult to convince Congress that deterrence could be maintained at this low level. In general, this means that the forces should be highly survivable against possible advanced-technology breakthroughs that might occur in the future. Hedging against unforeseen breakthroughs is particularly important in designing new systems, since the lead tirnes can be quite long and the threat technology (e.g., computers and sensors) may advance rapidly during the period of development and deployment of a new system.

\section{Bombers}

In the near term, bombers and cruise missiles might still play a role in the strategic force structure. But, as the number of allowed weapons becomes quite small, it will be more and more difficult to ensure their survivability. 
For example, to be really confident about the prelaunch survival of the bombers would probably require that all SSBNs be banned. Since there is also a potential threat to the bomber bases from "stealthy" cruise missiles, a detection and $C^{3}$ system in which one had extreme confidence would be necessary. Alternatively one might try to forbid cruise missile launch platforms such as submarinesan uriikely prospect. Even if successful, this would still leave cargo ships with hidden missiles and supposedly commercial aircraft with missiles. Also, there are possible threats from paramilitary forces using short-range smart munitions or even from "suitcase" nuclear bombs smuggled into the country.

In addition, there is the threat of the Soviet air defense system with its formidable array of sensors, interceptor aircraft, and SAMs. The continued penetrability of 100 or 200 ALCMs, even if stealthy, against an unconstrained air defense system would seem too uncertain to rely upon. Clearly, if the Soviets refused to abandon this air defense system, the U.S. should move away from reliance on a small number of aircraft and cruise missiles.

But even if the Soviets reduced their current air defense system, in the long run, there may be additional severe threats. For example, the Defense Department reports that "The technical promise of SDI could significantly improve air defense mission efficiency and effectiveness, especially against future threats." 87 It is likely that in time the Soviets will develop such capabilities also. If so, their advanced space-based sensors might be able to track bombers in mid-course ${ }^{88}$ and relay the information to a forward defense system, perhaps including surface ships and submarines, ${ }^{89}$ which could attack the bombers before they released their cruise missiles. Eventually, they might even be able to launch longrange nuclear missiles at the aircraft, with continual updating of tracking data being fed to a maneuvering warhead (see Section 9.2). All in all, a long-term reliance on bombers and their cruise missiles may not be warranted at very low forces levels.

\section{A Dyad Force Structure}

At low force levels it is essential to have high confidence in the survivability of all the weapons. Thus, if there were some doubt about the bombers, and at least 300 or so surviving weapons were desired, it may be more prudent to abandon a potentially weak Triad for a more survivable Dyad. ${ }^{90}$

This means that the survivability of the other two forces would have to be very high even against potential long-term advanced-technology threats. For a balanced force, each system should be designed for at least 300-400 surviving warheads. This would hedge against the development of a severe unforescen threat against one of the forces or moderate threats against both.

The exact nature of the kind of forces that would be desirable at these force levels would of course require careful analysis. However, just from the concepts now available, it would appear that a balanced force of highly survivable ICBMs and SLBMs could be deployed in a decade or so.

\section{SLBMs}

The deployment of 500 warheads on the current Trident submarines would require only seven SSBNs if each SLBM carried three warheads. Even if each SSBN carried only one RV, it would require only 21 boats to deploy 504 RVs. But this would be a very expensive way to deploy a small number of warheads.

But beyond the expense, there is the concern about long-term survivability. There are two potential problems with the Trident boats: (1) they are few in number, and (2) they are very large, which is likely to exacerbate any non-acoustic problem that might be associated with submersibles (see

\footnotetext{
${ }^{87} 1990$ Report to the Congress on the Strategic Defense Initiative, Strategic Defense Initiative Organization, May 1990, p. D-1.

${ }^{88}$ As one example, "Space-based radar, employing major advances in high-frequency and sophisticated signalprocessing techniques, will offer a valuable mix for confronting [bombers] with multispectral surveillance, tracking, and targeting capability." Ibid., p. D-4.

89 "Technological spinoffs from the High Endoatmospheric Defense Interceptor project could contribute to the development of a long-range, ship-based missile for intercepting bombers." Ibid., p. D-3.

${ }^{90}$ Politically, this obviously would be difficult to do since the Air Force (and its aliies) would raise strong objections against losing one of its two legs of the strategic Triad.
} 
Section 7). Hence, to assure the long-term security of a sea-based deterrent probably will require the development of a new system.

Small non-nuclear submarines carrying ICBMs have been discussed for many years, ${ }^{91}$ For example, 60 or 65 small boats carrying eight vrarheads each might present a difficult technical challenge for future Soviet ASW systems. Even better might be a system with 500 very small boats, each with a single-RV SLBM. ${ }^{92}$ At a high level of proliferation of small submersibles, pariticularly something like the latter system (if it proved technically and economically feasible), one might reasonably have a high expectation of their survivability. ${ }^{93}$

ICBMs

Silo Basing. One possibility is to base 500 single-RV missiles in hardened silos. However, since these silos are vulnerable to accurate Soviet missiles, this basing would not provide an effective hedge against a breakthrough in Soviet ASW. For example, a one-on-one attack by highly accurate Soviet missiles could leave the U.S. with only about 50 surviving warheads (assuming a Soviet missile reliability of 0.9 ), while the Soviets could retain 500 strategic warheads.

Modest advances in technology could make the situation even worse. For example, if an ICBM fails, it is most likely to do so in the early part of its flight. It should not be too difficult to deploy systems on board each ICBM to detect this failure. With modern computer technology, it should be possible to quickly reprogram other ICBM warheads to attark the targets originally assigned to the missiles that failed. If the reliability of the attacking ICBMs were $0.9,50$ of the original 500 missiles would fail. If they were replaced with 50 other warheads, only about 5 of the U.S. ICBMs might be expected to survive. If the Soviets had a modest ABM system to deal with these few surviving U.S. warheads, they might expect little or no damage.

It could be argued that a single strategic system consisting of 1000 single-RV missiles in silos would be more satisfactory than a mixed force (Dyad) since the attacker would have to use its entire force of 1000 warheads, effectively disarming itself while leaving the U.S. with about 100 warheads (because of the unreliability of the attacker's missiles). However, this would be true only if we could guarantee that there would be no hidden missiles. If the Soviets had an extra 100 or so hidden, accurate ICBM warheads (on 10 or 20 missiles) and could reprogram them, they might be able to reduce the number of surviving U.S. warheads to around 10. If they also had another couple hundred warheads (perhaps cruise missiles or bombs) hidden away, the U.S. could be in a very disadvantageous position.

Since strategic stability requires an ICBM basing mode that is not highly sensitive to hidden missiles or improvements in Soviet missile technology, deployment of ICBMs in a multiple-aimpoint or possibly a mobile system would seem preferable to silos.

$H M L$. A system of 500 missiles deployed on HMLs in principle should be very survivable in the near term if based in a random mobile mode. However, in the long run, the HMLs might be detected and followed by sophisticated space-based sensors which could make the HMLs vulnerable to short-timeof-flight SLBMs. Eventually, the Soviets might even have a system that could relay the data to inflight ICBM RVs which then would correct their trajectories to correspond to the relatively small changes in location of each HML. An attempt to ban such threatening systems could be made, but a high-confidence enforcement of the ban could prove difficult (particularly if all that was required was a surveillance system that could locate the HMLs at the time the SLBMs were launched).

Carry Hard. The survivability of the multiple-aimpoint Carry Hard System would appear to be very robust to hidden weapons and improvements in Soviet technology (see Section 9). For example,

\footnotetext{
91"ICBM Basing Options," Office of the Deputy Under Secretary of Defense for Research and Engineering (Strategic and Space Systems), December 1980.

${ }^{92}$ For a description of a concept of small two-man crew submarines, each with one missile, see A. Latter and R. Mesic, "A New Concept for Sea-Based Strategic Weapons," RDA-TR-609001-001, R\&D Associates, April 1980. The submersibles would be small enough to be delivered to their "patrol areas" by aircraft. The estimated cost for a system with 1250 submersibles (including supporting systems like aircraft) was about \$26 B.

${ }^{93} \mathrm{~A}$ very high percentage of the boats would have to be kept at sea at all times. Thus, an agreement that did not count boats in overhaul would be helpful.
} 
consider a system with 500 Carry Hard warheads based among 6000 shelters. ${ }^{94}$ If this system were attacked by the entire allowed 1000 Soviet RVs, 425 warheads would be expected to survive even if the Soviet missiles had perfect accuracy and a 90-percent reliability. If the Soviets managed to hide an extra 1000 of these zero-CEP missiles, at least 350 warheads would still be expected to survive an allout attack. Hence, if further research verifies that the Carry Hard System would be as survivable as preliminary tests indicate, Carry Hard would appear to be the preferred deployment mode of ICBMs, both in the near term and the long term. ${ }^{95}$

\footnotetext{
${ }^{94}$ The cost of this system using MX would be about $\$ 27.5 \mathrm{~B}$ (based on current estimates). With a 2-RV SICBM, the cost would be about $\$ 36$ B. See Section 9 .

${ }^{95}$ If the Carry-Hard System were deployed during ST ART II, it would only require the destruction of some of the missiles to reach the lower limit of START III.
} 


\section{Summary}

President Bush has called for the development of a new strategy to deal with the new geopolitical situation brought on by the collapse of the Warsaw Pact and the apparent ending of the Cold War. Principal interest so far has centered on the reorganizing of NATO's conventional force structure in the wake of these changes. But there have also been renewed calls for radical cuts in U.S strategic forces to levels far below the 10,000 or so warheads allowed each side under the current START proposal.

However, the military and the Defense Department argue that no cuts below the START level can be made since all these weapons are necessary to fulfill the requirements of the current strategic targeting doctrine. Hence, to reduce the strategic weapons on each side to 3000 or lower will require a re-evaluation of that doctrine.

Strategic force requirements have long been driven by the idea that U.S. strategic nuclear weapons can be used to deter a Soviet conventional attack on our Western European allies by threatening to initiate nuclear strikes against the Soviet Union. In an attempt to make this threat credible, the U.S. has pursued the chimera of a damage-limiting warfighting capability that would allow the U.S. to prevail against the Soviet Union. This strategy has produced a seemingly endless demand for nuclear weapons, but is no more feasible today than it was 20 years ago when the U.S. had "only" 3500 strategic nuclear warheads.

It now appears that, with the collapse of the Warsaw Pact, NATO will for the first time have the capability to defeat a Soviet attack without the necessity of threatening to resort to nuclear weapons. This should pave the way for the rethinking of U.S. strategy and the reduction of U.S. strategic weapons requirements.

In this new environment, it seems plausible that, with a modification of the Flexible Response doctrine to forego attempts to disarm the Soviet Union, deterrence could be maintained with 1500 or so survivable strategic weapons. With a new strategy that confined U.S. strategic weapons to the role of deterring the use of nuclear weapons by other countries, a survivable force of 500 or so weapons would seem sufficient.

\subsection{START II}

With a treaty that restricted each side to 3000 nuclear warheads, it should be feasible to deploy a Triad of strategic forces that would allow at least 500-600 survivors in each leg of that Triad.

\section{SSBNS}

A force of 18 Trident strategic submarines would provide about 1300 warheads with a firepower of over 800 EMT (if each missile carried 30.5 -MT warheads). Over 850 warheads could probably be at sea at all times. While this force should be survivable in the near term, in the future it would be prudent to develop and deploy smaller and more numerous submarines.

\section{Bombers/Cruise Missiles}

A force of about 950 advanced ALCMs deployed constantly on about 47 alert B-1 bombers should be highly survivable to even advanced SLBM threats-provided that the bombers were redeployed on numerous bases deep in the interior of the country and kept on a very quick reaction alert status. Hopefully, a significant percentage of a large force of long-range stealth ALCMs (once developed and deployed) could continue to penetrate the extensive Soviet air defense for some time into the future. However, in the long run, space-based sensors may be able to track bombers, presenting a serious potential threat.

\section{ICBMs}

The reduction in the number of Soviet strategic weapons could greatly aid in the solution of the land-based ICBM survivability problem. Deployment of about 750 warheads in a Carry Hard multiple aimpoint system should provide a large number of survivors-assuming that preliminary conclusions 
about the system's feasibility prove correct. The Carry Hard system does not depend on either strategic or tactical warning for survivability, and improvements in Soviet missile accuracy or space surveillance are unlikely to endanger survivability as would be the case if the missiles were deployed in silos or on mobile launchers. The system survivability would also be very robust against a large force of hidden Soviet missiles.

\subsection{START III}

Cutting strategic weapons to very low levels (1000 or less) would present unprecedented political and technical problems and undoubtedly raise many concerns about strategic stability. Any attempt to immediately push to such low levels in any START follow-on treaty would seem unlikely to succeed. Ultimately, it could require the transformation of the Soviet Union (or what remains of it) into a truly democratic, pluralistic society (matched by a reoriented military doctrine and posture) before such cuts could be negotiated.

If radical cuts are undertaken in the future, a revision of current strategic doctrine would be required. Also, even higher standards of survivability would be required since there would is little margin for error.

In the future, it may be difficult to have confidence in a small number of bombers and cruilise missiles surviving a surprise attack and penetrating the Soviet air defense. This is particularly true if the Soviets do not severely restrict that defense. But even with restrictions, future space-based surveillance capabilities could pose an unacceptable threat to such a small, exposed force.

Hence, if there are only small forces, it might be more prudent to try to build a very survivable Dyad of forces rather than to rely on a weak Triad. A redesigned submarine and ICBM force could probably provide a high-confidence force structure.

\section{SSBNs}

A small number of large submarines would dangerously concentrate the force. Thus, the U.S. should move to a large number of small submarines to decrease the strength of any non-acoustic signals from the submarines and increase the number of targets for Soviet ASW. The optimum size for the submarine would have to be studied, but, in principle, there could even be 500 two-man submersibles, each carrying a 1-RV missile.

\section{ICBMs}

A force of 500 warheads deployed on missiles carrying two or more warheads in a Carry-Hard System should prove very survivable and affordable. 


\section{Appendix A. START Agreement}

The terms of the START agreement agreed to in June 1990 are listed below. The completed treaty is expected by the end of the year.

\section{Strategic Nuclear Delivery Vehicles (SNDVs)}

- Ceiling of 1600 deployed ICBMs (and their associated launchers), deployed SLBMs, and heavy bombers.

- Ceiling of 154 deployed heavy ICBMs.

\section{Throw-weight}

The aggregate throw-weight on deployed ICBMs and deployed SLBMs shall not exceed approximately 50 percent of the current aggregate throw-weight of deployed Soviet ICBMs and SLBMs.

\section{Warheads}

- Ceiling of 6000$)$ attributed warheads.

- Ceiling of 4900 warheads on deployed ICBMs and deployed SLBMs.

- Ceiling of 1540 warheads on 154 "heavy" missiles.

- Ceiling of 1100 warheads on mobile ICBMs.

\section{Bombers}

- Each bomber counts as one SNDV.

- Each heavy bomber with no ALCMs counts as one warhead.

- Bombs and SRAMs not counted.

- Existing and future ALCM-carrying U.S. heavy bombers will be attributed with ten warheads each.

- Existing and future ALCM-carrying Soviet heavy bombers will be attributed with eight warheads each.

- ALCM-carrying heavy bombers must be distinguishable from other bombers.

- The U.S. can have 150 bombers attributed with ten ALCMs.

- The U.S.S.R. can have 210 bombers attributed with eight ALCMs.

- If either side exceeds this number of ALCM-carrying bombers, the excess bombers will be attributed with the number of ALCMs they actually carry.

- Existing and future ALCM-carrying U.S. heavy bombers may be equipped with no more than 20 ALCMs.

- Existing and future ALCM-carrying Soviet heavy bombers may be equipped with no more than 12 ALCMs.

- Long-range ALCMs have a range greater than $600 \mathrm{~km}$.

- Future long-range non-nuclear ALCMs must be distinguishable from nuclear ALCMs (no restriction on deployment of such systems on non-constrained aircraft).

\section{SLCMs}

- Not constrained by treaty.

- Unilateral, politically binding annual statement on the number of long-range nuclear SLCMs to be deployed over the next five years (not to exceed 880). 


\section{Mobile ICBMs}

- Number of non-deployed ICBMs for mobile launchers will be limited.

- Mobile ICBMs will be identified by tags.

\section{Bans}

- New types of heavy ICBMs.

- New types of ICBMs or SLBMs with more than ten RVs.

- Flight testing and deployment of existing ICBMs and SLBMs with more RVs than specified in 1987 statement.

- Rapid reload of ICBM launchers.

\section{Unresolved Issues}

- U.S. wants to count Soviet Backfire bomber as a "heavy" bomber; the Soviets disagree.

- U.S. wants to restrict modernization of SS-18. 


\section{Appendix B. Urban-Industrial Targeting}

\section{B.1 Industrial Concentration}

Soviet industry appears to be quite concentrated, with the top 100 cities containing about one-half of the country's industrial production and the top 200 cities containing almost two-thirds of the industry (see Fig. B-196). According to Representative Les Aspin, the following features were characteristic of Soviet industry a decade ago: ${ }^{97}$

- 150 plants comprised 50 percent of Soviet capacity to produce primary metals, chemicals, petroleum, construction equipment, agricultural equipment, railroad equipment, synthetic rubber, and electric power generators.

- 400 plants produced 75 percent of such output.

- Almost all chemical plants were in 25 cities.

- 60 percent of natural steel was produced in 25 plants.

- The entire Central and Volga regions (59 million people) received electric power from five power plants.

- The Moscow oblast had 11 cities (other than Moscow) with populations greater than 100,000 and heavy industrial concentrations. All fall within the "footprint" of a singld MIRVed missile.

- Sovict industry had only

8 copper refineries

34 major petroleum refineries

4 plants that produced the entire aluminum and alumina output

6 turbine gencrator works (in two cities)

5 cities that produced boilers

5 cities that produced diesel engines

17 meat packing plants

9 plants produced 80 percent of the tractors (20) percent in the Kama River factory, which also produces 20 percent of the nation's trucks)

7 cities contained almost all of the engineering work

4 cities produced all transmission equipment for Siberian power plants

8 major shipbuilding works

16 heavy machine plants

15 major agricultural machine producing plants

There are no indications that the Soviets have taken any steps in the ensuing period to greatly diffuse their production capacity. The concentration of production into a few giant factories is of course characteristic of the Stalinist central planning system and at this point has not been much affected by plans to reform the economy. If a market economy were introduced in the Soviet Uniori, eventually there could be a change in this concentration. But it would probably take quite a long time to make significant changes.

\footnotetext{
${ }^{96}$ Harold Brown, Department of Defense Annual Report, Fiscal Year 1981, U.S. Government Prirting Office, 1981, p. 79.

${ }_{97}$ Congressional Record, January 15, 1979, p. 366.
} 
FIG. B-1. CONCENTRATION OF SOVIET POPULATION AND INDUSTRY

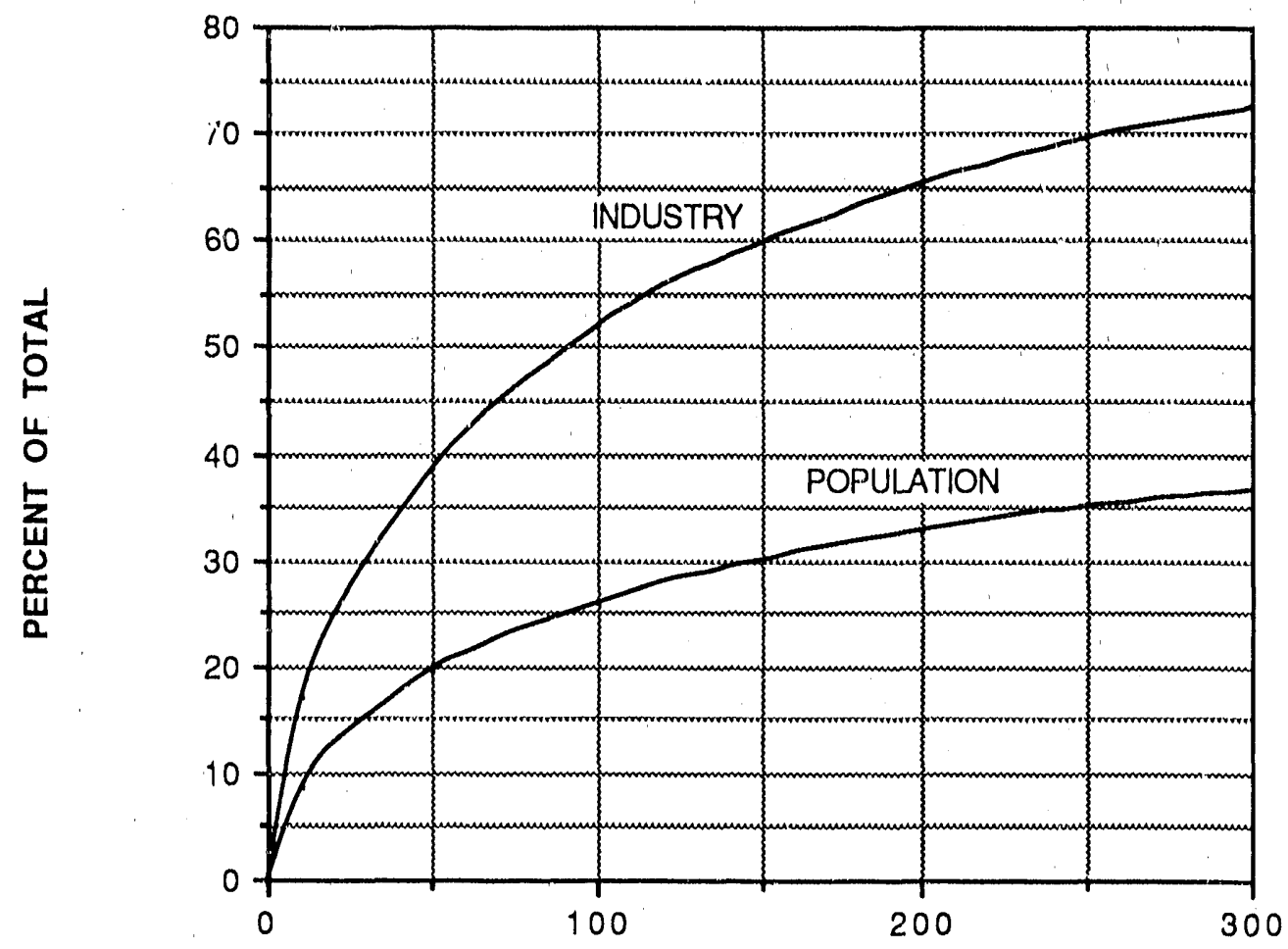

NUMBER OF CITIES

\section{B.2 Industrial Targeting}

According to William Kaufmann, there are about 1400 urban-industrial targets in the Soviet Union. ${ }^{98}$ If these were all individually attacked with 40-kt Poseidon warheads, it would take about 165 equivalent megatons (EMT) ${ }^{99}$. The use of larger weapons would reduce the number of aimpoints since each weapon may cover a number of targets. If we assume that the same area has to be covered by the larger-yield weapons, the number of these weapons required to cover the economic targets can be calculated. These targets probably represent about 65 percent of the industrial capacity of the Soviet Union. Since we are probably on the flat of the curve, it is likely that 50 percent of Soviet industry could be targeted with one-half or two-thirds of the weapons required to attack 65 percent of the industry.

Table B-1 gives the weapons requirements (for various-sized weapons) to attack Soviet industry. The weapons requirements for the destruction of 50 percent of Soviet industry was found by multiplying the requirements for 65 percent of the industry by a factor 0.6 .

If targeting were restricted to military support industries, there are only about 150 major factories producing weapons (armored vehicles, ships, aircraft, missiles, ammunition, and explosives) and 150 plants providing combat support equipment such as radar, trucks, and communication equipment. Furthermore, this military production is concentrated in only 36 cities. ${ }^{100}$

\footnotetext{
98 Aviation Week and Space Technology, May 2, 1988, p. 105.

${ }^{99} \mathrm{EMT}=(\text { Yield })^{2 / 3}$.

${ }^{100}$ Soviet Military Power, 1986, Department of Defense, U.S. Government Printing Office, 008-000-00464-1, 1966.
} 
Table B-1. Weapons requirements.

\begin{tabular}{cccc}
\hline $\begin{array}{c}\text { Weapon yield } \\
(\mathrm{kt})\end{array}$ & $\begin{array}{c}\text { Equivalent } \\
\text { megatons }\end{array}$ & $\begin{array}{c}\text { No. of warheads: } \\
65 \% \text { industry }\end{array}$ & $\begin{array}{c}\text { No. of warheads: } \\
50 \% \text { industry }\end{array}$ \\
\hline 100 & 0.215 & 770 & 460 \\
200 & 0.342 & 480 & 290 \\
335 & 0.482 & 340 & 200 \\
500 & 0.630 & 260 & 160 \\
\hline
\end{tabular}

\section{B.3 City Attacks}

While the U.S. does not target cities or the general population per se, many of the SIOP's economic, military, and leadership targets are located in or near cities; thus, considerable damage and casualties could be expected. As a point of comparison, let us consider the number of weapons it would take to deliberately (rather than incidentally) destroy the major cities of the Soviet Union.

As noted, the top 200 or so cities in the Soviet Union contain about 65 percent of the industrial production as well as about 60 percent of the urban population. According to Representative Les Aspin ${ }^{101}$, the area of these cities in 1978 was $5400 \mathrm{mi}^{2}$. According to an Arms Control and Disarmament Agency (ACDA) study, ${ }^{102} 60$ percent of the urban population in 1978 (corresponding to the top 200 cities) was concentrated in about $1500 \mathrm{mi}^{2}$. Presumably, this refers only to the urban housing areas. For this study, we will assume an urban area of about $6000 \mathrm{mi}^{2}$.

\section{Overpressure}

First consider blast overpressure as a destruction mechanism. A city is a mixture of residential, industrial, commercial, and administrative buildings as well as open spaces. Generally, an overpressure level of 5 or $10 \mathrm{psi}$ is thought to be sufficient to destroy most buildings, although some industrial facilities could require greater overpressures. For example, wood-frame buildings experience severe damage at about 3 psi, while overpressures of 5 psi are expected to cause severe damage to masonary buildings such as apartment houses. An overpressure of 10 psi will cause moderate damage to reinforced concrete buildings. Table B-2 gives the kill radius and area of kill for various medium-yield nuclear weapons for 5 - and 10-psi targets. If 500-kt weapons were used, $6000 \mathrm{mi}^{2}$ could be covered with 10 psi by about 410 weapons and with 5 psi by about 160 weapons. ${ }^{103}$

Table B-2. Overpressure area of kill.

\begin{tabular}{ccccc}
\hline $\begin{array}{c}\text { Weapon } \\
\text { yield } \\
(\mathrm{kt})\end{array}$ & $\begin{array}{c}\text { Kill radius } \\
10 \mathrm{psi} \\
(\mathrm{mi})\end{array}$ & $\begin{array}{c}\text { Area of kill } \\
10 \mathrm{psi} \\
\left(\mathrm{mi}^{2}\right)\end{array}$ & $\begin{array}{c}\text { Kill radius } \\
5 \mathrm{psi} \\
(\mathrm{mi})\end{array}$ & $\begin{array}{c}\text { Area of kill, } \\
5 \mathrm{psi} \\
\left(\mathrm{mi}^{2}\right)\end{array}$ \\
\hline 100 & 1.27 & 5.07 & 2.02 & 12.8 \\
200 & 1.61 & 8.14 & 2.55 & 20.4 \\
335 & 1.91 & 11.5 & 3.03 & 28.8 \\
500 & 2.18 & 14.7 & 3.46 & 37.6 \\
\hline
\end{tabular}

${ }^{101}$ Aerospace Daily, December 28, 1978, p. 263.

102 Armed Forces Journal International, May 1979, p. 26.

${ }^{103}$ Obviously, at least 200 weapons would be required to attack 200 cities. 


\section{Fires}

There are many uncertainties involved in predicting the extent of fires that would result from a nuclear explosion. Thus, strategic planners have generally avoided using fire as a primary kill mechanism in their targeting plans. Fires are expected to occur, but they are looked upon as a bonus effect.

Nevertheless, models of nuclear explosion induced fires do exist based on data from Hiroshima and Nagasaki and research sponsored by DNA. ${ }^{104}$ Based on these models, the range where 15 percent of the area is expected to be damaged by fire has been derived, and corresponds to a range where the overpressure is about 3.3 psi for a $40-\mathrm{kt}$ weapon or about $3.6 \mathrm{psi}$ for $1 \mathrm{MT}$. Table B-3 indicates that, in general, for a given weapon, the area subjected to fires is ahout 4 to 4.5 times the area covered by 10 psi and about 1.6 to 1.8 times that covered by 5 psi.

Table B-3. Fire burn area.

\begin{tabular}{ccc}
\hline Weapon yield $(\mathrm{kt})$ & Fire radius $(\mathrm{mi})$ & Area of burn $\left(\mathrm{mi}^{2}\right)$ \\
\hline 100 & 2.7 & 23 \\
200 & 3.3 & 34 \\
335 & 3.8 & 45 \\
500 & 4.4 & 61 \\
\hline
\end{tabular}

\section{B.4 Weapons Requirements}

An estimate of the number of weapons required to attack Soviet industry can be mi we by combining the data in Fig. B-1 (industrial capacity vs number of cities) with an attack on the area of individual cities. Most Soviet cities are quite compact. There are relatively few cars and few suburbs, and people live almost exclusively in large apartment buildings. While Moscow and Leningrad are quite large, they are not typical. Probably less than 30 Soviet cities ${ }^{105}$ have an area greater than $60 \mathrm{mi}^{2}$. Each of the rest could probably be effectively destroyed by one $500-k t$ warhead.

Figure B-2 indicates that about 150 medium-sized weapons could probably destroy over 50 percent of the Soviet industrial capacity, ${ }^{i 06}$ which is consistent with the estimate given in Table B-1. Thus, it would appear that a dedicated force of 150-250 survivable, medium-sized weapons could shatter the Soviet Union as a modern industrial society and should be sufficient to deter an attack (or the threat of an attack) on U.S. cities.

\footnotetext{
${ }^{104}$ Robert Port, "HOB Targeting Study," R\&D Associates, internal document, July 1982.

${ }^{105}$ Geoffrey Kemp, Nuclear Fories for Medium Powers: Part I: Targets and Weapons Systems, Adelphi Paper (London: IISS, Autumn 1974), p. 6.

${ }^{106}$ Fire damage was assumed as the kill criterion. If 5-psi overpressuce is used as the kill criterion, a few more weapons would be required.
} 
FIG. B-2. WEAPONS REQUIREMENTS

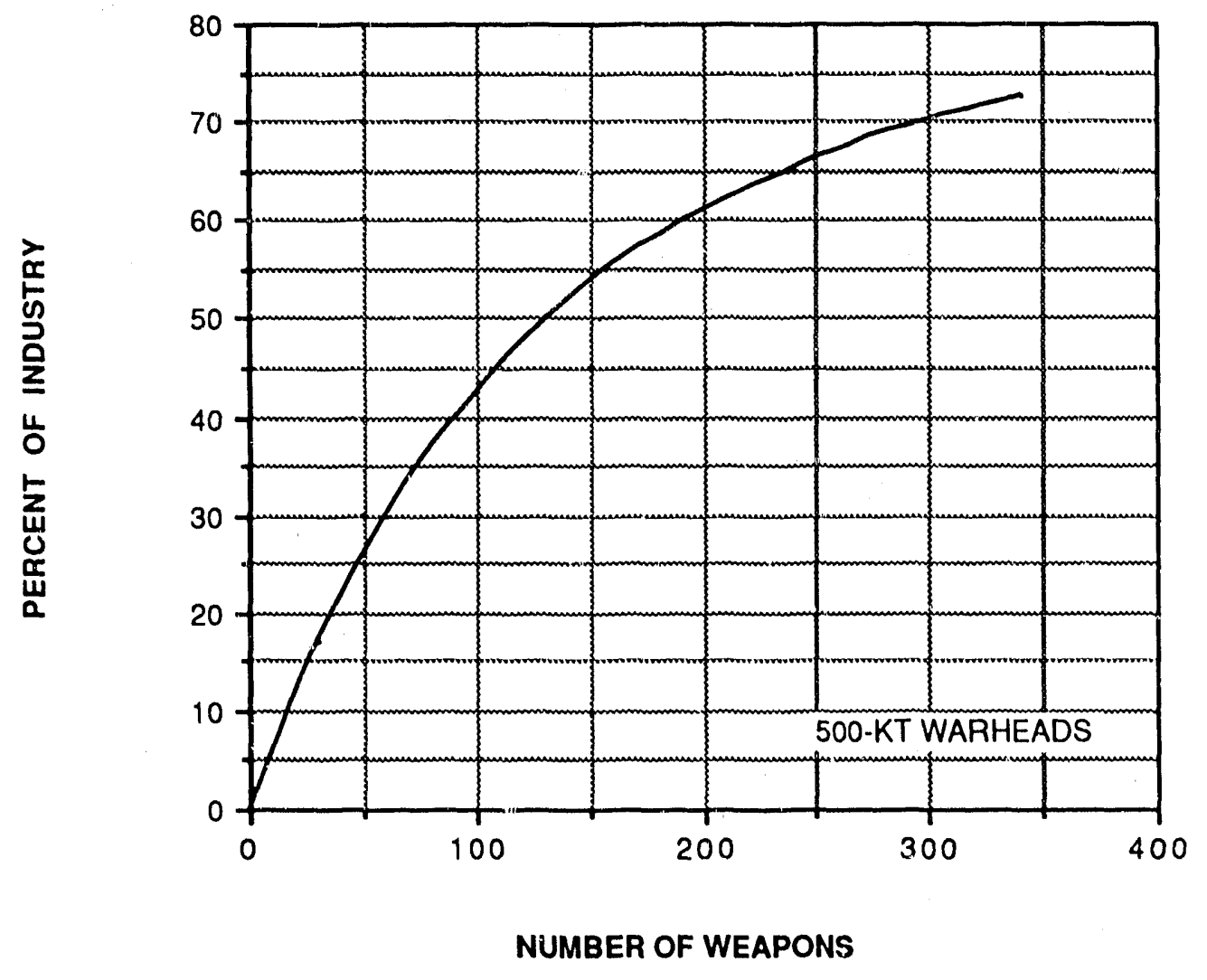




\section{Appendix C. Strategic Targeting}

The following is a brief sketch of some of the highlights in the history of strategic targeting with an emphasis on weapons requirements.

\section{C.1 Truman Administration}

In July of 1948, there were only 50 nuclear weapons in the U.S. stockpile. 107 They were all Mark 3 "Fat Man" bombs weighing 10,000 lbs each and having a yield of about $20 \mathrm{kt}$. It took $39 \mathrm{men}$ more than two days to assemble each weapon.

By 1953, the stockpile had expanded to about 1000 weapons, and the targets had been organized into three sets: 108

1. Soviet nuclear delivery capability (called BRAVO for blunting),

2. Targets affecting the mobility of Soviet conventional forces (called ROMEO for retardation), and

3. Urban industrial targets (called DELTA for disruption and destruction of Soviet war-making capacity).

\section{C.2 Eisenhower Administration}

In a 1952 NATO ministers meeting in Lisbon, it was estimated that it would require 96 divisions to provide an adequate defense for Western Europe against the Soviet conventional threat. However, none of the allies was prepared to pay the financial or manpower costs to meet this goal. Thus, they turned to nuclear weapons as a less expensive alternative to providing an adequate conventional defense.

To implement this policy, the Eisenhower administration quickly adopted a policy of "massive retaliation" as the appropriate response to a Soviet conventional or nuclear attack in Europe. The targeting doctrine to implement this strategy evolved out of the Air Force's experience with strategic bombing in World War II. A broad range of nuclear and conventional military forces were targeted with the objective of limiting darnage to the U.S. and its allies. In addition, cities were targeted in order to destroy war-sustaining industries, governmental control centers, and the civilian morale necessary to sustain the war effort. By the mid-1950s, the Strategic Air Command's basic war plan target list for the Soviet Union and Communist China contained about 3000 separate targets, ${ }^{169}$ and the target list expanded as the number of weapons increased.

\section{Hickey Committee Study, 1959}

The Hickey Committee Study, commissioned by President Eisenhower, was used as guidance for the first Single Integrated Operational Plan or SIOP. The study prepared a Comprehensive Strategic. Targeting List consisting of a total of 2021 targets which included: 110

121 ICBM sites 140 air defense bases

200 bomber bases

218 military and governmental control centers

124 other military targets

Most of the remaining targets were located in 131 urban centers in the Soviet Union and China.

${ }^{107}$ David Alan Rosenberg, "U.S. Nuclear War Planning, 1945-1960," in Desmond Ball and Jeffrey Richelson, eds, Strategic Nuclear Targeting (Ithica: Cornell University Press, 1986), p. 38.

${ }^{108}$ Ibid., p. 40.

${ }^{109}$ Ibid., p. 49.

110 lbid., p. 53. 


\section{SIOP-62}

The SIOP made from the Hickey Committee list was approved in December 1960 and went into effect in January of 1961 . There were different plans to account for the possible changes in the alert status of the strategic forces. In July of 1961, the following forces and targets were in SIOP-62 for a high alert status ("generated") and a normal day-to-day alert. ${ }^{111}$

Generated forces:

3267 nuclear weapons on 2244 delivery vehicles (including 188 ballistic missiles)

3729 installations designated for attack

1060 Designated Ground Zeros (DGZs) for the weapons

Including 151 urban-industrial targets

$\approx 800$ of the DGZs were military targets

Day-to-day alert:

1530 weapons on 1004 delivery systems (including 86 ballistic missiles)

650 DGZs (including 170 defense suppression targets)

All the weapons on alert would be launched at once, and there were no plans for a strategic reserve. About 360 to 425 million Soviet, Chinese, and Eastern European casualties were predicted if the SIOP was executed. ${ }^{112}$

\section{C.3 Kennedy-Johnson Administrations}

\section{SIOP-63}

In developing a new SIOP, the Kennedy Administration followed the basic approach laid down at the end of the Eisenhower Administration by including an optimum mix of military and urbanindustrial targets. However, the new SIOP for the first time included a number of options so that all the strategic forces would not have to be launched at once. The SIOP included three separate types of targets: nuclear targets, other military targets, and urban-industrial targets. ${ }^{113}$

Table C-1 shows the Defense Department's 1962 projection of the weapons requirements needed to target the Soviet Bloc in 1969. ${ }^{114}$

Table C-1. Weapons requirements projection.

\begin{tabular}{lcc}
\hline \multicolumn{1}{c}{ Target } & $\begin{array}{c}\text { Number of } \\
\text { targets }\end{array}$ & $\begin{array}{c}\text { Number of } \\
\text { weapons assigned }\end{array}$ \\
\hline Strategic nuclear-high urgency & 857 & 1501 \\
Strategic nuclear--moderate urgency & 793 & 1403 \\
Urban-Industrial & 210 & 349 \\
Total & 1860 & 3253 \\
\hline
\end{tabular}

Only 11 percent of the weapons were assigned to urban-industrial targets.

\footnotetext{
${ }^{11}$ Scott D. Sagan, "SIOP-62: The Nuclear War Plan Briefing to President Kennedy," International Security, Summer 1987 (Vol. 12, No. 1).

${ }^{112}$ Desmond Ball, "Development of the STOP, 1960-1983," in Desmond Ball and Jeffrey Richelson, eds, Strategic Nuclear Targeting (Ithica: Corncll University Press, 1986), p. 62.

${ }^{113}$ Sagan, op. cit., p. 38.

${ }^{114}$ Ball, op. cit., p. 66. This list does not include Soviet Bloc conventional force targets.
} 


\section{C.4 Nixon Administration}

In the late-1960s and 1970s, the Soviet survivable strategic arsenal continued to grow, making the threat to initiate a nuclear attack on the Soviet homeland seem less than credible. Nevertheless, the targeting strategy developed in an era when the U.S. was invulnerable did not basically change.

In an attempt to enhance the credibility of NATO strategy, Secretary of Defense Schlesinger introduced a policy of Limited Nuclear Options (LNOs) into U.S. warplanning. In response to a Soviet conventional attack in Europe, the U.S. would now be prepared to initiate limited (as opposed to massive) nuclear attacks on the Soviet Union. Because an attack would be limited, it was hoped that it would not automatically lead to a full-scale nuclear war between the two superpowers. It was thought that it would demonstrate that the U.S. would be willing to risk escalation if the Soviets did not desist. The problem with this strategy was of course the fact that the U.S. was just as vulnerable (if not more so) to limited strikes as the Soviet Union.

The Nixon administration also developed a new overall targeting criteria: in case of a nuclear war, the U.S. was to target in such a way that the U.S. would recover before the Soviet Union, and hence the U.S. would be seen as having the capability to "win" an all-out nuclear war. Nixon's policy guidance (NSDM-242) specified the destruction of 70 percent of the Soviet economic recovery base. However, few people thought that having the capability to dig out of the rubble a few years ahead of the Soviets would add much credibility to U.S. threats.

\section{C.5 Carter Administration}

The Carter administration rearranged the targeting somewhat, calling for a "countervailing" strategy. It was hoped that a renewed and expanded emphasis on killing the Soviet leadership in the event of war would add more credibility to the threats. More emphasis was also given to the idea of warfighting as a strategy.

The Carter Administration's policy guidance document, PD-59, switched the emphasis from targeting the Soviet recovery base to targeting Soviet political and military assets. Reportedly, in 1977, the resulting new war plan, SIOP-5, had the targets listed in Table C-2. ${ }^{115}$

Table C-2. SIOP-5 targets.

\begin{tabular}{lcc}
\hline \multicolumn{1}{c}{ Target type } & Generated alert & Day-to-day alert \\
\hline Nuclear & 2018 & 1761 \\
OMT & 1603 & 935 \\
Leadership & 736 & 423 \\
Economic/Industrial & $4400^{\dagger}$ & $2300^{\dagger+}$ \\
Total & $8757^{*}$ & $5419^{* *}$ \\
\hline
\end{tabular}

OMT $=$ Other Military Targets

${ }^{+} 3572$ aimpoints

H 1793 aimpoints

- 7160 weapons arriving on target

* 3840 weapons arriving on target

${ }^{115}$ Ball, op. cit., p. 81. 
Another breakdown of the target set under PD-59 (somewhat inconsistent with Table C-2) gives the following: 116

- 2000 strategic targets (1400 ICBMs, strategic air and naval bases, Command and Control bunkers, and nuclear storage sites)

- 700 underground shelters for the leadership

- 3000 OMTs

- 200-400 key factories. ${ }^{117}$

Secretary of Defense Harold Brown also specified, "It is essential that we retain the capacity at all times to inflict an unacceptable level of damage on the Soviet Union, including the destruction of a minimum of 200 major cities." 118

\section{C.6 Reagan/Bush Administrations}

Much of the Carter Administration's ideas of warfighting were retained by the Reagan Administration, although there now seemed to be emphasis on prevailing in a prolonged or protracted war. The new SIOP-6 (which took effect October 1, 1983) placed greater emphasis on targeting the Sovict leadership and relocatable targets. The counter-recovery mission was apparently abandoned and emphasis was placed on targeting military support industries. ${ }^{119}$

\section{C.7 Can the Number of Strategic Weapons Be Reduced?}

Throughout the changes in administrations and announced policies, the basic war plan remained remarkably constant although the number of weapons (and hence targets) added to the inventory has dramatically expanded since the 1960s. More limited, selective options were added, but the basic target structure of nuclear forces, conventional forces, leadership and control, and industrial facilitics remained the same.

If an arms control agreement that provides for deep cuts in the strategic forces is contemplated, there would have to be a serious reevaluation of the targeting requirements for deterrence. One recent study of targeting was conducted by May, Bing, and Steinbruner. ${ }^{20}$ They suggested that, based on public statements by the Department of Defense and others, the present primary Soviet target structure probably consists of about 6,000 targets. They also suggest that it is not necessary to cover all the targets in order to maintain deterrence. If one ignores the Soviet ICBM silos (many, if not all, of which would be empty following a Soviet first-strike ${ }^{121}$ ), the authors suggest an attack on about 1900 targets should be sufficient for deterrence (see Table C-3).

116Jeffrey Richelson, "Population Targeting and U.S. Strategic Doctrine," in Desmond Ball and Jeffrey Richelson, eds, Strategic Nuclear Targeting (Ithica: Cornell University Press, 1986), p. 242.

${ }^{117}$ This may be a subset of the industrial targets. Presumably, the other targets would be hit only in retaliation to a Soviet attack on U.S. cities.

${ }^{118}$ Department of Defense Annual Report, Fiscal Year 1979 (Washington, D.C., 1978), p. 77.

${ }^{119}$ Desmond Ball and Robert C. Toth, "Revising the SIOP: Taking War-Fighting to Dangerous Extremes," International Security, Spring 1990 (Vol. 14, No. 4) pp. 65-92.

${ }^{120}$ M. May, et al., op. cit., pp. 90-133.

${ }^{121}$ Following a first strike, the Soviets would be alerted and could launch their residual ICBMs if they detected a

U.S. retaliatory strike against those ICBMs remaining in silos. 
Table C-3. Strategic targets.

\begin{tabular}{lcc}
\hline \multicolumn{1}{c}{ Type of target } & Number & Number targeted \\
\hline ICBM Silos, LCCs & 1460 & - \\
Bomber, SSBN, Mobile ICBM bases & 330 & 310 \\
Other military targets & 1560 & 640 \\
Goverment and C ${ }^{3}$ I facilities & 1080 & 580 \\
Military manufacturing & 1000 & 280 \\
Refineries and electric power & 520 & 115 \\
Total & 5950 & 1925 \\
\hline
\end{tabular}

Taking this study as a starting point, it seems possible to go even farther. If we ignore mobile ICBM bases on the premise that they will "launch on warning" following a first strike, and note that many of the government control and conventional military targets are dubious at best, the target list could easily be reduced to around 400 industrial targets and 1000 (or less) military/government/ $\mathrm{C}^{3}$ I targets and deterrence would still likely be secure. 


\section{Appendix D. Flexible Response}

The U.S. has long threatened to use its strategic forces against the Soviet Union if it should invade Western Europe-even if the Soviets use only conventional forces. The present NATO policy (adopted in 1967) is called Flexible Response. Under this doctrine, the initial Soviet attack is to be met by a conventional defense. If this fails, NATO plans to introduce theater nuclear weapons and ultimately use strategic weapons against the Soviet homeland if necessary. The use of these strategic weapons is envisioned as limited (at least initially), and recent administrations have conducted studies to identify appropriate targets for these weapons. For example, President Carter's Secretary of Defense, Harold Brown, stated that if the Soviets engage in aggression, we must ensure that their leadership knows "we could, by selective, large (but still less than maximum) nuclear attacks, exact an unacceptably high price in the things that the Soviet leaders appear to value most-political and military control, military forces both nuclear and conventional, and the industrial capacity to sustain a war." 122 This essentially remains NATO policy today.

Of course, now that the Soviets have lost their Warsaw Pact allies, the prospects of a Soviet invasion of Western Europe in the near future seems quite remote. NATO, in recognition of the new situation, now suggests that it will use nuclear weapons only as a last resort, with the implication that it may never have to do so. But thus far, NATO professes that nothing fundamental has changed regarding Flexible Response-if nuclear weapons had to be used to stop an invasion, they would. The only major difference in targeting might be that now there probably would not be many targets in Eastern Europe. Since these "intermediate" targets are no longer available, the escalation to attacks on the Soviet homeland would have to come even earlier than before. ${ }^{123}$

The credibility of the U.S. carrying out a threat to initiate a campaign of nuclear warfare against the Soviet homeland when the U.S. had not been attacked has appeared quite low for decades. The problem is that NATO has no way to keep the Soviets from responding in kind or escalating the conflict to even higher levels. As Colin Gray has noted, "It would be imprudent to begin a small nuclear war unless one had on hand a capability of waging, surviving, and recovering from a large nuclear war." 124 The new circumstances in Europe have not provided this capability, and hence the credibility of the threat being implemented still appears quite low. Furthermore, it is not at all clear that the suggested targeting is even technically feasible or that it would be militarily or politically effective if implemented.

\section{D.1 Strategic Weapons}

The sine qua non for a U.S.-initiated attack on the Soviet Union would be a capability to disarm the Soviets. If successful, the U.S. could then demand that the Soviets withdraw from Western Europe, or, for that matter, surrender. Since the U.S. could then freely threaten to attack the Soviet Union without fear of retaliation, the Soviets might be expected to comply.

However, while the U.S. may have once come close to a disarming capability, since the mid-1960s, it clearly has not had such a capability. Although the U.S. is planning to deploy weapon systems with a better hard-target-kill capability (the MX missile and the D-5 SLBM ${ }^{125}$ ), throughout the next decade, even a theoretical capability to effectively limit damage to the U.S. will not be available. Furthermore, the Soviets are now moving more of their ICBM warheads to mobile systems, virtually eliminating the possibility of a first-strike against their ICBMs. ${ }^{126}$ And of course, the Soviets also

\footnotetext{
${ }^{122}$ Harold Brown, speech before Naval War College, 20 August 1980.

${ }^{123}$ NATO has neither a plan nor a desire to fight a nuclear war on the battlefield of Western Europe.

${ }^{124}$ Colin Gray, Nuclear Strategy and Strategic Planning (Philadelphia: Philadelphia Policy Papers, 1984), p. 70.

${ }^{125}$ Although the B-2 bomber and the cruise missile may be very accurate and thus hard-target killers, they cannot be considered an effective first-strike weapons since they takes many hours to reach their targets, giving the Soviets ample time to launch their alert missiles.

${ }^{126}$ The possibility of real-time space-based surveillance systems to detect the mobile missiles and maneuvering missile warheads to attack them would have to be considered in the future. But even here, the Soviets would be
} 
have bombers and strategic submarines, most of which would have been put on alert in the event of a war in Europe. Thus, a strategy based on coercion after a disarming strike would seem doomed to failure.

Even a redesigned force structure with an all-out attempt at damage limiting still might allow a retaliation that would result in the immediate death of 20-30 million Americans. ${ }^{127}$ Moreover, the economy would be shattered and undoubtedly our Constitutional form of government would be a thing of the past. It is hard to imagine any foreign policy objective that could justify the U.S. initiating the process that could lead to this result.

\section{D.2 Leadership and Control}

By attacking the Soviet leadership and control mechanisms, it is undoubtedly envisioned that a threat would be posed not only to the ongoing war effort but possibly to the very existence of the Soviet state as well. The case for this type of targeting is presented by Gray and Payne:

The most frightesing threat to the Soviet Union would be the destruction or serious impairment of its political system. Thus, the United States should be able to destroy key leadership cadres, their means of communication, and some of the instruments of domestic control. The USSR, with its gross overcentralization of authority, epitomized by its vast bureaucracy in Moscow, should be highly vulnerable to such an attack. The Soviet Union might cease to function if its security agency, the $K G B$, were severely crippled. If the Moscow bureaucracy could be eliminated, damaged, or isolated, the USSR might disintegrate into anarchy, hence the extensive civil defense preparations intended to insure the survival of the Soviet leadership. Judicious U.S. targeting and weapon procurement policies might be able to deny the USSR the assurance of political survival...

Striking the USSR should entail targeting the relocation bunkers of the top political and bureaucratic leadership, including those of the KGB; key communication centers of the Communist party, the military and the government; and many of the economic, political, and military records. Even limited destruction of some of these targets and substantial isolation of many of the key personnel who survive could have revolutionary consequences for the country. ${ }^{128}$

To some degree, the idea behind this type of targeting grew out of the Western concept of the nature of Soviet society. The decentralization and democratization now underway in the Soviet Union may significantly alter our view of this category of targets. But implementation of the strategy probably would not have been too effective even on its own terms.

While under certain circumstances it might be very desirable to be able to target the political leadership of the Soviet Union, it does not appear that this could be done with high confidence. U.S. intelligence has undoubtedly identified a number of bunkers associated with the leadership, but they are unlikely to have discovered them all. And more importantly, there is no way to be assured that the leadership will in fact occupy these shelters. There are a number of means that the leadership has to protect itself, ranging from airborne or ground-mobile command posts to small, hidden shelters. Thus, there would be considerable uncertainties involved in assuring that a large fraction of the leadership would be killed by a U.S. attack.

Of course, it is possible to argue that the U.S. could use its vast communication-intercept network to pinpoint the location of the leadership in real time. For example, one could assume that the leader-

alert and could launch their weapons upon warning of an incoming attack, leading to a significant escalation of the war.

${ }^{127}$ Colin S. Gray, "Targeting Problems for Central War," in Desmond Ball and Jeffrey Richelson, eds, Strategic Nuclear Targeting (Ithica: Cornell University Press, 1986), p. 176.

${ }^{128}$ Colin S. Gray and Keith Payne, "Victory Is Possible," Foreign Policy, Vol. 5, No. 1, Summer 1980, pp. 14-27. 
ship will be broadcasting to the military and civilian authorities. However, the Soviet leadership is undoubtedly well aware of U.S. capabilities to locate broadcasting radios and would probably take precautions to negate this threat. For example, when it is necessary to issue a directive, a low-datarate message (probably encrypted) can be used, which is difficult to intercept. Furthermore, the message can be fed into land-lines with the radio transmitter located a considerable distance from the leader's actual location.

The KGB (the "organ of state security") has been considered to be an important target because it is thought to be the principal means used by the Soviet leadership to maintain control over Soviet society. It is suggested that without the KGB the people would drift into anarchy and revolt, resulting in the end of the Sovict state and the power of the leadership.

The basic premise of this argument seems highly debatable, particularly now. But at any rate, there is little evidence to indicate that the general public would be inclined to rise up in revolt in the middle of a nuclear war, considering that they would be so dependent upon the state functioning in order to survive in the aftermath of the war.

Beyond this, there is no reason to believe that the KGB is particularly vulnerable to a nuclear strike. While the KGB leadership may be administratively concentrated in Moscow and a few other regional centers, it would be simple to disferse the personnel in times of crisis. And of course the police and military, which can also exert governmental control, are already widely dispersed.

The U.S. could attack the fixed elements of Soviet $C^{3}$ system. However, it is well known that the Soviet communications net is hardened, dispersed, and redundant. Any attempt to completely destroy the system is thus unlikely to succeed. Furthermore, in the post-attack environment, it might be relatively straightforward to reconstitute a communications system.

Since one cannot plan on successfully destroying the Soviet leadership and control system, it is difficult to see when this threat might be evoked other than after an all-out attack on the U.S. Under other circumstances, such as a war confined to Europe, the initiation of a U.S. attack at this level would surely evoke a massive response against the U.S. Since the U.S. would have such a small expectation of success with its attack, there would seem to be little advantage in instigating such an exchange.

\section{D.3 General Purpose Forces and Their Support Structures}

If the U.S. could destroy the Soviet general purpose forces, this would undoubtedly prevent the Soviets from achieving their military objectives and could even leave them vulnerable to invasion by their enemies. ${ }^{129}$ However, in this scenario, the Soviets have the advantage of the initiative. This would allow them to enhance the survivability of their ground, sea, and air forces by moving themeither during a crisis or right before a surprise attack on Europe. While an attack on the fixed facilities of the Soviet theater forces (army bases, shipyards, airfields, POL and ammunition storage sites, logistics facilities, etc.) would result in significant damage, it is not clear that this would cripple the dispersed Soviet general purpose forces. (Assuming of course that the Soviets were strong enoughsometime in the future- to threaten NATO's conventional forces with defeat in the first place.) Any plan to attack NATO would undoubtedly make preparations for carrying most of the required POL and ammunition or covertly dispersing it beforehand. And of course Soviet aircraft could operate from the hundreds of unpaved airfields that exist in the Soviet Union. In addition, the Soviet counterattack against NATO's support facilities could more than compensate for the damage done-giving a significant advantage to the side that was actually prepared to fight a war on the battlefield.

In addition to attempting to attack Soviet troops, the U.S. could attack the fixed elements of the Soviet military $\mathrm{C}^{3}$ system. While this system is hardened and redundant, it is possible that under some circumstances a well-designed attack could hinder Soviet efforts to pursue a war in Europe. But to be effective, the objective of the attack would have to be clearly defined. The specific mechanism of control would have to be understocd, and real-time data on the order of battle would be needed to keep

\footnotetext{
${ }^{129}$ This latter point would be mitigated somewhat if the Soviets retained a large reserve of strategic weapons. For example, while the Chinese might be tempted to move into Siberia if the Soviet troops in this area were destroyed, they might still be restrained by a threat to destroy Chinese cities in the event of an invasion.
} 
the attack to a manageable size. However, the U.S. has never seriously addressed many of the problems that would flow from a war in Europe fought with both conventional and nuclear weaponsand is unlikely to do so as long as Flexible Response remains NATO doctrine. Thus, it is not clear that the U.S. has identified, or even would be able to identify, the requirements of this kind of war.

The U.S. also threatens to extend its nuclear attacks to war support industries and facillties. This evidently would include ammunition-, bomb-, and missile-production facilities, military equipment (tanks, airplanes, etc.) assembly plants, repair facilities, POL refineries, etc. To be effective, this would be a very large urban attack, perhaps difficult for the Soviets to distinguish from an all-out attack. While such an attack might prove useful in a protracted war, it is likely that the Soviets (if they ever were strong enough to attack) would be planning on a war that could be fought (and won) with the forces and matericl on hand.

While an attack on either Soviet military facilities or war-supporting industries is unlikely to decisively affect the short-term outcome of a war in Europe, it would cause massive damage and casualties in the Soviet Union. Since this would invite reprisals by the Soviet Union, the likelihood of the U.S. initiating such an attack after a Soviet invasion of Western Europe remains questionable, particularly since the military effectiveness of the attack is likewise so questionable.

\section{D.4 Conclusion}

Over the past decades, most Western defense analysts concluded that if the Warsaw Pact invaded Western Europe, NATO appeared to have little means to reverse an almost certain defeat. The threat of an escalation to the use of strategic nuclear weapons was invoked to forestall a possible Warsaw Pact invasion. But efforts to identify useful targets for a less than all-out strategic attack appear not to have resulted in a strategy for victory, but instead in a list of targets that could be attacked to punish the Soviets. As a theory of deterrence, this policy is questionable since the Soviet Union can inflict just as much punishment in retaliation. Moreover, if the Soviets had attacked Europe, the use of U.S. strategic weapons against the proclaimed target list would seem to have had little chance of decisively affecting the course of the war, and thus would not have prevented or reversed a quick Sovict victory.

Thus, Flexible Response would seem to be both a non-credible theory of deterrence and a poor approach to warfighting if deterrence were to fail. Its repudiation as NATO policy is long overdue. Fortunately, the collapse of the Warsaw Pact now presents the possibility of a new beginning. 

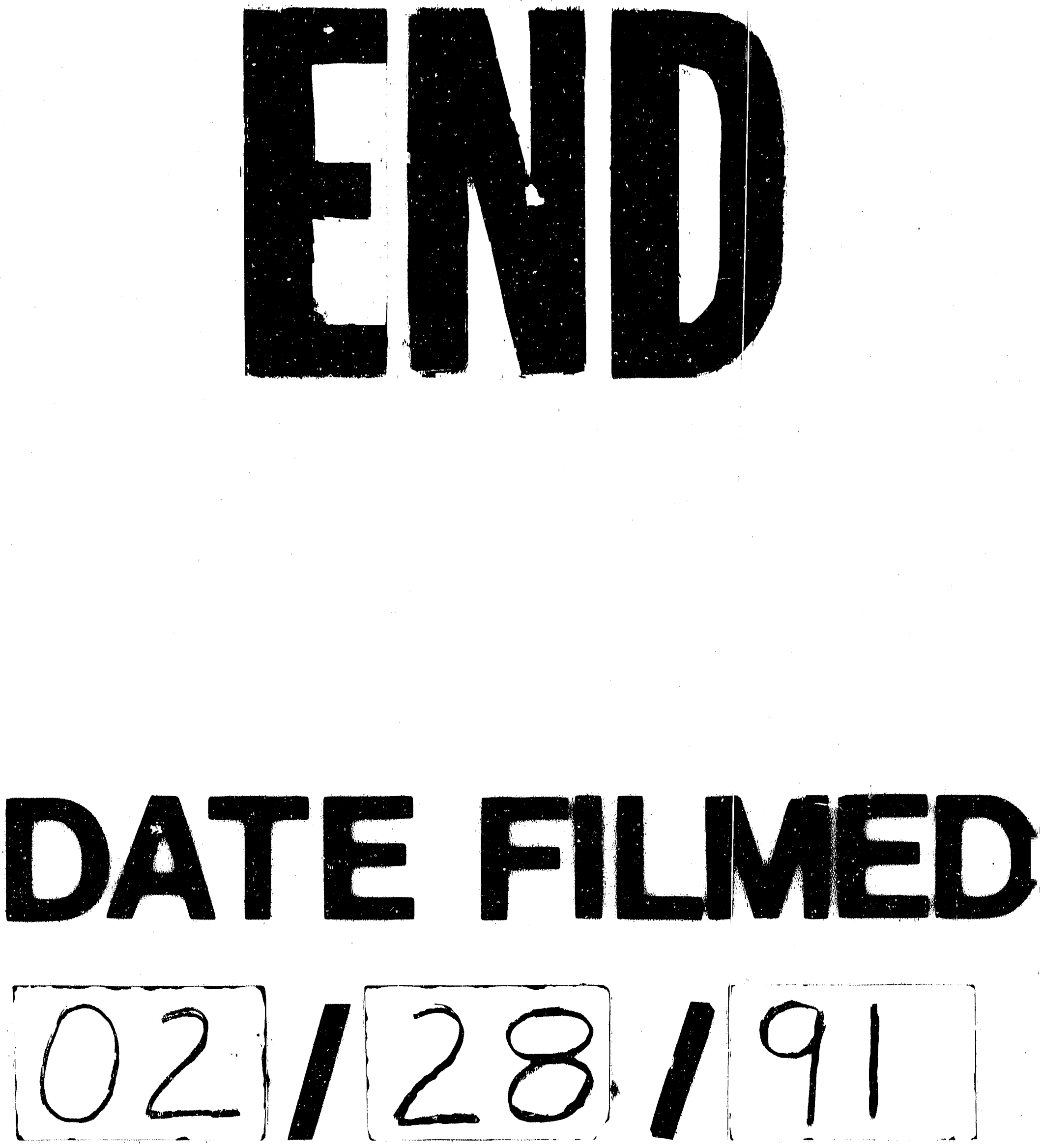
